\title{
Nationalismus und Nationalstaat in Deutschland und Europa. Ein Forschungsüberblick
}

Einleitung

Mehr als andere Forschungsfelder ist die Nationalismusforschung sensibel für ihre politischsoziale Umwelt. Der Motor und gleichzeitig das Ergebnis der politischen Kräfte zu sein, die auf sie einwirken, verbindet die Analyse der Nation mit ihrem Gegenstand.' Dieter Lange-

1 Folgende Titel werden unter anderem besprochen:

Benedict Anderson, Die Ertindung der Nation. Zur Karriere eines folgenreichen Konzepts, Übers. Benedikt Burkhard/Christoph Münz. 306 S., Campus Verlag. Frankfurt am Main 2005; Regula Argast Staatsbürgerschaft und Nation. Ausschließungs- und Integrationsprozesse in der Schweiz 1848 1928. 416 S., Vandenhoeck a Ruprecht, Gottingen 2006; Wolfgang Bialas (Hg.). Die nationale denthal der Deulschen. Phlosophische lmaginationen und historische Mentaltaten. 304 S., Peler Lang, Franklut am Main 2002, Soren Bhinkmann. Der Stok der Provinzen. Reglow (Hispno-Americana (18)

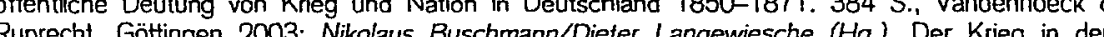
( Grundungsmylhen europalischer Nallonen und der USA. 20 S.. Campus Vellag, Frankfurt am Main

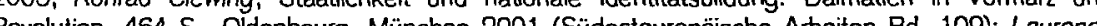

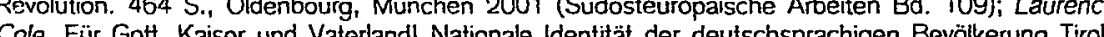

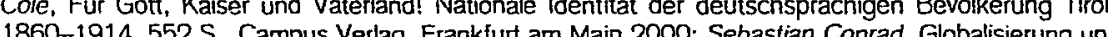
(860-ion Nalon in Deulschen Kaisenth. 206 S., C.H. Beck, Mische

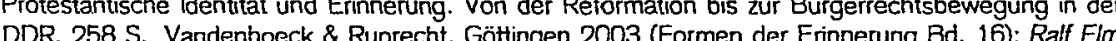
(H.) (Hg.), Europaische ldentitat. Paradigmen und Methodenfragen. 318 S., Nomos-Verlag, Baden-Baden (Sche

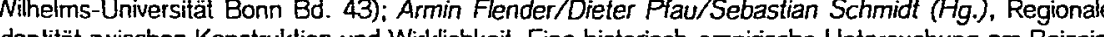
des Siegerandes $284 \mathrm{~S}$. Nomos Vertich und Macht Deutscer Nationalismus 1830-1851. Der Fall Schleswig Holstein. $256 \mathrm{~S}$. Steiner

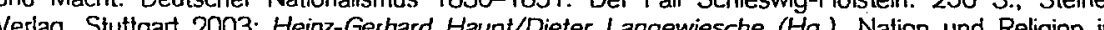
. Frankfurt am Main 2004: Ges $K$ Hoensch/Hans Lemberg Schlaglichter auf das Verhältnis von Tschechen, Slowaken und Deutschen 1815-1989. 3365 . Klartext-Verlag Essen 2001 Veröfentlichungen des Instituts für Kultur und Geschichte de Deutschen im Östlichen Europa Bd. 20); Carl A. Hoffmann (Ho) Kommunikation und Region 442 S. UVK Konstanz 2001 (Forum Suevicum Bd 4); Raph Jessen/Jakob Vogel ( H ) Wissensche 442 und Nation in der europäischen Geschichte. $316 \mathrm{~S}$. Campus Verlag Frankfurt am Missenschaft Jeremy King, Budweisers into Czechs and Germans: A Local History of Bohemian Politics, 18481948 284 S. Princeton University Press, Princeton 2002. Arpád von Klimó, Nation Kon 1848Geschichte. Zur nationalen Geschichtskultur Ungarns im europäischen Kontext 1860-1948. $453 \mathrm{~S}$., Oldenbourg, München 2003 (Südasteuropäische Arbeiten, Bd. 117); Thomas Kühne/Cornelia RauhKühne $(\mathrm{Hg}$.$) . Raum und Geschichte. Regionale Traditionen und föderative Ordnungen von der frühen$ Neuzeit bis zur Gegenwart. 270 S., DRW-Verlag, Leinfelden-Echterdingen 2001 (Schriften zur südwestdeutschen Landeskunde. Bd. 40): Birthe Kundrus ( $\mathrm{Hg}$. ). Phantasiereiche. Zur Kulturgeschichte des deutschen Koionialismus. 328 S., Campus Verlag. Frankfurt am Main 2003; Kurt Mühler/Karl-Dicter Opp. Region und Nation. Zu den Ursachen und Wirkungen regionaler und überregionaler Identifikation. 288 S., VS Verlag. Wiesbaden 2004; James Retallack (Hg.). Sachsen in Deutschland. Politik, Kultur und Gesellschaft 1830-1918. 296 S., Verlag für Regionaigeschichte, 
wiesche hob in seinem letzten Forschungsüberblick von 1995 vor allem die Herausforderungen und neuen Interessenprägungen der Nationalismusforschung durch den Zusammenbruch des Kommunismus und das Ende des Ost-West Gegensatzes hervor. ${ }^{2}$ Der Nationalstaat diente nach dem Ende der Sowjetunion als Ordnungsbild im untergegangenen kommunistischen Reich in Osteuropa, im Kaukasus und in Mittelasien. Aber auch darüber hinaus blieb er als politisches Ordnungsmodell erhalten, wie die Vorgänge auf dem Balkan im ehemaligen Jugoslawien zeigten. Im europäischen Raum bedeutete diese dritte Welle der Nationalstaatsgründungen nach 1830 bis 1870 und dem Ende des Ersten Weltkrieges jedoch lediglich eine Zwischenstation auf dem Weg zum Beitritt zur Europäischen Union. Die jüngste nationale Unabhängigkeitserklärung von Montenegro wurde getragen vom allseits geteilten und erklärten Willen, der EU beizutreten. Ein entscheidender Unterschied zu Logik des Untergangs der DDR 1989 / 1990 trat damit hervor. Während die Reformkom munisten Polens und Ungarns ihr System reformieren konnten, ohne die politische Existenz des Staates aufzugeben, gab es diese Möglichkeit für die SED nicht. Die DDR konnte ohne den Sozialismus nicht existieren. Die baltischen Staaten und die Zerfallsprodukte Jugoslawiens haben daraus die Konsequenz gezogen, zuerst ein Nationalstaat zu werden, um sich dann zu reformieren und Teil eines neuen Wirtschafts-, Kultur- und Politikraums zu werden. Der Nationalstaat erlebt so eine Renaissance, ohne dass er alleine das Ordnungsbild Europas bestimmt. Dies unterscheidet die dritte Welle der Nationalstaatsgründungen von der zweiten nach dem Ersten Weltkrieg.

In der Zwischenzeit sind weitere Veränderungen eingetreten, die auf die Nationalismusforschung zurückwirken. Der Nationalstaat wird von mehreren Seiten her relativiert. Die "neuen Kriege" (Herfried Münkler) in Afrika zeigen am deutlichsten, dass der Nationalstaat und generell der Staat in weiten Teilen der Erde nicht mehr in der Lage ist, das legitime Monopol physischer Gewaltsamkeit auszuüben. Ethnische, soziale und private Gewaltunternehmer machen ihm dies streitig. ${ }^{3}$ Die Zahl der "failed states" steigt und damit wird de Nationalstaat als "power container" (Anthony Giddens) relativiert. Sind "failed states" also auch failed nation-states"? ${ }^{4}$ Warum erweist sich die nationale Idee nicht in der Lage, die Gewaltmärkte zu regulieren? Ist der Nationalstaat als Ordnungsmodell gescheitert oder befindet er sich in der Reform und Transformation?

Vor diesem Hintergrund erörtem Sozialphilosophen nicht nur die Frage, wie gewaltsam der Nationalismus sein kann, sondern auch diejenige, was wir verlieren, wenn der Nationalstaat als typische staatliche Ordnungsformation verschwindet. Die Globalisienung der Märkte und die Europäisierung der Politik verstärken den verbreiteten Eindruck einer diffusen Lage von gleichzeitiger Fortdauer und Relativierung des Nationalstaates. ${ }^{5}$ Gerade auf

Bielefeld 2000 (Studien zur Regionalgeschichte, Bd. 14); Philipp Ther/Holm Sundhaussen/Imke Kruse (Hg.), Regionale Bewegungen und Regionalismen in europäischen Zwischentüumen sen/mke Krudes 19. Jahrhunderts. 297 S., Herder-Institut Marburg Mapaischen Zwischenräumen seit der Mitte pa-Forschung 18); Westfälische Forschungen 52 . 873 Marburg 2003 (Tagungen zur OstmitteleuroMünster 2002

2 Vgl. Dieter Langewiesche, Nation, Nationalismus, Nationalstaat. Forschungsstand und Forschungs-

3 perspektiven, in: Neue Poilische Literatur 40 (1995), S. 190-236. geschichte im Spiegel ihrer theoretisch, Reinbek 2002; ders., Über den Krieg. Slationen der Kriegsgeschichte im Spiegel ithrer theoretischen Reflexion, Göttingen 2002; ders., Alte Hegemonie und neve Kriege, in: Blätter für deutsche und internationale Politik 49 (2004), S. 539-553.

Vgl. Stephen D. Krasner, Sharing sovereignty: New institutions for collapsed and failing states, in: in Vgl dazu Security 29 (2004), S. 85-121.

5 Vgl. dazu die sozialwissenschaftlichen Analysen in: Joachim Hirsch u. a. (Hg.), Die Zukunft des Staates: Denationalisierung, Internationalisienung, Renationalisienung, Hamburg 2001. der politischen Linken wird die Ordnungsleistung des Nationalstaates im Zeitalter der Globalisierung oft vermisst. Jürgen Habermas spricht seit einiger Zeit dem Nationalstaat erstaunliche Leistungen zu, die in neuen Ordnungsmodellen nicht unterboten werden sollten. Er sah dabei in Umkehrung der linken Kritik an der Nation genuin demokratische Impulse:

${ }_{n}$ Eine demokratische Selbstbestimmung kann erst zustande kommen, wenn sich das Staatsvolk in eine Nation von Staatsbürgern verwandelt, die ihre politischen Geschicke selbst in die Hand nehmen. Die politische Mobilisierung der "Untertanen" erfordert jedoch eine kulturelle Integration der zunächst zusammengewürfelten Bevölkerung. Dieses Desiderat erfült die Idee der Nation, mit deren Hilfe die Staatsangehörigen - über die angestammten Loyalitäten gegenüber Dorf und Familie, Landschaft und Dynastie hinaus - eine neue Form kollektiver Identität ausbilden. Der kulturelle Symbolismus eines "Volkes", das sich in der präsumptiv gemeinsamen Abstammung. Sprache und Geschichte seines eigentümlichen Charakters, eben seines "Volksgeistes" vergewissert, erzeugt eine wie immer auch imaginäre Einheit und bringt dadurch den Bewohnem desselben staatlichen Territoriums eine bis dahin abstrakt gebliebene, nur rechtlich vermit telte Zusammengehörigkeit zu Bewusstsein. Erst die symbolische Konstruktion eines Volkes" macht aus dem modernen Staat den Nationalstaat. "6

Im Erschrecken über die Wirkung entfesselter transnationaler Kapitalmärkte ergreif Habermas damit Partei für die Globalisierungsprofiteure des 19. Jahrhunderts, als die $\mathrm{Si}$ cherungssysteme kleinräumiger Lebenswelten unter dem Druck von Marktbildung und politischer Selbstbestimmung zusammenbrachen und durch abstrakte Sicherungssysteme und mit der Migration mitwandernde Berechtigungstitel ersetzt wurden. ${ }^{7}$ Der Globalisienungsge winner des 19. Jahrhunderts war der Nationalstaat. Zu Beginn des 21. Jahrhunderts wird der Nationalstaat immer noch als Berechtigungs-, die Globalisierung jedoch als Entrech-

6 Jürgen Habermas, Die postnationale Konstellation und die Zukunft der Demokratie, in: ders., Die postnationale Konstellation. Politische Essays, Frankfurt am Main 1998, S. 91-169, 99f. „Der Territoralstaat, die Nation und eine in nationalen Grenzen konstituierte Volkswirtschaft haben damals ein historische Konstellation gebildet, in der der demokratische Prozess eine mehr oder weniger überzeugende institutionelle Gestalt annehmen konnte. Auch die Idee, dass eine demokratisch verfasste Gesellischaft mit einem ihrer Teile reflexiv auf sich als ganze einwirken kann, ist bisher nur im Rahmen des Nationalstaats zum Zuge gekommen." (Ebd., S. 94). Bereits 1990 hatte Habermas in "Staatsbürgerschaft und nationale Identität" darauf hingewiesen, dass "der rechtlich konstituierte Staatsbürgerstatus angewiesen [bleibtl auf das Entgegenkommen eines konsonanten Hintergrundes von rechtlich nicht erzwingbaren Motiven und Gesinnungen eines am Gemeinwohl orientierten Bürgers. [...] Die Verfassungsprinzipien können erst dann in den geselsschaftlichen Praktiken Gestalt annehmen und zur treibenden Kraft für das dynamisch verstandene Projekt der Herstellung einer Assoziation von Freien trebl Geichen und Gleichen wern, wenn sie im Kontext der Geschichte einer Nation von Staatsbürgern so situiert werden, dass sie mit Motiven und Gesinnungen der Bürger eine Verbindung eingehen." Ders., Staatsbürgerschaft und nationale ldentität (1990), in: ders., Faktizität und Geltung. Beiträge zur Diskurstheorie des Rechts und des demokratischen Rechtsstaates, Frankfurt am Main 1992, S. 632660, 641f. Ähnlich äußert sich Habermas in: Der europäische Nationalstaat - Zu Vergangenheit und Zukunft von Souveränität und Staatsbürgerschaft, in: ders., Die Einbeziehung des Anderen. Studien zur politischen Theorie, Frankfurt am Main 1996, S. 128-153, 141: „ Seinerzeit hat der Nationalstaat einen Zusammenhang politischer Kommunikation gestiftet, der es möglich machte, die Abstraktionsschübe der gesellschaftlichen Modernisierung aufzufangen und eine aus überlieferten Lebenszusammenhängen herausgerissene Bevölkerung über das Nationalbewusstsein in die Konlexte einer erweiterten und rationalisierten Lebenswelt wieder einzubetten.

7 Dieser Prozess ist beispielhaft nachgezeichnet in: Eckart Reidegeld, Bürgerschaftsregelungen, Freizügigkeit, Gewerbeordnung und Armenpflege im Prozeß der "Modernisierung", in: Zeitschrift der Savigny-Sliftung für Rechtsgeschichte. Germanistische Abteilung 116 (1999), S. 204-265, 247. 
tungsinstanz sozialer und kultureller Besitzstände konstruiert. Zeit- und ebenenverschoben kannte die Nationalstaatsgründung nach 1871 vergleichbare Debatten. Nation und Nationalstaat scheinen so flexibel zu sein, dass sie am Ende des 20. Jahrhunderts in neuen Konstellationen ihre Bedeutung behauptet haben. ${ }^{8}$

Das interesse am Nationalismus eriahmte daher nicht. Ein Beleg dafür sind nicht nur die zahlreichen Sammelbände, die zu diesem Thema erschienen sind, sondern auch die Überblicksdarstellungen ${ }^{9}$, Reader und Quellensammlungen von theoretischen Texten zur Nationstheorie. Hier zeigt sich eine Reflexionskraft der Nationsforschung auf ihre eigene Geschichte. ${ }^{10}$ Die Flut an Monographien, Artikeln und vor allem Tagungsbänden über $\mathrm{Na}$ tion und Nationalismus ist seitdem nicht abgebrochen. Doch ist die Debatte differenzierte geworden. Im Folgenden soll ein Forschungsbericht über die Nationalismusliteratur der lekten zehn Jahre gegeben werden. Dabei steht die Literatur zu Nation und Nationalstaat in Deutschland im Mittelpunkt. Sie wird ergänzt durch Ausblicke auf vergleichbare Entwicklungen beziehungsweise bestimmte Alternativen in anderen europäischen Staaten, ohne dass die folgenden Ausfühnungen dadurch zu einem europäischen Forschungsüberblick werden könnten.

Der Forschungsbericht folgt den großen Themen, die Dieter Langewiesche 1995 angesprochen hatte und behandelt die Europäisierung der Nationalismusforschung (Kapitel 1), die neueste kulturgeschichtliche Literatur zu Nationsbildung und Nationalismus (Kapitel 2) die Literatur zum Verhältnis von Religion und Nation (Kapitel 3) zum Verhältnis von Region und Nation (Kapitel 4) sowie zu Fragen von gender und Nation (Kapitel 5).

\section{Die Europäisierung der Nationalismusforschung}

Es fallen Blindstellen, Verengungen und Lücken in der Nationalismusforschung auf. Generell konzentriert sie sich immer noch auf das Zeitalter der Nationalstaaten. Vor allem die Zeit zwischen der Revolution von 1848 und dem Ersten Weltkrieg steht im Mittelpunkt des Interesses. Dagegen fällt die Nationalismusforschung für das 20. Jahrhundert ab. Sie folg dabei letzlich dem Gründungsmythos des geeinten Europas, dass der Nationalismus überwunden sei. Dies rechtfertigt sich lediglich durch die Gleichsetzung von Nationalismus und Nationalstaaten. Ausgeblendet wird dabei, dass auch Europa ein Gegenstand der Nationalismusforschung ist. Immer häufiger tauchen in der Debatte um die europäische integration Aspekte und Denkfiguren aus dem nation-building auf: Hierzu gehören

8 Die Flexibilität von Nation und Nationalismus arbeitet heraus: Christian Geulen, Die Metamorphose de Identität. Zur "Langlebigkeit" des Nationalismus, in: Aleida Assmann ( $\mathrm{Hg}$.), Identitäten, Frankfurt am

Main 1 . 3 , $346-373$.

9 Vgl. Hans-Ulrich Wehler. Nationalismus. Geschichte, Formen, Folgen, München 2001; Miroslav Hroch, Das Europa der Nationen. Die modeme Nationsbildung im europäischen Vergleich (Synthesen Bd. 2), Göttingen 2005; Rolf-Ulirich Kunze, Nation und Nationalismus (Kontroversen (Synthesen schichte), Darmstadt 2005; Siegtried Weichlein, Nationalbewegungen und Nationalismus in Europa (Geschichte Kompakt), Darmstadt 2006. 10 Vgl. Michael Jeismann/Henning Ritter $(\mathrm{Hg}$.), Grenztälle. Über neuen und alten Nationalismus, Leipzig
1993; im Englischen: Anthony D. Smith/John Hutchinson (Hg.), Nationalism, Oxford 1994; Omar Dahbour/Micheline R. Ishay $(\mathrm{Hg}$.), The Nationalism Reader, Atlantic Highlands NJ 1995; Gopal Balakrishnan (Hg.), Mapping The Nation, London 1996; Geoff Eley/Ronald Grigor Suny (Hg.), Becoming
national. A reader, New York/Oxford 1996. "der normativ universalistische Anspruch des europäischen Projekts, die derzeit intensive und intensiv geförderte Konstruktion einer europäischen Geschichte, der Ruf nach einer Definition der Außengrenzen der Europäischen Union, deren wiederum historische Begründung unter Verweis auf kulturelle Traditionen des Christentums oder der Aufklärung, die besondere Rolle der einzelnen Nationen im Diskursfeld ,Europa' als zu bewahrende Kulturräume [...] und schließlich die aktuellen Debatten über eine europäische Außen- und Sicherheitspolitik, eine europäische Armee oder auch die Einführung eines europäischen Bildungsstandards." 11

Diese Beispiele machen deutlich, dass die Konstituierung der europäischen politischen Gemeinschaft selbst dann, wenn sie explizit transnational sein soll, nur ein historisches Vorbild hat: die Nation. Diesem historischen Ordnungsmodell folgt sie zwar nicht. Aber sie arbeitet sich an ihm ab.

Ein neuer Trend ist, dass die intemational vergleichende Forschung zu Nation und $\mathrm{Na}$ tionalismus auf europäischer Ebene stark zugenommen hat. Der Nationalismus wird heute mehr als europäisches denn als spezifisch französisches oder deutsches Phänomen gesehen. Die Nationalismusforschung hatte - zumal wenn sie von Historikern betrieben wurde bis in die 1990er Jahre ein bestimmtes Land und eine Nationalbewegung zum Gegenstand. In der Politikwissenschaft, auch in der Anthropologie, sah dies schon zuvor anders aus, wie die Studien von Karl W. Deutsch belegen. ${ }^{12}$ Mehrere Gründe standen bis in die 1990er Jahre hinein einem gesamteuropäischen Vergleich der Nationalbewegungen entgegen. Der Vergleich selbst war nicht neu. Bereits lange vor 1990 war in der Nationalismusforschung verglichen worden. ${ }^{13} \mathrm{Er}$ blieb jedoch auf eine westeuropäische Binnenperspektive beschränkt. Zumal die deutsche Forschungsliteratur verlängerte damit die Frage nach den Ursachen für die nationalsozialistische Machtergreifung international komparativ in die Nationalismusforschung hinein. Als Leitfrage blieb, warum in Deutschland als einzigem entwickeiten Industriestaat die Demokratie der Weltwirtschaftskrise seit 1929 zum Opfer fiel. Vergleichsobjekte waren also die anderen Industriestaaten. Außerdem arbeitete die Nationalismusforschung mit einer typisierenden Begrifflichkeit, die in der Nachfolge von Theodor Schieder den politisch-voluntaristischen Nationsbegriff dem Westen und den ethnisch-kulturell-sprachlichen Nationsbegriff dem Osten Europas vorbehielt. Nach 1990 hat sich das analytische Interesse am internationalen Vergleich der Nationalbewegungen gründlich verändert. Der Vergleich zwischen West- und Osteuropa rückte ins Zentrum des Interesses. Das neue Interesse am West-Ost-Vergleich dokumentiert der Band "Nationalismen in Europa. West- und Osteuropa im Vergleich", den Jöm Leonhard und Ulrike von Hirschhausen 2001 herausgegeben haben. ${ }^{14}$ Die unerwartete Gewaltsamkeit der National-

11 Christian Geulen, Nationalismus als kulturwissenschattiches Forschungsfeld, in: Friedrich Gagger Jörn Rüsen $(\mathrm{Hg}$. Handbuch der Kulturwissenschaften, Bd. 3: Themen und Tendenzen, Stuttgart 2004, S. 439-457, 452.

12 Der Politologe Karl W. Deutsch untersuchte bereits 1953 die soziale Kommunikation in vier sprachlich gemischien Regionen: in Finnland (Finnisch versus Schwedisch), in Böhmen-Mähren (Tschechisch versus Deutsch), in Schottland (Galsch versus Englisch) und in indien-Pakistan (Hindi versus andere Dialekte versus Englisch). Vgl. Karl. W. Deutsch, Nationalism and Social Communication. An Inquiry into the Foundations of Nationalism, Cambridge/Mass. 1953.

13 Zum Vergleich vgl. Heinz-Gerhard Haupt/Jürgen Kocka ( $\mathrm{Hg}$.), Geschichte und Vergleich. Ansäze und Ergebnisse international vergleichender Geschichtsschreibung, Frankfurt am Main 1996.

14 Vgl. Ulike von Hirschhausen/Jöm Leonhard $(\mathrm{Hg}$.) Nationalismen in Europa. West- und Osteuropa im Vergleich, Göttingen 2001. Vgl. auch Willfried Spohn, Nationalismus und Religion. Ein historischsoziologischer Vergleich West- und Osteuropas, in: Politische Vierteljahresschrift 2002, Sonderheft 33, S. 323-346; Klaus Buchenau, Nationalisierung der Religion und Sakralisierung der Nation in Ost- 
bewegungen in den Nachfolgestaaten des kommunistischen Reiches in Osteuropa sowie die Probleme beim nation-building der neuen Nationalstaaten verschoben die Vergleichsachse nach Osten. Mit der Beitrittswelle der osteuropäischen Staaten in die europäische Union wuchs außerdem das Interesse an der Geschichte dieser Länder. Jetzt rücken die Nationalbewegungen in den baltischen Staaten, in Russland und auf dem Balkan in den Blickpunkt. Damit hat sich insgesamt der Kem des analytischen interesses am Nationenvergleich von der Frage nach der Ursache der ${ }_{n}$ deutschen Katastrophe ${ }^{\prime \prime}$ (Friedrich Meinecke) hin zu Gemeinsamkeiten und Unterschieden in Europa nach 1990 verschoben.

\section{Von der Typologie zur Differenz des Nationalen}

Freilich ist die Unterscheidung in einen west- und einen osteuropäischen Nationalismus sehr viel älter. Bereits Hans Kohn hatte sie für die Zwischenkriegszeit zum Ausgangspunk seiner Typisierungen gemacht. Osteuropäisch war dabei der kulturell ethnische Nationsgedanke, der idealtypisch einem politischen Nationsverständnis im Westen gegenübergestellt wurde. ${ }^{15}$ Dieser Ansatz neigte zum Holismus. Der neuere West-Ost-Vergleich dagegen arbeitet sehr viel stärker die Ambivalenzen innerhalb des osteuropäischen Nationalismus und seine teilweise Übereinstimmung mit dem politischen emanzipatorischen Nationsgedanken heraus. Im industrialisierten Raum um Riga stand ein nationalisierter Klassenbegriff de Letten einem traditionellen Standesbegriff der Deutsch Letten einem traditionellen Standesbegnf der Deutschen gegenuber. Die politisch-emanzipatorische Grundausrichtung des lettischen Nationsgedankens war unverkennbar und rückte ihn an die Seite dessen, was man westlichen Nationsgedanken nannte. Für Lettland haben Leo Dribins und Ulike von Hirschhausen diesen Zusammenhang herausgearbeitet. ${ }^{16}$ Im Falle von Ungam ist die Nähe zum französischen Nationskonzept ebenfalls auffällig, wie etwa der vermittelnde Einfluss des 1848er Ministers und ungarischen Politikers Joseph Eötvös belegt. ${ }^{17}$ Auch der russische Nationsgedanke kann nicht schlicht ethnisch und holistisch verstanden werden. Vieimehr spielte die Ausbildung einer neuen weit gespannten Öffentlichkeit nach dem Krim-Krieg eine wichtige Rolle bei der Ausbildung des russischen

miltel-, Südost- und Osteuropa, in: Bohemia 41 (2000), S. 432-437. In der englischsprachigen Forschung war dieser Ansatz schon länger verbreitet. Vgl. D. Djokic, Nationalism, history and identity in the baikans: an overview of recent histories of Europe's south-east, in: The Slavonic and East European Review 81 (2003), S. 511-525; Marija Obradovic, The sociohistoric roots of East European nationalism, in: Canadian Review of Studies in Nationalism 24 (1997), S. 63-75; Jacques Rupnik, The 15 Vgl. Hans Ko of European nationalisms, in: Social Research 63 (1996), S. 41-77.

Vgl. Hans Kohn, Die Idee des Nationalismus. Ursprung und Geschichte bis zur Französischen Revolution. Frankfurt am Main 1962; Taras Kuzio, The myth of the civic state: a critical survey of Hans Kohns framework for understanding nationalism, in: Ethnic and Racial Studies 25 (2002), S. 20-39 Jiri Koralka, Hans Kohns Dichotomie und die neuzeitliche Nationsbildung der Tschechen, in: Eva Schmidt-Hartmann $(\mathrm{Hg}$.$) , Formen des nationalen BewruBtseins im Lichte zeilgenössischer Nationalis-$ mustheorien, München 1994, S. 263-275.

6 Vgl. Leo Dribins, Nationalismus als soziokulturelle Emanzipation: Die Letten 1860-1918, in: von Hirschhausen/Leonhard $(\mathrm{Hg}$.): Nationalismen in Europa (wio Anm 14) $\mathrm{S}$. Hirschhausen, Stand, Region, Nation und Reich: Die Gleichzeitigkeit des Ung ichzelligen inke von Raum Osteuropas. Das Beispiel Riga 1860-1914, in: ebd., S. 372-397. 7 Vgl. Siegfried Weichlein, Qu'est-ce qu'une Nation: St., S. 372-397.

um Nation und Nationalität in der Reich une Nation?" Stationen der deutschen statistischen Debatte ( $\mathrm{H}$.) Demokratio in Deutat in der Reichsgründungszeit, in: Wolther von Kieseritzky/Klaus-Peter Sick sche Essays, München 1999 S 71 $r y$, 1840-1870: a study of , 71-90; Paul Body, Joseph Eötvös and the modernization of Hunga21985. Beispielhaft: Joseph Eotvös individuality and social pluralism in modern politics, Boulder CO 21985. Beispiethaft: Joseph Eötvös, Die Nationalitätenfrage, Pesth 1865.
Nationalismus. Umgekehrt entwickelte sich der italienische Nationalismus in einem Agrarland, freilich mit ausgeprägten urbanen Strukturen und Traditionen. Auch die irische Nationalbewegung stellt kein Beispiel für den politischen Nationsbegriff des Westens dar, ganz zu schweigen vom Staatsbürgerschaftsrecht und dem Nationsgedanken des modemen is rael, das ein fester Bestandteil des politischen Westens ist. So dient der Vergleich zwischen den Nationalbewegungen in West- und Osteuropa vor allem der Differenzierung innerhalb des Westens und des Ostens. ${ }^{18}$ Von dem einen östlichen Nationskonzept kann danach nicht mehr die Rede sein, vielmehr handelt es sich um mehrere einander überkreuzende und miteinander konkurnerende Auffassungen von Nationen, Nationalität und Nationalstaat.

Generell folgte die jüngste Nationalismusforschung nicht den Bahnen von Typologien, seien sie nun zweiphasig (Hans Kohn, Louis Snyder) oder dreiteilig (Theodor Schieder, Peter Alter). Auch die madernisierungsgeschichtichen Großerzählungen über den Ursprung von Nation und Nationalismus gerieten in die Kritik, besonders die Nationstheorie von Ernest Gellner, der Nationen als Korrelat von Modernisienungsprozessen sah. Nationen beruhten für ihn auf standardisierten Hochkulturen. ${ }^{19}$ Die sozialgeschichtliche Nationalismusforschung stellte den modemisierenden Impuls der Nationalstaaten in den Vordergrund. Nationen und Nationalstaaten waren Vehikel der Modemisierung, was sich in der Umgestaltung der Verfassungen, des Wahlrechts, des Rechtsstaats und des Soziaistaats äußerte. Die neuere Nationalismusforschung der 1970er Jahre ging von der Modemisierungstheorie aus. Modemisierung galt ihr als ein gleichsam natüricher Entwicklungspfad für alle Gesellschaften. Zu ihr gehörte auch die Entwicklung hin zum Nationalstaat. Modernisierungstheorien erlaubten der Nationalismusforschung, Abweichungen von der angenommenen normalen Entwicklung zu messen. Die generelle Erweitenung der Sozialgeschichte hin zu kulturellen Fragestellungen und Differenzierungen prägte auch die vergleichende $\mathrm{Na}$ tionalismusforschung, die inzwischen mehr an den ideellen, sozialen und politischen Differenzienungen interessiert ist als an Typen und Gemeinsamkeiten. Die Differenzbestimmung löste die Modernisierungstypologie ab.

Mit der Differenzienung des Nationalen auf der europäischen Ebene ging die Kritik am hierarchischen Konzept von Nationsbildung einher, das bis dahin - auch unter dem Einfluss

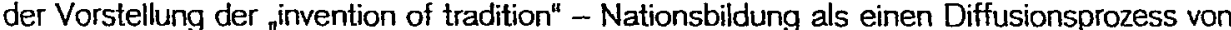
oben nach unten konzeptualisiert hatte. Den Eliten kam hierbei die entscheidende Rolle zu. Eliten propagierten, organisierten, politisierten ihr Konzept der Nation und verankerten es in der Masse. Nationsbildung wurde so als ein Prozess von oben nach unten aufgefasst. Dem kam die spätmarxistische Auffassung von Nationalismus als Manipulationsinstrument der politischen Eliten entgegen. Und davon war insbesondere Eric Hobsbawm geprägt. Nation und Nationalstaat kommen jedoch nicht primär durch "Sickerprozesse" des Nationalen (Hans-Ulrich Wehler) zustande. Das Nationale wird vielmehr zur Resultante von kulturellen Basisprozessen, etwa der Vergemeinschaftung von Tumem und der Vorstellung von nationalen Körpern, die - wie Moritz Föllmer gezeigt hat - zum beherrschenden Muster der nationalen Selbstdeutung deutscher Eliten nach 1918 wurde. ${ }^{20}$ Nicht die Logik des trickle-

18 Zum russischen Nationalismus vgl. Andreas Kappler, Nationsbildung und Nationalbewegungen in Russländischen Reich, in: Archiv für Sozialgeschichte 40 (2000), S. 67-89.

19 Vg Ernest Gellner, Nationalismus und Moderne, Berlin 1995 \& $=$ Nations and Nationalism, Oxforı 1983).

20 Vgl. hierzu Svenja Gollermann, Körper der Nation. Habitusformierung und die Politik des Turnen 1860-1890, Göttingen 1998; Stełan llig, Zwischen Körperertüchtigung und nationaler Bewegung 
down, sondem die sich wechselseitig verstärkende und überkreuzende Logik von kulturellen Prozessen, Diskursen und sozial repräsentativen Selbst- und Fremderfahrungen bildet den Ausgangspunkt für die neuere Nationalisierungsforschung. Ein beeindruckendes Ergebnis dieses Anti-Diffusionismus "von oben nach unten" ist die Studie von Oliver Zimmer zur Entstehung der Schweiz zwischen der Gründung der Helvetischen Gesellschaft 1761 und den 600-J Rütli-Schwures. Er folgt nicht den überkommenen Erählungen des liberalen Siegesmarsches oder des Gegensatzes von Föderalismus und Kommunalismus, sondern entwickelt aus den Geschichtsdiskursen der Helvetischen Gesellschaft nach 1761, der Haltung der einzelnen Kantone zur Verfassung der Helvetik, später zur 1848er Verfassung, zur Verfassungsrevision von 1874 und schließlich zu den Feiem von 1891 ein komplexes Bild der Anziehungs- und Abstoßungskräfte über einen längeren Zeitraum. Zimmer löst die Spannung zwischen den verschiedenen Sprachen, Konfessionen und Geschichtskulturen nicht reduktionistisch in ein schlussendlich siegreiches Prinzip auf, sondern differenziert nach Entscheidungsebenen und Eingriffsmechanismen. Besonderes deutlich wird dies bei der in den 1870er Jahren entscheidenden Frage des Volksvetos, als der katholische Bevölkerungsteil durch den demokratischen Gedanken eine Vetoposition gegen den auf nationaler Ebene tonangebenden Liberalismus erhielt. Diese gänzlich unenwartete Verbindung trug nicht unbeträchtlich zur Integration des katholischen Volksteiles bei. ${ }^{21}$ Zimmers Darstellung überwindet die begriffliche Entgegensetzung von Mobilisienungsprozessen "von unten" und "von oben" und entwickelt ein Modell der wechselseitigen Verstärkung beider Mobilisierungen. Für Italien argumentierte llaria Porciani ähnlich. Auch sie wandte sich von Ansätzen ab, die die Nation von unten nach oben, von der Stadt zur Nation hin konstruierten. Stattdessen geht sie von der parallelen Ausbildung lokaler und nationale Eliten in einem einheitlichen und parallel verlaufenden Prozess aus. ${ }^{22}$

\section{Identitäten in Grenzregionen}

Zur Europäisierung der Nationalismusforschung gehört auch das verstärkte Interesse an Hybrid- und Mischformen von nationalen Identitäten in sprachlichen und kulturellen Mischregionen, die sich dem Zugriff der nationalstaatlichen Geschichtsschreibung entzieht. Bevorzugte Gegenstände hierzu bilden etwa Südtirol, Elsass-Lothringen und die Nationalitätenprobleme in Österreich-Ungarn. ${ }^{23}$ Das Ende der weltpolitischen Blockbildung zwischen

Turnvereine in Bayern 1860-1890, Köln 1998; Moritz Föllmer, Der „kranke Volkskörper. Industrielle hohe Beamte und der Diskurs der nationalen Regeneration in der Weimarer Republik, in: Geschichte und Gesellschaft 27 (2001), S. 41-68; Thomas Alkemeyer, Images and politics of the body in the national socialists era, in: Sport Science Review 4 (1995), S. 60-90.

$21 \mathrm{Vgl}$. Oliver Zimmer, A Contested Nation. History, Memory and Nationalism in Switzerland, 17611891, New York, Cambridge 2003

22 Vgl. llaria Porciani, Lokale Identität - nationale Identität. Die Konstruktion einer doppelten Zugehörigkeil, in: Oliver Janz u. a. ( $\mathrm{Hg}$.), Zentralismus und Föderalismus im 10 einer doppelten Zugehörig2000, S. 103-136. 23 Vgl. vor allem Cole, Für Gott, Kaiser und Vateriand (wie Anm. 1); ders., Nationale Identität eines „aus-
erwählten Volkes: zur Bedeutung des Her-Jesu-Kultes unter der doutschspachigen Bewökeng Tirols 1859-1896, in: Heinz-Gerhard Her-Jesu-Kultes unter der deutschsprachigen Bevölkerung deutschen Geschichte. Frankfurt ard Haupt/Dieter Langewiesche (Hg.), Nation und Religion in de deutschen Geschichte. Frankfurt am Main 2001, S. 480-515; ders., The Construction of German Identity in Tirol, c. 1848-1945, in: Ther/Sundhaussen/Kruse (Hg.), Regionale Bewegungen (wie Anm. 1), S. 19-42; zum adriatischen Grenzraum vgl. Rolf Wörsdörfer, Krisenherd Adria 1915-1955. Konstruklion und Artikulation des Nationalen im italienisch-jugoslawischen Grenzraum, Paderborn 2004; zu osteuropäischen Grenzräumen vgl. Philipp Ther/Holm Sundhausen $(H g)$ Nationaliäten
Ost- und West hat die politische und die wissenschaftliche Wahmehmung von Grenzregionen gefördert. Nationale und kulturelle Mischregionen auf dem Balkan und im Kaukasus zeigten, wie explosiv diese Konstellation auch weiterhin ist.

Methodisch fordern diese Studien einen weithin geteilten Grundsatz der modemen $\mathrm{Na}$ tionalismusforschung heraus, den Giddens so formuliert hat: "frontiers become borders"24 Erst die Herrschaft über ein klar demarkiertes Territorium (Max Weber) machte die nationale Gemeinschaft genauso möglich wie die Demokratisienung des Wahlrechts oder den Ausbau eines Wohlfahrtsstaates. Die Funktionsweise von beiden setzt voraus zu wissen wer dazu gehört und wer nicht. Inklusion der einen bedeutet im Nationalstaat immer Exklusion der anderen. Grenzregionen wie die österreichisch-italienische, die deutsch-tschechsche oder die deutsch-französische Region kannten zwar rechtlich diese klare Demarkie rung, Nationalisierung und Demokratie konnten jedoch unter den Bedingungen von Mischbevölkerungen nie vollkommen zur Deckung gebracht werden. Die sprachlich-ethnische Grenze erwies sich als schwer demokratisierbar, weil das Verhältnis von Mehrheit und Minderheit durch Wahlen nicht umkehrbar war. Von diesem Wechsel von der Mehrheit zur Minderheit aber lebt die Demokratie.

Ein Beispiel für die Beziehungsgeschichte zwischen Nationalitäten in einer Grenzregion, die gemeinsam eine neue Identität ausbilden, ist Tirol, das von Laurence Cole in seiner Studie "Für Gott, Kaiser und Vaterland" untersucht wurde. ${ }^{25}$ Cole arbeitet heraus, dass sich die deutsch-tiroler Identität zwischen 1863 und $1909 \mathrm{im}$ Vereinswesen und in den ideologischen Kontexten in der Grenzregion herstellte. Zum Identifikationsobjekt der Deutschtiroler wurde Andreas Hofer, dessen Gedenken im Zentrum des konservativen politischen Lagers stand. An ihm orientierte sich die offizielle Version deutscher historischer Gedächtniskultur in Tirol. Bezeichnend ist dabei, dass die Ausbildung einer deutsch-tiroler Identität nicht ei-

konflikte im 20. Jahrhundert. Ursachen von interethnischer Gewalt im Vergleich, Wiesbaden 2001; Michael G. Müller/Rolf Petri $(\mathrm{Hg}$.). Die Nationalisienung von Grenzen. Zur Konstruktion nationaler Identität in sprachlich gemischten Grenzregionen, Marburg 2002; Stephen L. Harp, Leaming to be loyal: primary schooling as nation building in Alsace and Lorraine, 1850-1940. DeKalb 1998; Wolfgang Haubrichs, Huius regio, eius lingua. Literarische Spiegelungen der Sprachenpolitik im deutschfranzösischen Grenzraum seit 1871, in: Roland Marti ( $\mathrm{Hg}$.). Sprachenpolitik in Grenzregionen, Saarbrücken 1996, S. 213-249; David Hopkin, Identity in a Divided Province: The Folklorists of Loraine, 1860-1960, in: French Historical Studies 23 (2000), S. 639-682.

24 "Traditional states (class divided societies) are essentially segmental in character. The administrative reach of the political centre is low, such that the members of the political apparatus do not ,govem' in the modern sense. Traditional states have frontiers, not borders. " (Anthony Giddens, The Nation-State and Violence Volume Two of a Contemporary Critique of Historical Materialism, Berkeley 1985, S. 3f.).

25 Cole, Für Gott, Kaiser und Vaterland (wie Anm.1); ders., Nation, anti-enlightenment, and religious revival in Austria. Tyrol in the 1790s, in: The Historical Joumal $43(2000)$, S. 475-499; ders, Das letzte Aul ine Aus Aufgebot der Gegenreformation: Zum österreichischen Kulturkampf in Tirol, in: Comparativ. Leipziger Beilrage zur Universalgeschichte und vergleichenden Gesellschaftsforschung 12, 2002, S. 97-116 ders., Religion und patriotische Aktion in Deutsch-Tirol (1790-1814), in: Otto Dann/Miroslav Hroch/Johannes Koll $(\mathrm{Hg}$.). Patriotismus und Nationsbildung am Ende des Heiligen Römischen Reiches, Köln 2003, S. 345-378; ders., The Construction of German Identity in Tirol, c. 1848-1945, in: Philipp Ther $(\mathrm{Hg}$.), Regionale Bewegungen und Regionalismen in europäischen Zwischenräumen se der Mitte des 19. Jahrhundert, Marburg 2003, S. 19-42; ders., Nationale Identitäl eines „auserwähten Volkes: zur Bedeutung des Herz-Jesu-Kultes unter der deutschsprachigen Bevölkerung Tirols 1859-1896, in: Haupt/Langewiesche $(\mathrm{Hg}$.$) , Nation und Religion in der deutschen Geschichte (wie$ Anm. 23), S. 480-515; ders., Province and Patriotism: German National Identity in Tirol, 1850-1914, in: Österreichische Zeilschrift für Geschichtswissenschaften 6 (1995), S. 61-83. 
nen Prozess von manipulativer sozialer Integration von oben darstellte, sondern dass sie auf Schützenvereinen, also einer patriotischen Begeisterung der Basis gründete. Zum wichtigsten Bezugspunkt für die Identitätsbildung der Deutschen in Tirol wurde die Landesebene, nicht die nationale und schon gar nicht die Reichsebene der österreich-ungarischen Monarchie. Sie definierten sich als Deutsche in Österreich. Coles Analyse der Identitätsbildun nut der Deutschtiroler kulminiert in der Einsicht, dass „die Region als primärer Ort nationaler Identifizierung und ihre Städte, Gemeinden, Talschaften und so weiter als unmittelbare Arenen politischer Aktivität"26 interpretiert werden müssen. Dies galt auch für die nichtdeutsche Bevölkenung in Tirol, die sich zusehends als Bewohner des "Trentino" oder als "Trentiner" - so der Identifikationsbegriff - verstand. Erst die Evakuierung von Teilen der Bevölkerung durch die Wiener Regienung, das Kriegsrecht und der wachsende Einfluss deutschnationaler Gruppen während des Ersten Weltkriegs entfremdeten die Masse der Bevölkerung des Trentino der österreichischen Herrschaft in entscheidendem Maße.

Aber nicht nur Hybridkulturen, auch Dissoziationen von nationalen identitäten können das Ergebnis von Beziehungsgeschichten in Grenzregionen sein. Ein Beispiel für die Dissoziation von "Budweisers into Czechs and Germans" ist das Buch von Jeremy King ${ }^{27}$ Dass deutsche Budweiser ihr Deutschsein um die Jahthundertwende um 1900 plötzlich entdeckten, mythisierten und in Gegensatz zur tschechischen Bevölkenng brachten, lag an den Katalysatoren Sozialisation und Schulwesen. Diese Bereiche rückten immer mehr an Zentrum der Nationalitätenkation und Schulwesen. Diese Bereiche rückten immer mehr ins Zentrum der Nationalitätenkonflikte. Hieß es noch zu Beginn des 20. Jahrhunderts im südlichen Böhmen, es gebe drei Nationen, nämlich Deutsche, Tschechen und Budweiser, so konnte wenige Jahre später davon keine Rede mehr sein. Die Budweiser waren verSchwunden. Jeremy King zeigt, dass die Ethnizität nicht gemäß der gängigen nationalen Sichtweise der Nationalität vorausging. Nationalisten gaben immer wieder vor, die älteren ethnischen Ursprünge eines Volkes nur in Erinnerung zu rufen. Tatsächlich folgte die Kategonien der Ethnizität derjenigen der Nationalität, ging ihr also nicht voraus. Die Sprache des nationalen Erwachens oder Wiedererwachens darf durch die analytischen Kategorie der Nationalismusforschung nicht reproduziert und in die Gegenwart hinein verlängert wer-
den:

"Ethnic Groups are not antecedents but national products, projected ahistorically yet with history-making effect into the past. Far from constifuting distinct and robust categories of historical analysis, the ethnic group and the ,nation' stand in a relationship of

Ein anderer Fall einer solchen Grenzregion ist Oberschlesien. Die nationale Mischkonstellation Oberschiesiens besaß mehrere Dimensionen, die sich anhand von Wahlen, im Vereinsleben, in der staatlichen Politik Polens und Deutschlands, aber auch im religiösen Bereich, den Pfarrgemeinden und den Frömmigkeitsstilen nachzeichnen lassen. Dabei fält in jedem Fall auf, dass die sprachliche Konstellation sich nicht identisch auf die Pobei fall die Religion abbilden löstien Politik oder Ther für Politik und politische Auch in Oberschlesien kam es zu Hybridbildungen, die Philipp deleben unters ${ }^{29}$ Orem deleben untersuchten. ${ }^{29}$ Oberschlesien, das lange Gegenstand der Memorialiteratur der

26 Cole, Für Gott, Kaiser und Vaterland (wie Anm. 1), S. 517.

27 King, Budweisers (wie Anm. 1)

28 Ebd., S. 8.

29 Vgl. Philipp Ther, Die Grenzen des Nationalismus: Der Wandel von Identitäten in Oberschlesien von Europa (wie Anm. 14), S. 322-346; ders., Schlesisch, deutsch Leonhard ( $\mathrm{Hg}$.), Nationalismen in
Vertriebenen war, ist auf die Tagesordnung seriöser Nationalismusforschung zurückge kehrt. Es stellt geradezu einen Paradefall für Mischungen, aber auch Antagonismen von nationalen Identitäten in Grenzregionen dar. Der Osteuropa-Historiker Philipp Ther arbeitet im von Nationalitätenkämpfen geprägten Oberschlesien die Region als zentrale Identifikationsebene heraus. Bei den mehmaligen Wechseln der politischen Zugehörigkeit in den letzten 200 Jahren zeichnet sich als roter Faden eine Nähe zur Region, weniger aber zur Nation ab. Die räumliche Kategorie der Grenzregion konstituierte sich so als Ort sozialer Praktiken mit hohem kulturellem Eigensinn. "Wenn eine Identifikation stabil war, dann noch am ehesten jene mit der Region. 30 Manifest wurde dieser nicht auf die Sprachenzugehörigkeit zurechenbare Eigensinn der Region in den Abstimmungen nach dem Ersten Weltkrieg. 1919 erreichten die poinischen Listen bei den Kommunalwahlen in Oberschlesien noch über $60 \%$ der Stimmen, was etwa dem Anteil der polnischsprechenden Bevölkerung entsprach. Beim Plebiszit über den Anschluss an Deutschland oder Polen am 21. Mär 1921 votierten Oberschlesier dagegen überwiegend für Deutschland: 707.393 (59,6\%) gegen 479.365 Stimmen - die Stimmenverhältnisse hatten sich damit genau umgekehrt. Es müssen also im größeren Umfang Polen für die Zugehörigkeit zum Deutschen Reich gestimmt haben, sei es aus Loyalität gegenüber der überkommenen staatlichen Ordnung, sei es aus ökonomischen Erwägungen. Die regionale Bewegung des „Bundes der Oberschlesier", die für eine Autonomie eintrat, brachte es aur 350.000 Mitglieder. Dahinter stand ein hoher Anteil an zweisprachigen Bewohnern Oberschlesiens, die sich der eindeutigen Zuordnung zu ihren Titulamationen entzogen. Erst das Optionsrecht zur Auswanderung nach der Teilung Oberschlesiens machte bis 1925 das deutsche und das polnische Oberschlesien homogener. Mischlagen mit wechselnden und doppelten Loyalitäten wurden politisch zur Eindeutigkeit gezwungen.

Die europäischen Grenzregionen waren damit so etwas wie Laboratorien des Nationalen. Zwischen nationalen Identitäten kam es zu Distanz, Abstoßung, Radikalisierung, Anziehung und Hybridisierung. In ihnen fühtten sich die Protagonisten nicht am Rande, sondern im Zentrum des Geschehens. Die Ethnisierung nationaler Identität am Ende des 19. Jahrhunderts machte Grenzregionen zur Entscheidungszone nationaler Kämpfe. Laboratorien des Nationalen waren Grenzregionen auch deswegen, weil in ihnen Konstellationen des Nationalen entstanden, die nicht dem klassischen Verständnis von Volkssouveränität ent-

Oberschlesien 1921-1956, in: Philipp Ther/Kai Struve $(\mathrm{Hg}$.$) , Die Grenzen der Nationen. Identitäten-$ wandel in Oberschlesien in der Neuzeit, Marburg 2002, S. 169-202; Jim Bjork, Neither German nor Pole: Catholicism and National Indifference in a Central European Borderland, 1890-1922, Ann Arbor 2007; ders., Beyond the Polak-Katholik: Catholicism, Nationalism, and Particularism in Modem Poland, in: Urs Altermatt/Franziska Metzger ( $\mathrm{Hg}$.), Religion and Nation, Freiburg (Schweiz, im Druck); ders., Nations in the Parish: Catholicism and Nationalist Conflict in the Silesian Borderiand, 18901922. in: Michael Geyer/Hartmut Lehmann ( $\mathrm{Hg}$.), Religion und Nation - Nation und Religion: Beiträge zu einer unbewältigten Geschichte, Göttingen 2004, S. 207-224; ders., Getrennt durch einen gemeinsamen Glauben: Die Organisierung katholischer Arbeiter in Oberschlesien, 1870-1914, in: Claudia Hiepel/Mark Ruff (Hg.), Die christliche Arbeiterbewegung in Europa, 1850-1950, Stuttgart 2003, S. 176-198; ders., Everything Depends on the Priest: Religious Education and Linguistic Change in Upper Silesia, in: Ther/Struve $(\mathrm{Hg}$.). Die Grenzen der Nationen (wie oben), S. 71-101; ders., A Polish Mitteleuropa? Upper Silesia's Conciliationists and the Prospect of German Victory, in: Nationalities Papers 29 (2001), S. 477-492.

30 Philipp Ther, Der Zwang zur Nationalen Eindeutigkeit und die Persistenz der Region: Oberschlesien im 20. Jahrhundert, in: Ther/Sundhaussen/Kruse ( $\mathrm{Hg}$.), Regionale Bewegungen und Regionalismen (wie Anm. 1), S. 233-257, 241. 

Sprachen: der Identität von Staatsgebiet, Staatsvolk und Staatsgewalt. ${ }^{31}$ Die verschiedenen Grenzregionen entwickelten sich völig anders. Wahrend in Südtirol, Katalonien, Galizien und im Baskenland ${ }^{32}$ eine eigene identität entstand, verschärfte sich andernorts (zumal auf dem Balkan) der Konflikt. Grenzregionen konnten einerseits den Weg in die Regionalisierung und Autonomisierung gehen, oder aber auch in die Krisenverschärfung und Sezession. Mehrere Faktoren bestimmten diesen Weg. Die Addition von Konflikten über Sprache, Religion und Kultur war vor allem dot explosiv, wo Religon Konnikten über Sprache, Rerchä scharften. Eine knitische Rolle spielte auch der soziale Faktor, vor allem die Mittelschichten, Quebecs gezeigt im Vergleich der Nationalismen Nordirlands, des Baskenlands und Quebecs gezeigt hat. ${ }^{33}$ Dass der Ausbruch des Zweiten Weltkrieges in einer Grenzregion wie Oberschlesien inszeniert wurde (Gleiwitz), zeigt, wie sehr diese Gemengelagen Raum für politische und ideologische Instrumentalisienngen anders als im 19. Jahthundert Zwanghomo "ethnische Säucrungen" "ethnische Säuberungen" genannt, versuchten, die Identität von Staatsgebiet und Nation
polisch zu erzwingen.

\section{Transnationale Geschichte}

Sowohl der Vergleich als nationalismusgeschichtliche Methode als auch das Interesse für Nationalitäten in Grenzregionen lenkten die methodische Debatte in den Geschichtswissenschaften auf en schaft au eine Ebene oberhalb der Nationalstaaten. Transnationale Geschichtswissenschaft - nach dem stichwortgebenden Buch von Jürgen Osterhammel - bricht die nationalJahren als historische Methen der Historiker auf. Selbst der Vergleich, der in den letzten 10 Jahren als historische Methode immer weiter reüssierte, neigte dazu, die verglichenen Einheiten zu gegenständlichen und als Nationalgesellschaften vorauszusetzen Wo der Vergleich eine Ebene oberhalb der Nationalstaaten suchte trug rer nale Zuschreibungen weiterzutragen. Die Gefahr des historischen Vergichs bestand datio das explanandum mit dem explanans zu verwechseln. ${ }^{34}$ Dagegen stellt die transnationale

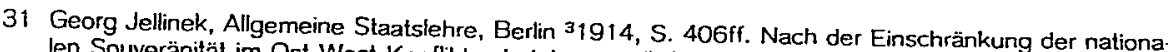
len Souveränität im Ost-West-Konflikt scheint generell die Kategorie der Souveränität im Niedergan begriffen zu sein. Vgl. Heinhard Steiger, Geht das Zeitaller der Souveränităt zu Ende?, in: Der Staal
41 (2002) S. 331-357.

32 Zum baskischen Nationats

Zum baskischen Nationalismus jüngst: Ludger Mees, Nationalismus und Arbeiterbewegung im spani384, Baskenland zwischen 1876 und 1923, in: Geschichte und Gesellschaft 20 (1994), S. 364 derts, in: Archiv für Soze "Sonderweg". Staat und Nation(en) im Sparien des 19. und 20. Jahrhunrise and deveprors rise and development of Basque nationalism in the light of social movement theory, in: Theory and Society 33 (2004), S. 311-331; ders., Zwischen Mobilisierung und Institutionalisierung. Der baskische Nationalismus 1953-1995, in: Heiner Timmermann ( $\mathrm{Hg}$.$) , Nationalismus in Europa nach 1945$ 1975-1981, Stuttgart 2002 Antje Helmerich, Nationalismus und Autonomie. Die Krise im Baskenland 33 Vol Peter Waldtgart 2002.

flikte am Beispiel Separatismus. Wel des Baskenlandes, Nordirands und Quebecs, Opladen 1989; ders., Gewaltsame Winkler. Nationalismus, Natione Nationalitätenkonflikte in vergleichender Perspektive, in: Heinrich A vergleichend: Peter W. Nationalităten, Supranationalität, Stuttgart 1993, S. 82-107. Internationa vergleichend: Peter Waldmann, The radical community: A comparative analysis of the social back-

34 Vgl. zu dieser Kritik and Herbollah, in: Sociologus 55 (2005), S. 239-259.

ders., Les tranfers franco-allemands, Paris 1999 . Michel Espagne, Au delà du comparatisme, in gen Osterhammet, Geschichlswiss, Pans 1999, S. 35-49. Zentraler Auslöser der Debatte war: Jür-
Geschichte kulturelle und politische Transferprozesse in den Mittelpunkt. Damit geraten neue Räume in den Blickpunkt der Historiker: Räume, die quer zu Nationalstaaten lagen und die Teile verschiedener Nationalgesellschaften miteinander verbanden. Transnationale Geschichte lenkt zum einen die Aufmerksamkeit auf die nationale Voreingenommenheit der Historiker auch dann noch, wenn sie international vergleichen. Zum anderen macht sie Prozesse sichtbar, die mit nationalen Begriffen, Raumbildem und Wirkungsmustem nicht zu ertassen sind. Vielfach neigen Historiker dazu, nationaler zu sein als ihr Gegenstand. Die Debatte geht seither darum, welches das Objekt der Analyse sein muss, um Nation und Nationalismus beschreiben und verstehen zu können: der Nationalstaat selbst oder die übernationale Ebene. Welches ist der Referenzrahmen für Prozesse der Nationsbildung? Die Transnationalisierungsdebatte hat darauf aufmerksam gemacht, dass Nationalbewegungen nicht einfach Phänomene innerhalb einer Gesellschaft sind, sondern dass sie entscheidend von Transfer-, Lem- und Austauschprozessen mit anderen Gesellschaften abhängen.

Die Forschung zur transnationalen Geschichte berührt eine Grundannahme der Nationalismusforschung im Kem. Nation und Nationalstaat entwickelten sich nicht nur "von unten nach oben" als Ergebnis von Mobilisierungsprozessen einer Basis, die national vergemeinschaftet wurde. Vielmehr ist ihre Dynamik erst zu verstehen, wenn sie auch als Antwort auf klassische transnationale Phänomene des 19. Jahrhunderts wie Massenmobilität und Migration verstanden werden. Besonders die Mobilität war ein Kennzeichen des späten 19. Jahrhunderts. Wirtschaft und Arbeit standen im Zeichen dieser Globalisierung. Das Schiagwort der "nationalen Arbeit" war nicht nur Ausdruck einer innenpolitischen Wende 1878/79, sondem auch ein "nationalisierender Effekt globaler Zirkulation“. Sebastian Conrad arbeitete in seiner Berliner Habilitationsschrift die Formveränderung des Nationalen vor dem Ersten Weltkrieg unter den Bedingungen intensivierter Globalität heraus.

${ }_{n}$ Nationalismus und nationale Selbstverständigung werden nicht lediglich als Ausdruck

kultureller Traditionen, sozialen Wandels oder intemer Spannungen verstanden, sondern zugleich auch als Produkt und Effekt von Interaktionen, Austausch und Zirkulation innerhalb einer zunehmend vemetzten Welt. [...] Ohne die Vemetzung der Welt durch kapitalistische Produktions-, Konsumtions- und Handelskreisläufe, ohne die politische Formatierung der Welt im Kontext von Imperialismus und Völkerrecht ist auch die Konsolidierung von Gesellschaften als Nationalstaaten nur unvollständig beschrieben." ${ }^{35}$

Transnationale Geschichte als Voraussetzung von Nationsbildung ist keine Reformulierung der marxistischen Ableitung des Nationalismus vom Kapitalismus, der die Welt umspannt. Aber die innere Nationalstaatsbildung und der Nationalismus standen immer auch unter globalem Vorzeichen. Ambivalent bleibt die transnationale Geschichte jedoch, wenn es um die Art und Weise des Bezugs auf die globale Ebene geht. Die Akteure werden vor allem der transnationalen Ebene zugeschrieben, der nationalen Ebene bleibt die Reaktion darauf. Transnationale Geschichte als Rahmen der Nationalismusforschung neigt daher dazu, der Nation den Part der Modernisierungskritik zuzuweisen Übersehen wird dabei, was Jürgen Habermas als den politischen Mehrwert des Nationalstaats bezeichnete: die Her-

schichte und Zivilisalionsvergleich, Göttingen 2001; ders., Transnationale Gesellschaftsgeschichte: Erweiterung oder Aliernative?, in: Geschichte und Gesellschaft 27 (200)), S. 464-480. Zur Anwendung dieses Begrifts vgl. Gisela Mettele, Eine „imagined community jenseits der Nation. Die Hernhuter Brüdergemeine als transnationale Gemeinschaft, in: Geschichte und Gesellschaft 32 (2006)

35 Conrad, Globalisierung und Nation (wie Anm. 1), S. 201

276 I Neue Politische Literatur, Jg. 51 (2006)

Neue Politische Literatur, Jg. 51 (2006) I 277 
stellung nationaler Gleichheit als Voraussetzung von Demokratie und Sozialstaat. Auf der transnationalen oder der globalen Ebene wird nicht gewählt und werden keine Renten ausbezahit.

Absolut neu ist die Einsicht in die transnationalen Bedingungen des Nationalen jedoch nicht. Bereits frühere Studien hatten gezeigt, wie der Weg Bremens in den Nationalstaat mmer vor dem Hintergnund der internationalen Handelsbeziehungen der Hansestadt zu sehen ist. Bremens Nationalisierung war nicht nur eine Mobilisierung "von unten", sondern mindestens so sehr eine Umorientierung der intemationalen Handelskontakte auf deutsche Marktbeziehungen hin. National eingestellt zu sein, war für die Bremer Patrizier mit ihren intemationalen Handelsbeziehungen um 1860 wenig plausibel. An fünf Punkten gerieten die Bremer Eliten seit den 1860er Jahren unter Nationalisienungsdruck: in militärischen Fragen, im Vereinsrecht, über Handelsbeziehungen, Bevölkerungswanderungen und durch die nationalistische Mobilisierung. ${ }^{36}$

II. Die kulturgeschichtliche Vertiefung der Nationalismusforschung

Diese Forschungsdebatten haben den Umstand stärker ins Bewusstsein gerufen, dass Kultur für den Historiker in nationalgeschichtlich gebundener Form vorliegt. Die kulturgeschichtliche Vertiefung der Nationalismusforschung, die auch in den letzten zehn Jahren anhielt, stand vor allem vor dem methodischen Problem, dem Gegenstand, den sie analysieren wollte, nicht bereits die analytischen Kategorien zu entnehmen. Nicht wie sich "Nationalkultur" ausbreitete, wer sie organisierte etc. stand im Zentrum des Interesses, sondern wie und warum sich die Vorstellung und Praxis der Nation durch Kultur konstituierte. Die Erfindung der Nation und die Aufwertung von Kultur waren ineinander verschränkte Phänomene. Die modemen Begriffe der Kultur und der Nation entstanden gleichzeitig und verwiesen aufeinander. Die Nation bezog sich auf die Kultur - die Kultur fand in der Nationalgesellschaft ihren Resonanzraum und Geltungsanspruch. Ähnliches hatte Jeremy King be reits für das Verhältnis von Nation und Ethnizität herausgearbeitet, die sich ebenfalls wechselseitig konstituierten. Methodisch verbietet sich daher jedweder Reduktionismus auf eine der beiden Dimensionen.

Dass die beiden Texte von Benedict Anderson und Eric Hobsbawm und Terence Ranger zu "imagined communities" und "invented traditions" geradezu kanonisch wurden, war Ausdruck eines kulturanthropologischen Paradigmenwechsels in der Geschichtswissenschaft. Diese "Instantklassiker" signalisierten die allgemeine Umorientienung der Geschichtswissenschaft, ohne die sie wohl kaum einen solch durchschlagenden Efolg gehabt hätten. Bekannt wurde Andersons Buch durch den Begriff der "imagined community". Den größten Teil seines Buches verwandte er allerdings darauf, die sozialen, kulturellen, wirtschaftlichen und institutionellen Bedingungen für nationale Imagination, besonders den Print-Kapitalismus, auszuführen. Diese Tendenz, nicht die Imagination, sondern ihre materellen Voraussetzungen aufzuzeigen, setzte sich in der zweiten Auflage durch das neue Kapitel über " census, map, museum" fort:

36 Vgl. Dieter K. Buse, Urban and National Identity: Bremen, 1860-1920, in: Joumal of Social History 26 (1993), S. 521-537; ders., Lower Middle Class Nationalism in early 19 th Century Bremen, in: Ca nadian Review of Studies in Nationalism $14(1987)$, S. 93-103; Siegfried Weichlein, Das Spannungsfeid von nationaler und regionaler Identität, in: Werner Bramke (Hg) in Zusammenarbeit mit

Thomas Adam, Politische Kultur in Ostmittel- und Südosteuropa, Leipzig 1999, S. 241-252.
"Fast nirgendwo wird diese Grammatik klarer sichtbar als im Kontext dreier Institutionen politischer Macht, die - obgleich bereits vor der Mitte des 19. Jahrhunderts erfunden ihre Form und Funktion veränderten, als die Kolonialgebiete in das Zeitalter der mechanischen Reproduktion eintraten. Diese drei Institutionen waren der Zensus, die Landkarte und das Museum; gemeinsam prägten sie tief greifend die Art und Weise, in denen der Kolonialstaat sich seine Herrschaft vorstellte: das Wesen der von itm beherrschten Menschen, die Geographie seines Herrschaftsgebietes und die Legitimität seiner Herkunft." 37

Die Nationalismusforschung übertrug diesen Zusammenhang auf die Nationsbildung in Europa. ${ }^{38}$ Dies führte in den letzten Jahren verstärkt zu einem methodischen Paradigmenwechsel von der Kausalität hin zur Repräsentation, der generell in der Kulturgeschichte zu beobachten ist. Die Analyse der Ursachen und Wirkungsmechanismen der Nationsbildung und des Nationalismus wurde ergänzt - wenn nicht mehrheitlich abgelöst - von der Beschreibung und Typisierung seiner Repräsentationsformen in den Medien, der Wissenschaft, der Kunst, seinen semantischen Ausdrucksformen und Symbolpolitiken. Diese Tendenz mündete in die so genannte "Zweite Geschichte" (Winfried Schulze), d. h. in die Untersuchung der Erinnerung von historischen Ereignissen. In den Vereinigten Staaten führte dieser Paradigmenwechsel von der Re- zur Dekonstruktion sogar zur Spaltung des Historikerverbandes. 1998 gründeten die Gegner der dekonstruktivistischen Sichtweise die "Historical Society", und zwar "als Abwehrbastion, von der aus sie den Dekonstruktivisten unter dem Banner ,reconstructing History' entgegentraten." ${ }^{39}$ Weit über die Nationalismusforschung hinaus geht seitdem die Kontroverse, ob ein historischer Gegenstand durch seine Repräsentationen adäquat analysiert werden kann oder ob es - so der Vorwurf nicht den Verlust wissenschaftlicher Standards bedeutet, wenn Repräsentationen verschiedener Gruppen unverbunden nebeneinander stehen.

1. Wissen(schaft) und Nation

Die Verwissenschaftlichung der Nation und die Universalisienung von wissenschaftlichen GesetzmäBigkeiten ihrer Entwicklung hingen innertich zusammen. Die Verwissenschaftlichung des Sozialen war engstens mit der Nationalisierung der Gesellschaften verbunden, wie es Lutz Raphael ausgedrückt hat:

„Die 'Nation' als elementare Form sozialer Kategorienbildung und wichtigste Zwischenstufe zur Formulierung universeller, Gesetzmäßigkeiten' stellt jedenfalls eine jener zählebigen Selbstverständlichkeiten dar, deren Existenz nur aus der Kombination der Deutungsmacht und der Realität von ,Nationalstaaten' zu verstehen ist."40

37 Anderson, Die Ertindung der Nation (wie Anm. 1), S.163f.

38 Das Verhältnis von Kultur und Nation was bereits der Gegenstand von: Bernhard Giesen ( $\mathrm{Hg}$.), Nationale und kulturelle Identität (Studien zur Entwicklung des kollektiven BewuBtseins in der Neuzeit 1) Frankfurt am Main 21991. Vgl. Hroch, Das Europa der Nationen (wie Arm. 9), S. 201-234.

39 Dieter Langewiesche, Was heiBt ,Erfindung der Nation'? Nationalgeschichte als Artefakt-oder Geschichtsdeutung als Machtkampf, in: Historische Zeitschrift 277 (2003), S. 593-617, 593f.: vgl. Elizabeth Fox-Genovese/Elisabeth Lasch-Quinn ( $\mathrm{Hg}$.). Reconstructing History: The Emergence of a New Historical Society. New York 1999. Bedenken gegen eine radikalkonstruktivistische Lesart von Imagination und Invention äußert auch: Anthony D. Smith, The Nation. Invented, Imagined, Recon-

stucled?, in: Milenium. Joumal of lnternational Studies 20 (1991), S. 353-368.

Lut Raphael, Die Verwissenschallichung des Sozialen als meth, s. 35 (1996) S. $165-193,182$. 
Die Vorstellung des Nationalen in den Naturwissenschaften steht im Zentrum des von Ralph Jessen und Jakob Vogel herausgegebenen Bandes Wissenschaft und Nation in der europäischen Geschichte" ${ }^{41}$ Bisher fand vor allem die Geschichte der Geschichtswissenschaften und der Philologien das Interesse der Nationsforschung. ${ }^{42}$ Hier war die Verbindung zwischen Wissenschaft und Nation schon deswegen offensichtlich, weil die Nationalismen Vorstellungen von Nationalliteratur, Nationaltheater, Nationaldrama und National dichtern produzierten, die zum Gegenstand wissenschaftlicher Betrachtung avancierten. Die Geschichtswissenschaft verstand sich als nationale Wissenschaft, zumal nationale identität regelmäßig ihre eigene Geschichtsdeutung beinhaltete. Das Nationalbewusstsein lag in historisierter Form vor. ${ }^{43}$ Diese Historisierung konnte in gegensätzlichen Narrativen stattfinden. Während die Reformation zum zentralen oder historischen Referenzpunkt der deutschen Nationalbewegung wurde, war dies in Frankreich die Französische Revolution. In Italien machte es einen großen Unterschied, welche Form von Romanitá gemeint war: die vorchristliche pagane Antike, die pagane Kaiserzeit, das christliche oder gar das päpstliche
Rom ${ }^{44}$

Stefan Berger arbeitete wesentliche Unterschiede zwischen den Nationalhistoriographien Deutschlands, Frankreichs und Italiens heraus. Im faschistischen Italien war die nationale Geschichtsschreibung nicht völlig gleichgeschaltet. Resistenz blieb möglich. Die Exilierung der historiographischen Opposition erfolgte erst relativ spät. Noch 1928 veröffentlichte Benedetto Croce seine "Storia d'Italia dal 1871 al 1915", "in der er den Faschismus als ganz und gar unhistorisches Phänomen beschreibt, das den langen und beschwerlichen Weg Italiens zu einer freiheitlichen Verfassung und Zivilisation brutal unterbrochen habe" ${ }^{45}$

$41 \mathrm{Vgl}$. Jessen $/$ ogel $(\mathrm{Hg}$.), Wissenschaft und Nation (wie Anm. 1).

42 Vgl. Antoinette $\mathrm{J}$. Lee, Historians as managers of the nation's cultural heritage, in: American studies international 42 (2004), S. 118-137. Zum Beispiel des deutschen Historikers Friedrich Meinecke vg Guido Koch, Nation und Nationalismus bei Meinecke, in: Zeitschrift für Politikwissenschaft 15 (2005)

S. 419-447.

43 Vgl. für Osteuropa: Dennis Deletant/Harry Hanak $(\mathrm{Hg}$.), Historians as Nation-builders: Central- and South-East Europe, London 1988; für Westeuropa: Stefan Berger/Mark Donovan/Kevin Passmore (Hg.). Writing national histories. Western Europe since 1800, London 1999. Unter dem Titel Representations of the past: The Writing of national histories in 19th and 20th Century Europe" vergleich ein von der European Science Foundation (ESF) gefördertes internationales Forschungsprojekt seil 2003 die Nationalgeschichtsschreibungen verschiedener Länder miteinander. Die Analyse erstreck sich aut Insthutionen nationaler Geschichtsschreibung, ihre Erzähistrategien, thre Abgrenzungen von regionaler und lokaler Ebene und wechselseitige Überlappungen. Geplant ist eine sechsbändige Dar44 Vol on wang the Nation.

gischen gischen Antagonismus im frühen italienischen Risorgimento, in: Quellen und Forschungen aus italienzismus und Nand Bibliotheken 80 (2000), S. 495-542. Friedrich Wolfzettel/Peter Ihring, Katholidurch Religion in durch Religion, in; Bernhard Giesen $(\mathrm{Hg}$.). Nationale und kulturelle Identität. Studien zur Entwicklung Traum: Nationate Usprungsmyther in Itaien Frankfurt am Main 1991, S. 388-425; dies., Der föderale (Hg.), Nationales Ursprungsmythen in Italien zwischen Aufklärung und Romantik, in: Helmut Berding wuBtseins in der Neuzeit 2 . literarischen Mythos der 2, Frank Furt am Main 1994, S. 443-483; ders., Vom nationalen Symbol zum der Generation wo der der Generation von 1898, in: Helmut Berding ( $\mathrm{Hg}$.), Mythos und Nation. Siudien zur Entwicklung des

45 Vgl. Stefan Bertser, in der Neuzeit 3, Frankiurt am Main 1996, S. 220-244.

schen, französischen und italienischen Nation. Einige vergleichende Thesen zur deutschen, englirad/Sebastian Conrad $(\mathrm{Hg}$.) Die Nation schrebeschichtsschretbung seit 1800, in: Christoph Congleich, Göttingen 2002, S. 49-77, 53; ders., The Search for normality. National ldentity and Historical
In Deutschland war so etwas nach 1933 undenkbar. Bereits in der Weimarer Republik hatten linke Historiker wie Gustav Mayer keine Chancen im akademischen Establishment. ${ }^{4}$ In Frankreich waren politisch rechts stehende Historiker in der akademischen Geschichtsschreibung schwach vertreten, was auch an der Verankerung der nationalen idee auf de Linken lag. Durchgängig spielen zwei methodische Gemeinsamkeiten für alle Nationalhistoriographien eine Rolle. Einerseits argumentierten Historiker mit dem Objektivitätspostulat, wenn sie von der Nation sprachen. Es bewahrte die Historiker davor. ,bloßer Transmissionsriemen für dominante Ideologien" zu werden, machte die Geschichtswissenschaft aber zur Legitimationswissenschaft des nationalen Zeitalters. Andererseits waren Gündungsmythen das Geschäft der Historiker. Und davon gab es immer mehrere. Der deutsche Gründungsmythos von Hermann dem Cherusker sah die Entstehung Deutschlands im Kampf gegen Rom, der katholische Bonifatiusmythos, von Kirchenhistorikem wie Ignaz Döllinger mit wissenschaftlicher Definitionsmacht vertreten, sah Deutschland dagegen im Bunde mit Rom entstehen. ${ }^{47}$ In Frankreich gaben Republikaner und Katholiken dem Jeanne-d'Arc-Mythos eine jeweils entgegengesetzte Pointe: "Joanna nostra est" (Leo XIII., 1894) stand gegen "Notre Jeanne d'Arc" (Lucien Herr, Ecole normale, Paris, 1890). ${ }^{48}$

Nationale Historiographien variierten in ihren politischen Konstellationen erheblich. Während die französische liberale Geschichtsschreibung die Nation mit der Revolution verband, spielte in England die Magna Charta diese Rolle. Dennoch gab es vergleichbare Entwicklungen in Europa. Wissenschaftliche Historiker, die die Nation mit einem Objektivitätspostulat verkündeten, trennten sich von den Dilettanten. Nationalhistoriographie wurde an den Universitäten betrieben. Eine wichtige Ausnahme bildete England, wo die Tradition der deutschen akademischen Mandarine nie richtig Fuß fassen konnte. Alle Nationalhistoriographien neigten jedoch dazu, der eigenen Nation einen Primat zuzusprechen. Selbst Kosmopoliten wie Carlo Cattaneo unterstützten diese Sicht, die Vincenzo Gioberti auf die Formel des primato morale e civile degli italiani" brachte. In Deutschland und Frankreich spielte der Modernitäts- und Fortschrittsgedanke die gleiche Rolle und diente der Propagierung des "people elect"-Motivs. ${ }^{49}$

Aber auch die Naturwissenschaften unterstützten den Nationalisierungsprozess. ${ }^{50}$ thre Modernität war resonant auf diejenige der Nation. Beide verband auch eine Zurückweisung der Gestallungsansprüche von Religion und Kirche für das menschliche Leben. Zwischen Naturwissenschaften und Nation gab es eine Strukturaffinität, da beide "kulturelle Phänomene der europäischen Modeme [sind], die einen spezifischen Antitraditionalismus mit uto-

consciousness in Germany since 1800, Oxford 1997; ders., A return to the national paradigm? National history writing in Germany, Italy, France, and Britain from 1945 to the präsent, in: Journal of Modem History 77 (2005), S. 629-679

46 Vgl. Jens Prellwitz, Jüdisches Erbe, sozialliberales Ethos, deutsche Nation: Gustav Mayer im Kaiserreich und in der Weimarer Republik, Mannheim 1998.

47 Vgl. zum Hermann-Mythos: Charlotte Tacke, Denkmal im sozialen Raum. Nationale Symbole in Deutschland und Frankreich im 19. Jahrhundert, Göttingen 1995; Harry Fröhlich, Arminius und die Deutschen. Ein politischer Mythos des 19. Jahrtunderts, in: Aurora 59 (1999), S. 173-189.

$48 \mathrm{Vgl}$. Daniel Mollenhauer, Symbolkämpfe um Nation. Katholiken und Laizisten in Frankreich (18711914), in: Haupt/Langewiesche ( $\mathrm{Hg}$.), Nation und Religion in Europa (wie Anm. 1), S. 202-230, bes. 223-227.

49 Stefan Berger/Mark Donovan/Kevin Passmore, Apologias for the nation-state in Western Europe since 1800, in: dies., Writings national Histories (wie Arm. 43), S. 3-14.

50 Die Immunität der Naturwissenschaften gegen den Nationsgedanken behauptet Hans Hauge, Nationalizing Science, in: Roger Chartier/Pietro Corsi (Hg.), Sciences et langues en Europe, Paris 1996 S. $159-168$ 
pischen, auf Verbesserung und Vervollkommnung angelegten Momenten verbinden." 51 Gemeinsam mit der Nation war den an Bedeutung zunehmenden Naturwissenschaften auch die Tendenz zur Verwissenschaftlichung und Objektivierung. Nicht nur die Naturgesetze, auch die Nation galt als objektiv.

Gerade der Aufstieg der Naturwissenschaften schien den Erfolg der Nation zu untermauem. Nationalstaaten legitimierten sich durch die Entdeckungen ihrer Wissenschaftler, die wiederum zu nationalen Heroen stilisiert wurden, wie etwa der Mediziner Rudolf Virchow. ${ }^{52}$ Die Vorliebe für bestimmte Wissenschaften wie der französische „esprit de finesse" und der deutsche "esprit de géométrie" fand Eingang in den Katalog der nationalen Stereotypen und Dichotomien. Auf mehreren Ebenen trieben sich Nationalisienung und Verwissenschaftlichung im 19. und 20. Jahrhundert wechselseitig an:

„Der sich entwickelnde Nationalstaat bildete [erstens] einen entscheidenden Kontext, in dem sich die Institutionen des modemen Wissenschaftsbetriebs in Europa seit dem ausgehenden 18. Jahrhundert formierten und expandierten. Der Nationalstaat prägte ihre organisatorische Form, schuf nationale Kommunikationsräume und trug dazu bei, dass institutionelle Lösungen national konnotiert wurden." ${ }^{53}$

Erst der Nationalstaal konzentrierte in den Universitäten Ressourcen, damit naturwissenschaftliche Forschung Erfolge zeitigen konnte. ${ }^{54}$ Das deutsche Humboldtsche Universitätsmodell entstammte der politischen Situation um 1900 mit ihren institutionellen Wissenschaftsarrangements und nicht der Zeit der preußischen Reformen, wie Sylvia Paletschek herausgearbeitet hat. ${ }^{55}$ Doch bereits im frühen 19. Jahrhundert entstanden zahlreiche Vereine zur Fördenung der Wissenschaften vor einem betont nationalen Hintergrund. In Deutschland verstand sich die 1822 gegründete "Gesellschaft Deutscher Naturforscher und Ärde" explizit als "nationales Forum" und "geistiges Symbol [...] der Einheit des deutschen Volkes". ${ }^{56}$ Ganz unterschiedliche Einrichtungen dienten dem Zweck, die Naturwis-

51 Jessen/Nogel ( $\mathrm{Hg}$.): Wissenschaft und Nation (wie Anm. 1), S.11.

52 Vgl. dazu Constantin Goschler, Rudolf Virchow. Mediziner - Anthropologe - Politiker, Köln 2002 ders., Deutsche Naturwissenschaftler und naturwissenschaftliche Deutsche Rudoff Virchow und die deutsche Wissenschaft', in: Jessen/Nogel (Hg.). Wissenschaft und Nation (wie Anm. 1), S. 97-114, ders., "Wahrheit" zwischen Seziersaal und Parlament. Rudolf Virchow und der kulturelle Deutungsanspruch der Natumissenschaften, in: Geschichte und Gesellschaft 30 (2004), S. 219-250.

53 Jessen $/$ ogel ( $\mathrm{Hg}$.): Wissenschaft und Nation (wie Anm. 1), S. 221

.On the one hand, scientific praclitioners identified themselves with a sense of national achievemen and well-being; on the other, the well-being and prowess of nations was associated - that is, identified - with the success of individual scientific and medical figures, and increasingly with the idea of collective achievement. "Ludmila Jordanova, Science and nationhood: cultures of imagined communilies, in: Geoffrey Cubitt ( $\mathrm{Hg}$.), Imagining nations, Manchester 1998, S. 192-211, 200. Zur Medizi vgl. dies., Social construction of medical knowledge, in: Social History of Medicine 8 (1995), S. 361 -

55 Vgl. Sylvia Paletschek, Verbreitete sich ein Humboldtsches Modell an deutschen Universitäten im 19 Jahrhundert? in: Rainer Christoph Schwinges ( $\mathrm{Hg}$.), Humboldt intemational. Der Export des deutschen Universitätsmodells im 19. und 20. Jahrhundert, Basel 2001, S. 75-104.

Jessen Nogel ( $\mathrm{Hg}$. ), Wissenschaft und Nation (wie Anm. 1). Vgl. hierzu Renato G. Mazzolini, Nationale Wissenschaftsakademien im Europa des 19. Jahrhunderts, in: Lothar Jordan/Bemd Kortländer ( $\mathrm{Hg}$.), Nationale Grenzen und internationaler Austausch, Tübingen 1995, S. 245-260: Marc Schalenberg, Die Nation als strategischer Einsatz? Wissenschaftliche Geselligkeit und Wissenschaftspolitik in der "Geselschant Deutscher Naturforscher und Arzie" und der "British Association for the Advancement of Science* im Vergleich, in: Wissenschaft und Nation in der europäischen Geschichte, S. 41 182, Ulch Kuse, Die Pharmazie im Rahmen der Gesellschaft Deutscher Naturforscher und Ärte 1822-1938, Stulgart 2001 ; Peter Sitte, Die Geselschant Deutscher Naturforscher und Arde nach dem Ersten Weitkrieg, in: Zwei Jahmunderte Wissenschaft und Forschung in Deutschland, Stuttgar senschaften zu fördern: die 1782 gegründete "Società italiana delle scienze", die "British Association for the Advancement of Sciences" oder die 1911 gegründete Kaiser-WilhelmGesellschaft. Sie folglen unterschiedlichen Mustern, gemeinsam war ihnen das Bestreben, der Wissenschaft ein nationales Forum zu bieten

Zweitens bildete sich ein intemationaler Wettbewerb unter den nationalen Naturwissenschaften und ihrem Entdeckergeist aus. In hohen nationalen Ehren standen die Franzosen Antoine Lavoisier (1743-1794), Louis Pasteur (1822-1895), der Russe Michael Lomonosov (1711-1765) oder der Deutsche Rudolf Virchow (1821-1902). Dieser Wettbewerb bestand nicht trotz, sondern eher wegen der behaupteten Internationalität und Objektivität der Naturwissenschaften. Universalismus und Wissenschaftlichkeit dienten der Bekräftigung der nationalen Wissenschaft, nicht ihrer methodischen Relativierung. Vier Jahre nachdem Wilhelm II. seine berüchtigte Hunnenrede gehalten hatte, in der er die drakonische Bestrafung Chinas für den Boxerautstand forderte, formulierte Max Weber in seinem 1904 erschienenen berühmten Objektivitätsaufsatz: ${ }_{\text {DDenn }}$ es ist und bleibt wahr, dass eine methodisch korrekte wissenschaftliche Beweisführung auf dem Gebiete der Sozialwissen schaften, wenn sie ihren Zweck erreicht haben will, auch von einem Chinesen als richtig erkannt werden muss." 57 Ihr Allgemeinheitsanspruch sollte den Entdeckerruhm in alle Weltgegenden tragen. Einen Gegensatz zwischen nationaler Voreingenommenheit und absolute Objektivität verrieten diese Zeilen nicht. Entsprechend engagierten sich die Wissenschaftler auf beiden Seiten während des Ersten Weltkrieges. ${ }^{58}$ Der Gewinn dreier Nobeipreise 1919 (davon zwei nachträglich für 1918) wurde von der deutschen Seite als nachträglicher geistiger Sieg im Ersten Weltkrieg gefeiert. 59

Drittens unterstrich die nationale Bedeutung der Naturwissenschaften den säkularen Charakter der Nation. Die Nation war auf innerweltlichen Erfolg angewiesen, sie legitimierte sich in erster Linie durch diesen. Die Entdeckungen der Naturwissenschaften untermauerten diesen Anspruch auf eine radikal wissenschaftliche Gestaltung des Lebens und der Gesellschaft. Zum Vorreiter dieser Verwissenschaftlichung der Lebensführung und des sozialen Denkens wurde Ernst Haeckel, der Begründer des Monismus. Die Begeisterung für die Naturwissenschaft und für die Nation hatten ihren gemeinsamen Fluchtpunkt in der erfolgreichen und von der Tradition emanzipierten Nationalgesellschaft. 60

2. census, map, museum

Man muss kein Anhänger des „iconic turn" sein, um begreifen zu können, dass die Bilder, die die Naturwissenschaften von der Nation konstruierten, nicht weniger wirkmächtig waren

998. S. 139-150; Dietrich von Engelhardt ( $\mathrm{Hg}$. .). Forschung und Fortschritt. Festschrift zum 175jährigen Jubiraum der Gesellschaft Deutscher Naturforscher und Ärcte, Stuttgart 1997.

57 Max Weber, Die "Objektivität sozialwissenscharticher und sozialpollischer Enkenntnis, in: ders., Wissenschaftslehre, in: ders., Gesammelte Aufsäzze zur Wissenschaftslehre, Hg. Johannes Winckelmann, Tübingen ${ }^{8} 1988$, S. 146-214, 155.

58 Ein gutes Beispiel hierfür ist der deutsche Chemiker Fritz Haber. Vgl. Margit Szöllösi-Janze, Fritz Haber (1868-1934). Fine Biographie, München 1998.

591919 erhielten Max Planck (nachträglich für 1918) und Johannes Stark den Nobelpreis für Physik und Fritz Haber (nachträglich für 1918) den Nobelpreis für Chemie. Vgl. Gabriele Metzler, „Welch ei deutscher Sieg!" Die Nobelpreise von 1919 im Spannungsfeld von Wissenschaff, Politik und Gesellschaft, in: Vierteljahrshefte für Zeitgeschichte 44 (1996), S. 173-200.

$60 \mathrm{Vgl}$. Frank Simon Ritz, Kulturelle Modemisierung und Krise des religiösen BewuBtseins. Freireligiöse, Freidenker und Monisten im Kaiserreich, in: Olaf Blaschke/Frank-Michael Kuhlemann (Hg.), Religion In Kaiserreich. Milieus, Mentalitäten, Krisen, Gütersloh 1996, S. 457-473. 
als diejenigen der Historiker oder Philologen. Die Naturwissenschaften waren nicht nur bildgebend, sondern auch biickgebend. Ihre Bilder bestimmten die Sichtachsen der Betrachter und lenkten ihre Beobachlungsweisen. ${ }^{61}$ Dazu gehörten in besonderer Weise die Geographie und die Statistik. Bekannt ist, dass der Geograph Friedrich Ratzel 1897 den Begriff "Lebensraum" prägte. Ratzel erblickte den Lebensraum für die Deutschen in Übersee, seine Nachahmer wie der Schwede Rudolf Kjellén, der Brite Halford Mackinder und der Deutsche Karl Haushofer dagegen in Osteuropa. ${ }^{62}$ Über Karten wurden nicht nur Grenzen imaginiert, sondem nationale Kollektive historisch und aktuell abgegrenzt. Ein bezeichnendes Beispiel für die nationsbildende Wirkung von Karten stellte die so genannte Schweizer Dufourkarte dar, die der Züricher Historiker David Gugerli untersucht hat. ${ }^{63}$ DreiBig Jahre Vorbereitung führten schließlich 1865 zur Anfertigung dieser Militärkarte. Die Karte sollte ein "naturgetreues" Abbild der "nationalen Landschaft" bieten. Praktisch brachte sie die nationale Standardisierung der Ortsnamen und Landschaftsbezeichnungen voran, wirkte also an der Konstruktion des von ihr angeblich jungfräulich vorgefundenen Gegenstandes entscheidend mit. ${ }_{n}$ Schweizer Ingenieure [schrieben] die Topographie der Nation als kartographisches Bild neu. "64 Die Geographen machten sich die Evidenz des nationalen Raumes zu eigen. Ihre Karten verbargen den konstruierten Charakter des abgebildeten Gegenstandes geschickt, was zumal auf die Schweiz zutraf. "Wie ein Blick auf die Karte lehrte ..." wurde zum nationalen Argument der Geopolitik. Der US-amerikanische Kartographiehistoriker Harley fasst diesen Umstand pointiert zusammen: "The map is never neutral "65 Nationalgeographien wie diejenigen von Friedrich Ratzel und dem Franzosen Paul Vidal de la Blaches objektivierten die Nation. Im Frankreich der Dritten Republik führte die Wandkarte in jedem Klassenzimmer die Annexion von Elsass-Lothringen durch Deutschland täglich vo Augen.

Analytisch hat die neueste Forschung diesen naiven Bezug auf die Objektivität der Karte durch das Konzept der kognitiven Landkarten oder der "mental maps" aufgebrochen. Die beeindruckenden Ergebnisse dieses Ansatzes sind in einem Themenheft von "Geschichte und Gesellschaft" dokumentiert. Die nachhaltige historische Wirkung von zuma politischen Karten an der Wand lag in der Konstruktion von Karten im Kopf", die die altä̈ liche nationale Wahrnehmung prägten. Mental maps umfassen das gesamte räumliche

61 Zum Zusammenhang von Verräumlichung und Wissensgenerierung vgl. Hans-Jörg Rheinberger u. a (Hg.), Räume des Wissens. Repräsentation, Codierung, Spur, Berlin 1997; Sybille Nikolow, Die Na tion als statistisches Kollektiv: Bevölkerungskonstruktionen im Kaiserreich und der Weimarer Republik in: JessenNogel ( $\mathrm{Hg}$.). Wissenschaft und Nation (wie Anm. 1). S. 235-259, 240: Bernhard Klein "The Whole Empire of Great Britain". Zur Konstruktion des nationalen Raums in Kartographie und Geographie, in: Ulrich Bielefeld/Gisela Engels $(\mathrm{Hg}$.), Bilder der Nation, kulturelle und politische Konstruktionen des Nationalen am Beginn der europäischen Moderne. Hamburg 1998, S. 40-75.

62 Hans-Diefrich Schultz, "Jeder Raum hat sein Volk." Der Beitrag der klassischen deutschsprachigen Geographie zur Nationalstaatsbildung im Zeitalter der indusiriellen Moderne, in: Hans-Dietrich Schultz Ute Luig $(\mathrm{Hg}$.$) . Die Natur in der Moderne, Berlin 2002, S. 87-148. Zu Lebensraum und Geopolitik$ vil. Holger H. Herwig, Geopolitik: Haushofer, Hiller and Lebensraum, in: The Journal of Strategic

Sgl. David (199), S. 218-242.

Vgl. David Gugerli/Daniel Speich, Topographien der Nation. Politik, kartographische Ordnung und Landschaft im 19. Jahrhundert, Zürich 2002, ders., Kartographie und Bundesstaat. Zur Lesbarkeit der Nation im 19. Jahrhundert, in: Andreas Ernst (Hg.), Revolution und Innovation. Die konfliktreiche Entstehung des schweizerischen Bundesstaates vor 1848, Zürich 1999, S. 199-215.

64 Gugerli/Speich, Topographien der Nation (wie Anm. 63), S. 95.

Chrian Harley, Deconstructing the map, in: Cartographica 26 (1989), S. 1-20, 14; vgl. dazu jett. Christof Dipper/Ute Schneider $(\mathrm{Hg}$.$) , Kartenwelten. Der Raum und seine Repräsentation in der Neu-$

284 I Neue Politische Literatur, Jg. 51 (2006)
Wissen einer Person sowie die Lemprozesse, in denen sie sich dieses Wissen aneignet, speichert und auf es zugreift. In die Planung und Vorhersagbarkeit menschlicher Handlungen gehen mental maps entscheidend ein. Sie prägen die kognitive Wahmehmung von Räumen und Relationen. Robert Kitchin und Mark Blades verstehen unter cognitive maps individuals' knowledge of spatial and environmental relations, and the cognitive processes associated with the encoding and retrieval of the information from which it is composed". 66 Der nordamerikanische Geograph Robert M. Downs und der Psychologe David Stea definieren sie in ihrem einflußreichen Band "Maps in minds" so:

"Eine kognitive Karte ist ein Produkt, eines Menschen strukturierte Abbildung eines Teils der räumiichen Umwelt. [...] Sie spiegelt die Welt so wider, wie ein Mensch glaubt, dass sie ist, sie muss nicht korrekt sein. Tatsächlich sind Verzerrungen sehr wahrscheinlich. Sie gibt unser spezielles Verständnis der Welt wieder, und sie ist vielleicht nur von Feme der Welt ähnlich, wie sie auf topographischen Karten und Photos gezeigt wird." 67

Ihrer umfassenden Bedeutung wegen werden mental maps auch als "cognitive collages" (Barbara Tversky) oder als "cognitive atlas" (Stephen C. Hirtle) bezeichnet. ${ }^{68}$ Kollagen betonen den Entstehungsaspekt, der kontingent ist und nicht kohärent sein muss, während die Atlasmetapher mehr den prozessualen holistischen Aspekt der Matrix räurnlicher Wahrnehmungen in Erinnerung ruft. 69

Im europäischen Raum - selbst ein Konstrukt der Geographen! - dienten mental maps in erster Linie der Fremdwahmehmung und Positionierung von Nationalstaaten im internationalen Feld. Nationale Karten verliehen den Konstruktionsleistungen der Kartographen Dauer und suchten die Deutungsmacht ihrer Zeichner unsichtbar zu machen. "Maps are preeminently a language of power, not of protest. "70 Sie stabilisierten mentale Herrschaftsgefälle durch ihre Verobjektivierung im Raum. Besonders deutlich trat dieser Umstand bei der Achsendrehung des Ordnungsmusters Süd - Nord hervor, das seit der Antike den europäischen Raum in einen zivilisierten Süden und einen barbarischen Norden teilte. Noch die napoleonischen Kriege mit Russland wurden zeitgenössisch als Konflikt zwischen Süd und Nord wahrgenommen. Das Zeitalter der Nationalstaaten veränderte die Konfliktachsen. Seit den dreißiger Jahren des 19. Jahrhunderts galt der Osten als der barbarische, der Westen dagegen als der zivilisierte Teil Europas. Der Norden wurde gleichzeitig immer

66 Rob Kitchin/Mark Blades, The cognition of geographic space, London 2002.

7 Robert M. Downs/David Stea, Kognitive Karten. Die Welt in unseren Köpten, Hg. Robert Geipel, New York 1982. S. 24 (Hervorhebung im Original).

$68 \mathrm{Vgl}$. Barbara Tversky, Cognitive maps, cognitive collages, and spatial mental models, in: Andrew U. Frank u. a. (Hg.), Spatial information theory, Berlin 1993, S. 14-24; David M. Mark u. a.. Cognitive models of geographical space, in: Intemational Journal of Geographical information science 13 (1999), S. 747-774; Stephen C. Hirle, The cognitive allas: Using GIS as a metaphor for memory, in: Max J. Egenhofer/Reginald G. Golledge ( $\mathrm{Hg}$.), Spatial and temporal reasoning in geographic information systems, Oxford 1998, S. 263-271.

69 Die Forschungsdiskussion ist resümiert in: Frithjof Benjarnin Schenk, Mental maps. Die Konstruktion von geographischen Räumen in Europa seit der Aufklärung, in: Geschichte und Gesellschaft 28 (2002), 5. 493-514. Zur historischen Langzeitperspektive: Larry Wolff, Inventing Eastern Europe. The Map of Civilzzation on the Mind of the Enlightenment, Stanford 1994.

70 John Brian Harley, Knowledge and Power, in: Denis Cosgrove u. a. ( $\mathrm{Hg}$.$) , The lconography of land-$ scape. Essay on Symbolic Representation, Design and Use of Past Environments, Cambridge 1988, S. $277-312,301$ 
mehr als Teil eines germanischen Sprachraums interpretiert und damit positiv verstanden. ${ }^{71}$ Zu dieser Neudefinition trug nicht zuletzt eine neu aufkommende Wissenschaft bei, die Slavistik. Bevor die Geschichtswissenschaft von den "mental maps" nahm, arbeiteten vor allem Kulturgeographen wie Hans-Dietrich Schultz damit und wiesen auf die weltbilddeteminierende Funktion geographischer Modelle hin. ${ }^{72}$ Die Nation als Raumbild ist inzwischen ein Feld gemeinsamer Forschungen für die Geschichte und die Geographie. ${ }^{73}$

Im Unterschied zur Geographie fällt bei der Statistik auf, dass bereits die Zeitgenossen ein entwickeltes methodisches Sensorium für den konstruktiven Charakter ihrer Disziplin besaßen. Darauf haben mehrere Studien in jüngster Zeit hingewiesen. Zu Deutschland und Italien ist die Forschungslage hierzu am besten. ${ }^{74}$ Auch in der Statistik entstanden die Kategorien Nation und Nationalität mit dem politischen Willen zum Nationalstaat. Zuvor waren die Rubriken Bevölkerungszahl, Mortalität, Kriminalität und auch Konfession erfasst worden. Anders als in der Geographie war - zumindest nach den bisher vorliegenden Ergebnissen in der Statistik lange nicht klar, was unter Nation und Nationalität zu verstehen sei. Die Diskussion folgte mindestens zwei Dichotomien: objektiv versus subjektiv und individuell versus kollektiv. Die im Allgemeinen Westeuropa zugeordnete subjektive Willensnation fand bis in die zweite Hälfte des 19. Jahrhundert auch in Deutschland Anhänger. Zu ihnen gehörten der Begründer der württembergischen Statistik Gustav Rümelin und der Mitbegrün-

71 Zum historischen Wandel des Raumbildes des Nordens vgl. Bernd Henningsen, Der Norden. Eine Erfindung, in: Fritz Dressler/Hauke Dressler u. a. (Hg.), Der Norden. Norwegen, Schweden, Dänemark Finnland, München 1993, S. 13-110; ders., Tango des Nordens. Transformation, Konsens und Soli-

72 Vgl. Hans-Dietrich Schult, Raumkonstrukte der klassischen deutschsprachigen Geographie des 19./20. Jahrhunderts im Kontext ihrer Zeit, in: Geschichte und Gesellschaft 28 (2002), S. 343-77; ders., Die Nationalizätenfrage als Begriffsproblem, in: Geographie und Schule 17 (1995), H. 95, S. 44; ders., Fantasies of 'Mitte' 'Mittellage' and ,Mitteleuropa' in German geographical discussion of the 19th and 20th century, in: Political Quarterly Geography 8 (1989), S. 315-339; ders., .Was ist des Deutschen Vaterland?" Geographie und Nationalstaat vor dem Ersten Weltkrieg, in: Geographische Rundschau 47 (1995), S. 492-497; ders.. Deutsches Land - deutsches Volk. Die Nation als geographisches Konstrukt, in: Benchte zur deutschen Landeskunde 72 (1998), S. 85-114; ders., schaft und - Staat. Der geagratische Antel an der "Ertindung der Nation, in: Geschichte in WissenPolens. Fin Beitrag zur Geschichte des Nationalismus und der deutschen Geographie, in: Studien zur internationalen Schulbuchforschung 104 (2000). S. 9-57, ders. Iteten und der Mittelmeerraum im tenung 104 (2000). S. 9-57; ders., llakien und der Mittelmeerraum im geographischen Disk

73 Vgl. die Sammlung von Texten zum nationalen Selbstverständnis der Geographie: Hans-Dietrich Schultz, Geographie, Arbeitsberichte Heft 88, 89, 100, Geographisches Institut der Humboldt Universität, Berlin 2003-2004.

74 Vgl. Weichlein, "Qu'est-ce qu'une Nation?" (wie Anm. 17), Nikolow, Die Nation als statistisches Kollektiv (wie Anm. 61): Morgane Labbé. "Race" et "Nationalité" dans les recensements du Troisième Reich, in: Histoire et mesure 13 (1998), S. 195-222; dies., Dénombrer les nationalités en Prusse au Annales de Démographie Historique, 2003 locale et connaissance stalistique de la population, in: antrichien: la multinationalité dans „l'ordre des choses", in: Revue du Comitè Francais de Cartographie 180 (2004), S. 71-84; dies., Le projet d'une statistique des nationalités discuté dans les sessions du Congrès Intemational de statistique (1853-1876), in: Francis Rosin discuté dans les sessions du politique, Dijon 1997, S. 127-142. Für ltalien ist dieser Zusammenhang besonders gut untersucht: Silviana Patriarca, Numbers and Nationhood. Writing statistics in 19th century Italy, Cambridge 1997; dies., Statistical Nation Building and the Consolidation of Regions in Italy, in: Social Science History 18 (1994), S. 359-376. Zum Hintergrund vgl. Stuart J. Woolf, Statistics and the modem state, in: CSSH 31 (1989). S. 588-604.

286 I Neue Politische Literatur, Jg. 51 (2006) der der Hochschule für die Wissenschaft des Judentums Moritz Lazarus. Rümelin vertrat 1872 in seinem Vortrag "Über den Begriff des Volkes" einen subjektivistischen Nationsbe1872

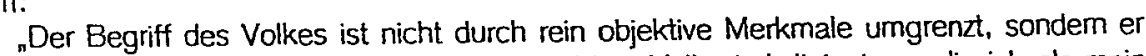
erfordert auch die subjektive Empfindung. Mein Volk sind diejenigen, die ich als mein Volk anshe; die ich die meinen nenne, denen ich mich verbunden fühle durch unlösbare Bande. ".75

bare Bande. ${ }^{.75}$ Eine Schlüsselrolle in der Debatte um Nation und Nationalität in der Statistik nahm der Berliner Statistiker Richard Böckh ein. ${ }^{76}$ Er verband in der Tradition des Sprachdenkens und der Nationsvorstellung Herders die Volksgeistlehren des 19. Jahrhunderts mit der $\mathrm{Na}$ tion. Böckh verfocht die Sprachnation als objektiven Kem jedweder nationalen Vergemeinschaftung wegen des sprachlich vermittelten Verständnisses und der für ihn dadurch ermöglichten ideellen Gemeinsamkeit. „Die Sprache [war] das äußere Abbild seines [sc. des Volkes] innersten Gemüthes, der Spiegel eines Volkes, wie es kein geistigeres und ureigeneres Lebenselement des Volkes gebe." Böckh forderte daher auch völkerrechtliche Garantien zum Schutz der Volkssprachen, "mit welcher die Nationalität von dem geistigen Druck der Staatsangehörigkeit gelöst wird". Als die Nation objektivierendes Zählkriterium bestimmte die von Böckh Favorisierte Volkssprache in den 1860er Jahren die Diskussion. Letzllich trieben die Unklaheiten um das vermeintlich eindeutige Sprachenkriterium die Diskussion weiter und eröffneten ihr neue Felder. Es machte schließlich in weiten Teilen Europas einen großen Unterschied, ob man vor Ort die Schulsprache, die Behörden- oder die Geschäftssprache, die Umgangssprache, die Kirchensprache, die Familiensprache oder eine andere Sprache zählte. Auch Fragen der Zähleinheit, also ob das individuelle Bekenntnis oder eine kollektive Zuschreibung gezählt werden sollte, verkomplizierten die Sache. Das Erfassen und Definieren von Nation und Nationalität war keine deutsche Eigenheit. Die Debatte darum wurde europaweit geführt und fand ihren Niederschlag in den Verhandlungen des Intemationalen statistischen Kongresses, der zwischen 1872 und 1878 auf seinen Internationalen Kongressen die Frage verhandelte: „Qu'est ce que la Nationalité?". ${ }^{77} \mathrm{Zu}$ einem Ergebnis kam er trotz umfangreicher Gutachtertätigkeit, die er an Statistiker aus Österreich-Ungam vergab, nicht. Um 1878 gerieten die Statistiker in ihren Ländern so sehr unter politischen Druck, dass eine Einigung über ein gemeinsames Zählkriterium auf europäischer Ebene in weite Feme rückte.78 Die Nationalisierung der Statistik war damit in solch einem Maß fortgeschritten, dass eine statistische Erfassung der Nation nach übema-

75 Gustav Rümelin, Über den Begriff des Volks (6.11.1872), in: ders., Reden und Aufsätze, Freiburg i. Br. 1875, S. 88-116, 102

76 Zu Böckh vgl. Weichlein, „Qu'est-ce qu'une Nation?" (wie Anm. 17); Torsten Leuschner, Richard Böckh (1824-1907). Sprachenstatistik zwischen Nationalitätsprinzip und Nationalstaat, in: Historiographia Linguistica 31 (2004), S. 385-417; ders., „Die Sprache ist eben ein Grundrecht der Nation, das sich nur bis zu einer gewissen Grenze verkümmern läßt." Deutsch-polnische Gegensätze in der Entstehungsgeschichte des preuBischen Geschäftssprachengesetzes von 1876, in: Germanistische Mitteilungen 52 (2000), S. 149-165.

77 Vgl. dazu Weichlein, „Qu'est-ce qu'une Nation? (wie Anm. 17); Morgane Labbó, Le projet d'une statistique des nationalités discuté dans les sessions du Congrès International de Statistique (18531876), in: Francis Ronsin/Hervé Le Bras/Elisabeth Zucker-Rouvillois $(\mathrm{Hg}$.). Démographie et Politique, Dijon 1997, S. 127-142.

78 Richard Böckh, Der Deutschen Volkszahl und Sprachgebiet in den europäischen Staaten. Eine statistische Untersuchung, Berlin 1869, 1, S. 18; vgl, auch seine andere Hauptschrift: ders., Die statistische Bedeutung der Volkssprache als Kennzeichen der Nationalität, in: Zeitschrift für Völkerpsychologie und Sprachwissenschaft 4 (1866), S. 259-402

Neue Politische Literatur, Jg. 51 (2006) I 
tional geteilten Kriterien unmöglich wurde. Dieser Umstand bestätigt eine Beobachtung Emst-Wolfgang Böckenfördes: „Die Nation, wenn sie entsteht, bestimmt selbst die Merkmale, die sie bestimmen." ${ }^{79}$

Überhaupt ist mittlerweile in der Forschung deutlich geworden, dass in ganz Europa zwischen 1860 und 1890 eine Diskussion um Nation, Nationalstaat und Nationalität geführt wurde. Die Diskussionen der Statistiker in Deutschland und auf dem Internationalen statistischen Kongresses bildeten einen Teil dieser internationalen Debatte. Intellektuelle Netzwerke wie dasjenige um Ernest Renan und Joseph Eötvös beschäftigten sich mit der Frage, wie die politisch-soziale Einheit Nation zu verstehen und zu messen sei. Dabei zeichnete sich ganz generell ein Konsens unter den intellektuellen Eliten ab, dass die Nation nicht essentialistisch durch Geographie, Religion oder gar Rasse definiert werden könne, sondern dass sie ein ideelles Gebilde sei, das auf Kommunikation und geistiger Gemeinsamkeit beruht. Wenn der Begriff der Kulturnation heute gegen die Willensnation gestellt wird, dann entspricht das nicht der ursprünglichen Konstellation. Für Autoren wie Moritz Lazarus, Joseph Eötvös, Emest Renan, Gustav Rümelin oder Friedrich Julius Neumann war die Kultumation gerade nicht unveränderlich, sondem sie beruhte auf dem individuellen Zugang zur fluiden geistigen Sphäre der Gemeinschaft, wie sie die Sprache zu garantieren schien. Die Kulturnation stand damit auf der Seite der Willensnation gegen die unveränderliche Gemeinschaft der Rasse, des Territoriums und der Religion. Besonders deullich wurde dies in der Frage der Zugehörigkeit der Juden zur Nation, zeitgenössisch "The Jewish question" genannt.80 Die Kulturnation war für Moritz Lazarus ein Mittel, um die selbstverständliche Zugehörigkeit der Juden zur deutschen Nation auszudrücken. Die geistig-ideelie Sphäre war tendenziell universalistisch aufgeladen. Für jüdische Linksliberale war die Verbindung zwischen Nationalismus und Universalismus gang und gäbe. ${ }^{81} \mathrm{Nach}$ 1890 artikulierten Liberale immer häufiger ihre Unzufriedenheit mit den Ergebnissen de Nationsbildung in der Bismarckzeit. Nicht nur Max Weber meinte, die Reichsgründungszeit seien für die Nation verlorene Jahre gewesen. Seit 1890 zeichneten sich neue Formen des Nationalismus ab, die auf direkte Massenwirkung abzielten und die Nationsbildung nicht mehr dem Staat überlassen wollten. ${ }^{82}$

Methodisch steht die an mentalen Strukturen, mental maps, Symbolen, Narrativen und Tropen orientierte Kulturgeschichte des Nationalen allerdings in der Gefahr, dass die Sprecher und Akteure des Nationalen quasi als Instrumente einer überindividuellen Semantik begriffen werden, die sie benutzt, um zu sprechen. Diese Perspektive liegt auf der Linie de theoretischen Arbeiten Michel Foucaults, der ,Macht' als ein selbst erhaltendes System beschrieben hat. ${ }^{83}$ Methodisch verführt dieser Ansatz dazu, Nation und Nationalstaat aus de Perspektive der Kulturgeschichte zu reifizieren. Die Gefahr besteht dann darin, dass überindividuelle nationale Narrative durch historische Akteure sprechen und die Konstruktion dieser Semantik in den Hintergrund tritt. Um dem vorzubeugen, sollte die Diskursgeschichte die Akteursperspektive einschließen und den historischen Kontext einarbeiten. Daher ist es

79 Ernst-Wolfgang Böckenförde, Die Nation - Identität in Differenz, in: Krzystof Michalski (Hg.), IdentiErnst-Wolfgang Böckenförde, Die Nation - ldent
tät im Wandel, Stuttgart 1995, S.129-54, 133.

80 Joseph Jacobs, The Jewish Question, 1875-84. Bibliographical Handist, London 1885; Uffa Jensen, Gebildete Doppelgänger. Bürgerliche Juden und Protestanten im 19. Jahrhundert, Göttingen 2005. $1 \mathrm{Vgl}$. Ulrich Sieg, Bekenntnis zu nationalen und universalen Werten. Jüdische Philosophen im Deut2 schen Kalsenteh, in: Historische Zellschint 263 (1996), S. 609-639.

82 So vor allem Geoff Eley, Reshaping the German Right. Radical Nationalism and Political Change after Bismarck, Ann Arbor 1980

83 Vgl. Michel Foucault, Dispositive der Macht. Über Sexualität, Wissen und Wahrheit, Berlin 1978. entscheidend, einerseits die Einsichten der Diskursgeschichte beizubehalten, sie aber andererseits nicht akteurs- und kontextfrei zu gestalten. Wie auch dies theoretisch eingeholt und begründet werden kann, hat Pierre Bourdieu in seinem Habitus-Konzept zu zeigen versucht, indem er Diskursgeschichte, sozialen Kontext und Akteursperspektive miteinander verbindet. ${ }^{84}$

\section{Museen, Musik und kulturelle Nationsbildung}

Mehr noch als die Kartographie, die Geographie oder die Statistik spiegeln Museen bürgerliche Werthaltungen, ästhetische Einstellungen sowie Anerkennungs- und Geltungswünsche lokaler und regionaler Eliten. Ihre Nähe zum Nationalen wird jedoch häufiger als in den beiden anderen Fällen kosmopolitisch überfornt. Dennoch bildete gerade der Aufbau einer nationalen Museumslandschaft einen wichtigen Teil der kulturellen Nationsbildung. ${ }^{85} 1858$ stimmten die Organisatoren einer Ausstellung von deutschen Künstlern darin überein, dass sie in der deutschen Kunst diejenige Einheit herstellen wollten, die das Vaterland noch nicht aufwies: "Die Einheit, die uns das Vaterland nicht bieten kann, wir wollen sie wenigstens gründen in der deutschen Kunst, wir wollen die nationale Kunst und die nationale Einheit. "86 Zahlreiche Nationalbewegungen agitierten für nationale Kunst, nationale Musik, nationale Literatur und so weiter. Den Museen und zumal einem Nationalmuseum kam damit eine doppelte Funktion zu: zum einen zeitgenössische Kunst zu ihrem "nationalen Beruf" zu ermutigen, zum anderen aber durch ihre Zurschaustellung in einem Museum die Einheit der nationalen Kunst und damit die Einheit der Nation sinnlich erfahrbar zu machen. Museen sollten nicht nur vergangene Kunstprodukte zeigen, sondem zur Produktion zeitgenössischer Kunst im nationalen Sinne aufrufen. In Deutschland lassen sich diese Bestrebungen in den Plänen für eine Nationalgalerie aufzeigen. 1838 meinte Rudolf Marggraff, dass Kunstwerke den Volksgeist nicht nur entdeckten, sondem auch stimulierten und enoben und daher ein Bildungsmittel des nationalen Geistes seien. Bezeichnenderweise wurde die Berliner Nationalgalerie weder von Reformbürokraten wie Franz Kugler noch von Organisationen wie der Kunstgenossenschaft, sondern vielmehr durch eine Kombination aus privater Philanthropie und königlicher Patronage gegründet. 1861 vermachte der Berliner Kaufmann Johann Heinrich Wilhelm Wagner dem preußischen König Wilhelm 262 Gemälde und stellte ihm frei, daraus eine Nationalgalerie aufzubauen. König Wilhelm griff am Beginn der Neuen Ära diesen Gedanken auf und nahm Wagners Erbe an, um sie in einem neuen Gebäude, das von August Stüler entworfen und unter der Leitung von Heinrich Strack gebaut wurde, auszustellen. ${ }^{87}$

$84 \mathrm{Vgl}$. Pierre Bourdieu, Die feinen Unterschiede. Kritik der gesellschaftlichen Urteilskraft, Frankfurt am Main 1987.

85 Vgl. hierzu James J. Sheehan, Museums in the German Art World. From the End of the Old Regime to the Rise of Modernism. Oxford 2000. Eine Theoriefigur, in der Bürgerlichkeit und Nationalismus ineinander gelesen werden, präsentiert auch Alexa Geisthövel, Eigentümlichkeit und Macht (wie Anm. 1). Die Verfasserin setzt burgerliches Selbstbewusstsein und nationales Selbstbewusstsein in einen intrinsischen Zusammenhang. Die Teilhabe des Einzelnen an der Gesellschaft reflektierte die Geltung der Nation in der Gemeinschaft der Völker.

86 Geschichte der allgemeinen deutschen Kunsigenossenschaft von ihrer Entstehung im Jahre 1856 bis auf die Gegenwart, Düsseldorf o. J., S. 8, zil. in: Wolfgang J. Mommsen, Die Herausforderung de bürgerlichen Kultur durch die künstlerische Avantgarde, in: ders., Bürgerliche Kultur und politische Ordnung. Künstler, Schriftsteller und intellektuelle in der deutschen Geschichte 1830-1933, Frankfurt
am Main 2000 S. 158-177, 158. 87 Vgl. Sheehan, Museums, (wie Anm. 85), S. 110 u. 112. 
Museen beschränkten sich nicht auf Kunst, sondern dienten ebenfalls der Wissenspopularisierung. Beispiele hierfür waren die ethnologischen und naturwissenschaftlichen $\mathrm{Mu}$ seen wie in Leipzig oder Berlin. Der nationale Sinn dieser Einrichtungen bestand im Forscherstolz und im Leistungsbewusstsein einer national onientierten Wissenschaftselite. Für das Ethnologische Museum in Leipzig hat Glenn Penny die Bedeutung lokaler Identitäten und Interessen sowie kosmopolitischer Visionen herausgearbeitet. Museen und Nationsbildung stehen also nicht in einem einfachen und direkten Verhältnis. Museen waren Orte des Austausches und der Verhandlung zwischen lokalen, nationalen und kosmopolitischen Haltungen. ${ }^{88}$ Im Lokalen und Regionalen konnte sehr wohl Nationales ausgesagt werden was Alon Confino und Celia Applegate anhand des Heimatgedankens gezeigt haben. ${ }^{89}$ Gerade Heimatmuseen wurden zu einem Ort nationaler Verehrung. Sie zielten auf die Integration der ländlichen Bevölkerung in die Nation. Wo die Bewegung der Heimatvereine einerseits die nationale Integration der ländlichen Bevölkenung vorantrieb, verschärfte sie andererseits den Gegensatz zwischen der Modemität und der Antimodemität in der Nationalbewegung. 90

Sehr viel stärker tritt der Zusammenhang von Museen und Nationsbildung dort hervor, wo ihn Benedikt Anderson ursprünglich verortet hatte: in den ehemaligen Kolonien. Hierfür liegen zahireiche Spezialuntersuchungen vor. In den Kolonien, wo die Mitspracherechte eines einheimischen Bildungsbürgertums fehlten, kam die nationsbildende Intention von $\mathrm{Mu}$ seen noch stärker zum Tragen als in der europäischen Bildungseinrichtung Museum. Besonders die außereuropäische Geschichtswissenschaft und die Ethnologie hat sich diesen Aspekt der Nationalismustheorie Andersons zu eigen gemacht, indem sie die Nationsbildung durch Museen etwa in der Türkei, in China und in Südafrika untersuchte. ${ }^{91}$

Das Verhältnis von Lokalem, Nationalem und Universalem tritt auch bei der kulturellen Nationsbildung durch Musik hervor. Schon Thomas Mann stellte mit dem Komponisten Adrian Leverkühn einen Musiker, der Arnold Schönberg nachgebildet war, in den Mittelpunkt seiner Katastrophengenealogie "Dr. Faustus".92 Mann benutzte das Faustmotiv,

$88 \mathrm{Vgl}$. Glenn Penny, Fashioning Local Identities in an Age of Nation-Building: Museums, Cosmopolitan Visions, and Intra-German Competition, in: German History 1999. S. 489-505; ders., Wordly provin cialism. German anthropology in the age of empire, Ann Arbor 2003.

$89 \mathrm{Vgl}$. Alon Confino, The Nation as a Local Metaphor. Württemberg, Imperial Germany and Nationa Memory, 1871-1918, Chapel Hill North Carolina 1997; Celia Applegale, A Nation of Provinces. The German Idea of Heimat, Berkeley 1990

$90 \mathrm{Vgl}$. Wolfgang Hardwwig, Nationalismus - Regionalismus - Lokalismus. Aspekte der Erinnerungskultur im Spiegel von Publizistik und Denkmal, in: Lieux de mémoire, Erinnerungsorte, Hg. Etienne François, Cahier Nr. 6. Berlin 1996, S. 91-104; ders., Nation - Region - Stadt. Strukturmerkmale des deutschen Nationalismus und lokale Denkmalskulturen, in: Gunther Mai ( $\mathrm{Hg}$.). Das Kyffhäuser-Denkmal 1896-1996. Ein nationales Monument im europäischen Kontext, Köln 1997, S. 54-84; Bjarne Stiklund, How the peasant house became a national symbol. A chapter in the history of museums and nation-building, in: Ethnologia Europaea. Journal of European Ethnologe 29 (1999), S. 5-19.

91 Vgl. Julie Scott. Mapping the past: Turkish cypriot narratives of time and place in the Canbulal museum, northern cyprus, in: History and Anthropology 13 (2002), S. 217-230; James M. Gore, A Lack of Nation? The Evolution of History in South African Museum, c. 1825-1945, in: South African Histo History and memory in the Bejing war of resistance museum, 1987-1997, in: The China Quarterly

92 Zur philosophischen Rekonstruktion der politischen Theorie von Thomas Mann, wie er sie in seinen Roman darlegl, vgl. Reinhard Mehring. Thomas Mann. Künṡtler und Philosoph, München 2001 ders., Apokalypse der deutschen "Seele“? Thomas Manns „Doktor Faustus" als „Zeitroman", in: Wei-
marer Beiträge 51 (2005), S. 188-206. (in eschichte des Abgründigen transponierte es jedoch in die abstrate. Der Schriftsteller rezipierte damit einen allgemeinen Topos deutscher Identität. Deutschland wurde als Kultumation seit langem mit der abTopos deutscher ldent der symphonischen Musik in Verbindung gebracht. Das idealistische strakten Musik, zumal der symono Erbe der deutschen Nationalbewegungen fand hier bis ins 20 . Jahrhundert velleicht seine subtilste Verlängerung. Ganz im Sinne der Aufwertung deutscher Innerlichkeit galt Musik als die innigste der Künste und als das nationale Verschmelzungsmedium schlechthin. Die Seelenlage der Deutschen war danach musikalisch gestimmt. ${ }^{93}$ Dies entging bereits Zeit列 genossen wie Theodor W. Adorno nichen Vorlesungen so beschrieb:

„Zu politischen Ideologien sind Musiken seit der Mitte des 19. Jahrhunderts dadurch geworden, dass sie nationale Merkmale hervorkehrten, als Repräsentanten von Nationen auftraten und allerorten das Nationalprinzip bestätigten. Musik prägt aber wie kein nen auttraten und allerorten nationalen Prinzips in sich aus." ${ }^{\text {and }}$

Musik wurde zu einer Ebene kultureller Nationsbildung. Dies zeigte sich sowohl in der Selbst- wie auch in der. Fremdwahmehmung. Bis weit ins 20. Jahrhundert hinein wurden die Orchester in den USA von deutschen Dirigenten geleitet. Im nordamerikanischen Kondie Orchester in den USA vis Symphonische Musik und deutsche Identität zertprogramm uberwog die Wiener Klassik. Symphon als zwei Seiten einer Medaille. ${ }^{95}$ In galten in US-amerikanischer Sicht auf Deutschland als zwei Seiten einer Medaille. In Deutschland korrelierte die nationale Selbstbeschreibung mit der musikalischen Kanonbildung. Ein aussagekräftiges Beispiel hierfür bildete die Karriere Johann Sebastian Bachs als deutscher Nationalkomponist. Insbesondere das protestantische Geschichtsbild stilisierte das 16. Jahrhundert, das Jahrinundert der Reformation, zur Glanzzeit der Religion, der Musik und der Nation im Geiste von Gründlichkeit, Tiefsinn, sittlichem Ernst und idealem Streben. Der musikalische Nationalheros Bach schien alle diese Eigenschaften zu besitzen. Die nationale Wertschätzung Bachs bezog sich auf sein Orgelwerk, während seine Vokalwerke ein Problem darstellten, da der für die protestantische Tradition wichtige Choral stärker mit ein Problem darstellten, da der uur die protestaigi da Palestrina in Verbindung gebracht wurkatholischen Komponisten wie Giovanni Pierluigi da Palestrina in Verbindung gebracht wurde. Die nationale Verehrung des Chorals war lange Zeit noch bikonfessionelles Gemeingut. Der Musikwissenschaftler Franz Brendel stelte 1848 "Palestrina als den Retter des ,schönen Stils', Luther aber als Retter sikreform von oben, Luther aber von unten, aus der Mitte des Voikes, vollzogen. Wer 1848 so dachte, nahm damit politisch Partei für die "Reform von unten". Brendels Kollege Eberhard Krüger machte gar die Gieichung auf: Deutsch $=$ Evangelisch $=$ Choral. ${ }^{96}$ Damit aber war die Konfessionalisierung des Chorals eingeleitet. Einerseits kulminierte die nationale

93 Vgl. Hans Rudolf Vaget, Seelenzauber. Thomas Mann und die Musik, Frankfurt am Main 2006. O4 Main ${ }^{7} 1989$. S. 186 Mit diesem Tenor: Jessica C. E. Gison 36 art, music and emols

96 Markus Rathey, Bach-Renaissance, Protestantismus und nationale Identilät im deutschen Bürgertum des 19. Jahrhunderts, in: Eibach/Sand H. 
Lutherverehrung im Choral, besonders in "Ein feste Burg ist unser Gott". ${ }^{97}$ Friedrich Nietzsche kommentierte diesen Vorgang in "Die Geburt der Tragödie":

So tief, muthig und seelenvoll, so überschwänglich gut und zart tönte dieser Choral Luther's, als der erste dionysische Locknuf, der aus dichtverwachsenem Gebüsch, im Nahen des Frühlings, hervordringt. Ihm antwortete in wetteiferndem Wiederhall jener weihevoll übermüthige Festzug dionysischer Schwärmer, denen wir die deutsche Musik danken - und denen wir die Wiedergeburt des deutschen Mythus danken werden!"98

Andererseits war die Bewunderung für das 16. Jahrhundert schwer mit einem protestantischen Choralkomponisten zu verbinden. Palestrina war Sänger an der päpstlichen Kapelle und Schöpfer der lateinischen Kirchenmusik. Vor diesem Hintergrund wurde Bach zum sächsischen Palestrina stilisiert. Bach wurde so zum ${ }_{n}$ auditiven Vaterland" ${ }^{99}$

Gegen diese Lesart regt sich neuerdings Widerstand. Celia Applegate differenzierte die Sicht auf die kulturelle Nationsbildung durch Musik erheblich. Sie wirft dieser Sichtweise vor, ähnlich zu argumentieren wie ältere Muster des Schemas "Von Luther zu Hitier". ${ }^{100}$ Der Nationalismus, der die Musik beeinflusste, müsse vielmehr als ein

"emergent cognitive model for a number of educated Europeans" gesehen werden, „a way of ordering experience, of looping at the world and making sense of one's place and identity in it - in Bourdieu's terms, a mode of ,vision and devision' of the world." 101 Applegates Vorschlag zur Erklärung dafür, wie Musik und Nation zusammenhängen, geht auf den organisatorischen und sozialen Wandel in der Musikproduktion vom späten 18. Jahrhundert bis zum napoleonischen Zeitalter zurück. Die Musik verlor mit den Höfen des Alten Reiches ihre wirtschaftlichen Träger, ihre soziale Anerkennung und ihre kulturelle Bedeutung. Die Musiker und die dem Musikbetrieb Zugehörigen waren „movers and doers", nach einer Formulierung von Mack Walker aus einer Studie über Weißenburg ${ }^{102}$, quasi ständig ${ }_{n}$ on the go" und immer auf der Suche nach einem neuen Patron. ${ }^{103}$ In dieser Krisen- und Umbruchsituation setzten sie nicht auf das Wirtschaftsbürgertum, sondern auf das staatsnahe Bildungsbürgertum, das die hohen bürokratischen Posten innehatte. Das Wirt-

97 Vgl. Rathey. Bach-Renaissance (wie Anm. 96). S. 185; Tobias R. Klein, Wartburg-Mythos und biblisches Mysterium. Nationale und religiöse Identitätsbildung im Werk von August Bungert, in: Herfried Münkler/Mermann Danuser $(\mathrm{Hg}$.). Deutsche Meister - Böse Geister? Nationale Selbsttindung in der Musik, Schliengen 2001, S. 343-366; Bernd Sponheuer, Über das "Deutsche" in der Musik. Versuch einer idealtypischen Rekonstruktion, in: ebd., S.123-150; Adolf Nowak, Vom "Trieb nach Vaterländischem". Die idee des Nationalen in der Musikästhetik des 18. und 19. Jahrhun-

98 Friedrich Niezzsche, Die Geburt der Tragödie, Nr. 23, in: ders., Sämiliche Werke. Kritische Studienausgabe, hg. von Giorgio Colli und Mazzino Montinari, München 1980, Band 1. S. 147

Zur Stilisierung von Johann Eccard als preußischer Palestrina durch Carl von Winterfeld vgl. Rathey, Bach-Renaissance (we Anm. 96), S. 186 u. S. 189f.

"It forces musicology back on yesterday's models of German national development, the tendentious and deterministic Luther-to-Bismarck-to-Hitler models. [...] like the Hollywood sound tracks that render the most banal conversation portentous. " Celia Applegate, How German is it? Nationalism and the idea of serious music in the early 19th century, in: 19th century Music 21, Nr. 3, 1998, S. $1274-296,280$.

Ebd., S. 281. Vgl. Pierre Bourdieu/Loíc J. D. Wacquant, An invitation to Reflexive Sociology, Chi-

Vgl. Mack Walker, German Home Towns. Community, State, and General Estate, 1848-1871, It-
haca 1971. Nachdruck 1998

3 The new man of music on the

his old circles of acquaintance and experience and doers - state officials, merchents experience, and coming into contact with the other movers and is it? (wic Anm. 100), S. 285.

292 I Neue Politische Literatur, Jg. 51 (2006) schaftsbürgertum verfügte in den reformabsolutistischen Staaten des Alten Reiches noch immer über wenig Einfluss und Macht. Der Schlüssel zum Verständnis der Nähe der Musik zur Nation ist für Celia Applegate die Nähe der Musik zum staatlichen Reformprogramm in Preußen nach 1806. Die seriöse Musik empfahl sich als Teil eines Reformprogramms. Sie nahm Abschied vom höfischen Dilettantismus samt seinen "unseriösen" Musikinszenierungen. Die Zustimmung der gebildeten Schichten gewann sie durch ihre Seriosität, ihre Nähe zu Philosophie und Neuhumanismus und ihre Entfernung von den Traditionen des Ancien Régime. Der Zwang zur sozialen Neuverortung begünstigte das ästhetische Distinktionsprogramm der Abstraktion und der künstlerischen Autonomie. Neue Repräsentationsformen der Musik, nunmehr staatlich gefördert, übersetzten dieses Programm ins Politische. So befürwortete bekanntlich Wilhelm von Humboldt die Gründung einer staatlichen Musikakademie unter der Leitung Carl Friedrich Zelters. Die zweckfreie seriöse Musik wurde zum musikalischen Ausdruck eines Emanzipationsstrebens, genauso wie die Nation im politischen Raum für Emanzipation von der Ständegesellschaft stand. Die abstrakte seriöse Musik in der neuen sinfonischen Form, wie es sie bis dato nicht auf breiter Basis gegeben hatte und die jetzt in Gebrauch kam, begründete die Einheit des Geschmacksurteils und transzendierte die territorialen Grenzen. Die deutsche Sinfonie wurde zum kulturellen Exportschiager, was der Identifikation deutscher Kultur mit sinfonischer Musik. Vorschub leistete. Humboldt schrieb an Goethe aus Paris, wer immer sich mit Philosophie und Künsten beschäftige, gehöre dem Vaterland enger an als andere. Musik stand jetzt in enger Beziehung zu vermeintlich preußischen Eigenschaften, nämlich Treue und Ernsthaftigkeit. Zelter sah in ihr den "alten deutschen Emst" wieder aufleben. Die Aufladung mit preußischprotestantischen ldealen wurde vollends deutlich, als Humboldt ins Zentrum der so zu schaffenden Nation preußische Rechtlichkeit und alte Treue [...], deren Summe Frömmigkeit ist", stellte. Seinen öffentlichen Ausdruck erhielt diese neue Begeisterung für emste Musik bei der Neu-Aufführung der seither sprichwörtlich deutschen "Matthäus-Passion" von Johann Sebastian Bach durch Felix Mendelssohn 1829 in Berlin. Sinfonien und die Musik Bachs galten seither als Synonym für deutsch. Die emste Musik stand damit im Zentrum der nationalen Kultur in Deutschland.

3. Erinnerung, Gedächtnis, Totenkult und Mythen der Nationen

Das Feld von Erinnerung, Gedächtnis, Geschichtspolitik und Mythen weist die größten Zuwachsraten innerhalb der Nationalismusforschung auf. Beigetragen hat dazu die Rezeption der Ansätze von Maurice Halbwachs sowie von Jan und Aleida Assmann. Dass Gedächtnis und Erinnerung konstitutiv für die nationale Identität sind, darf in der Zwischenzeit als ein Gemeinplatz gelten. Ihren öffentlichen Ausdruck fand dieses historische interesse in den beiden Ausstellungen "Mythen der Nationen". 104

Immer wieder untersuchte historische Gegenstände waren Feste, historische Feiem, Jubiläen, Schulbücher, Denkmäler, Totenkulte, Symbole, die national orientierte Geschichtsschreibung und die Geschichtsvereine. ${ }^{105} \mathrm{Es}$ ist bereits mehrfach beobachtet wor-

104 Vgl. dazu den Forschungsüberblick: Arpád von Klimó. Das Ende der Nationalismusforschung? Bemerkungen zu einigen Neuerscheinungen über Politische Religion", FFeste" und "Erinnerung", in merkungen zu einigen Neuerscheinungen über "

105 Die Angaben wären gerade hier Legion. Herausgegriffen seien: Markus Furrer, Die Nation in Schulbuch - zwischen Überhöhung und Verdrängung. Leitbilder der Schweizer Nationalgeschichte in Schweizer Geschichtslehrmitteln der Nachkriegszeit und Gegenwart, Studien zur internationalen 
den, dass die zahlreichen neueren Studien zu Gedächtnis, Erinnerung, Mythen und Geschichtsbildern der Nation in der Geschichtswissenschaft wenig Kontroversen ausgelöst haben. ${ }^{106}$ Dies liegt zum einen in methodischer Hinsicht daran, dass die Hinwendung $z$ anthropologischen und kulturellen Themen unumstritten ist. Zum anderen liegt es aber auch an den methodischen Schwierigkeiten, die jede Beschäftigung mit Erinnerung, Gedächtnis und Mythen begleiten. Das wichtigste Problem dürfte sein, dass die inhaltliche Beschreibung, die zumeist entlang von Texten erfolgt, noch nichts über die soziale Geltung und die Rezeption dieser Mythen aussagt. Erinnenung, Gedächtnisgeschichte und Mythenpolitik nähem sich damit dem Begriff der Ideologie an, worauf Alon Confino jüngst eindrücklich aufmerksam gemacht hat. Autoren wie Confino und Thomas Mergel haben daher akzentuiert, dass die Pointe der kulturgeschichtlichen Beschreibung der Nation nicht in einer Nacherzähiung von Gedächtnisinhalten, Erinnerungsinhalten und Mythen bestehen kann, sondem dass neben dieser Aufgabe gleichberechtigt die Rezeption dieser Inhalte im Alltag stehen sollte. ${ }^{107}$ Nur so lässt sich verhindem, dass aus der Geschichte der Repräsentation die Geschichte einer Ideologie wird. Ansonsten werden Intentionen für soziale Realitäten gehalten, eine Gelahr, die die Nationalismusforschung für den Nationalismus selbst besonders empfänglich machen würde. Ihre methodische Integrität erfordert es gerade, die Analyse nicht nur auf das immer schon Gewollte und Gemeinte, sondem auch auf das sozial Konsentierte und Paktierte auszudehnen.

So sehr dieser Kritik im Grundsatz zuzustimmen ist, so sollte doch unterschieden werden, um welche Textsorten es sich bei den untersuchten Gedächtnisinhalten handelt. Es macht einen großen Unterschied, ob geistige Höhenkammliteratur für die Rekonstruktion von Erinnerung und nationaler Vergangenheitspolitik herangezogen wird oder Texte, die im alläglichen Gebrauch stehen, wie Schulbuchtexte oder Texte der religiösen Liturgie. ${ }^{108}$ Nicht jede Textsorte ist auf Geistesgeschichte und Ideologie reduzierbar. Der pragmatische Sinn von Schulbuchliteratur liegt gerade in der begründeten Vermutung ihrer sozialen Verbreitung. Schließlich war der Geschichtsunterricht in der Schule verbindlich. Ähnliches gill für Texte zum Gegenstandsbereich Religion und Nation, solange eine hohe Kirchlichkeit unterstellt werden kann. Völlig anders sieht es selbstverständlich aus, sobald freie Schriftsteller, literarische Erzeugnisse oder Feuilletonartikel herangezogen werden. In diesen Text-

Schulbuchforschung, Braunschweig 2004; Franziska Metzger, Die Koniession der Nation. Katholische Geschichtsschreibung und Eninnerungskultur der Reformation in der Schweiz zwischen 1850 sche Geschichtsschreibung und Eninnerungskultur der Retormation in der Schweiz zwischen 1850
und 1950, in: Zeitschrift für schweizerische Kirchengeschichte 97 (2003). S. 145-63: Oliver Jan?, Zwischen Traver und Triumph. Politischer Tolenkult in Italien nach dem Ersten Weltkrieg, in: Jost Zwischen Traver und Triumph. Politischer Totenkult in Italien nach dem Ersten Weltkrieg, in. Jost 2002, S. 61-75; Manuel Borulta, Die Kultur des Nationalen im liberalen Italien. Nationale Symbole und Rituale in Rom 1870/71 und 1895, in: Quellen und Forschungen aus italienischen Archiven und Bibliotheken 79 (1999). S. 480-529; Helke Rausch, "Nationaie" Denkmalsymboliken in Paris, Nerlin und London um die Mitte des 19. Jahrhunderts: Facetten einer westeuropäischen Kultur des schaftsforschung 14 (2004), S. 98-125; Berger/Donovan/Passmore ( $\mathrm{Hg}$.). Writing National Hislores (wie Anm. 43). Zu den Geschichtsvereinen vgl. Georg Kunz, Verortete Geschichte. Regionales Geschichtsbewußtsein in den deutschen historischen Vereinen des 19. Jahrhunderts, Göttingen 2000; Gabriete B. Clemens, Sanctus amor patriae. Eine vergleichende Sludie zu deutschen und italienischen Geschichtsvereinen im 19. Jahushundert, Tübingen 2004.

106 Vgl. Klimó, Das Ende der Nationalismusforschung (wie Anm. 104), S. 272.

107 Vgl. Confino, Collective Memory and Cultural History: Problems of method. in: American Historical Review 102 (1997), S. 1386-1403; Thomas Mergel, Nachwort zu: Benedict Anderson, Die Erindung der Nation (wie Anm. 1), S. 218-299.

108 Vgl. hierzu Furrer, Die Nation im Schulbuch (wie Anm. 105) gattungen spiegelt sich zwar die Intention des Autors, aber das lässt noch keinen Rückgatlungen spiegelt sich zwar die Intention des Autos, aber das lasst noch keinen RückTexte, Gesetzestexte oder Texte aus der Rechtsprechung den großen Vorteil, in ihrer Entstehungsgeschichte, d. h. im Prozess des Aushandelns, analysiert werden zu können. Hier beschränkt sich die kulturgeschichtliche Beschreibung von Gedächtnisinhalten gerade nicht auf Intentionen.

Die methodischen Schwierigkeiten im Umgang mit Erinnerung und Gedächtnis zeigen sich auch bei dem Projekt "Deutsche Erinnerungsorte", dessen drei Bände 2001 und 2002 von Etienne François und Hagen Schulze herausgegeben wurden. Analog zu den "Lieux de mémoire" von Pierre Nora machten die Herausgeber in der deutschen Geschichte materielle und immaterielle Symbole aus, die das Kollektivgedächtnis prägen und die sie als „Errielle und immaterielle Symbole aus, die das Kollektivgedachtnis prägen und die sie als "Erinnerungsorte" bezeichnen. Die drei Bände fragen explizit nach den Entstehungs-, VermittErinnerungsorte aus dem 19. und dem 20. Jahrhundert, da sich parallel zum deutschen nation-building" ein memory-building" vollzogen habe. ${ }^{109}$ Wie qualitativ durchwachsen die einzelnen Beiträge sind, zeigt etwa der Artikel von Joachim Fest über den Führerbunker. Fest erzählt eine Realgeschichte und keine Erinnerungsgeschichte des Führerbunkers. ${ }^{110}$ $\mathrm{Zu}$ den methodischen Fallstricken dieses Projektes, eine Kultur nationaler Erinnerung zu umschreiben, tritt noch ein anderer wichtigerer Gesichtspunkt. Die "Deutschen Erinnerungsorte" unterscheiden sich an einem wichtigen Punkt von ihrem Vorbild, den französischen „lieux de mémoire". Anders als in Frankreich muss in Deutschland die Erinnerung an das Nibelungenlied (Peter Wapnewski, Bd. 1, 159-169), den Bamberger Reiter (Wolfgang Ullrich, Bd. 1, 322-334) oder Langemarck (Gerd Krumeich, Bd. 3, 292-309) durch den Zivilisations- und Erinnerungsbruch des Nationalsozialismus hindurchgehen. Die Kontinuität der Erinnerungsorte ist in Frankreich ausgeprägter als in Deutschland.

Die Herausgeber versuchen diesem Umstand dadurch gerecht zu werden, dass sie eine Reihe von europäischen "geteilten Erinnenungsorten" integrieren (Straßburger Münster, Versailles, Tannenberg / Grunwald, Rom, Karl der Große). ${ }^{111}$ Die geteilte transnationale Erin nerung ist ein Resultat der erinnerungsgeschichtlichen Zäsur „Drittes Reich". Auf den Bedeutungswandel von Erinnerungsorten macht zum Beispiel der Artikel über ,Langemarck von Gerd Krumeich aufmerksam. „Viel lebendiger als das Ereignis von 1914 selber ist heute das Bewusstsein, dass hier "ein, falscher Mythos' aufgebaut worden war, eine pro-

109 Vgl. Etienne François/Hagen Schuize (Hg.), Deutsche Erinnenungsorte, 3 Bde., München ${ }^{4} 2002$ Bd. 1. S. 19. Die Herausgeber definieren Erinnerungsorte in Anlehnung an Pierre Nora folgendermaßen: „Erinnerungsorte können ebenso materieller wie immaterieller Natur sein, zu ihnen gehören etwa reale wie mythische Gestalten und Ereignisse, Gebäude und Denkmäler, Institutionen und Begriffe, Bücher und Kunstwerke - im heutigen Sprachgebrauch ließe sich von ,ikonen' sprechen.
Erinnerungsorte sind sie nicht dank ihrer materiellen Gegenständlichkeit, sondern wegen ihrer symbolischen Funktion. Es handelt sich um langlebige, Generation überdauernde Kristallisationspunkte kollektiver Erinnerung und Identität, die in gesellschaftliche, kutturelle und politische Ublichkeiten eingebunden sind und die sich in dem Maße verändern, indem sich die Weise ihrer Wahrnehmung, Aneignung, Anwendung und Übertragung verändert." (Bd. 1, 17f.). Zu den, "lieux de mémoire" vgl.
Hue-Tam Ho Tai: Remembered Realms: Pierre Nora and French National Memory, in: American Historical Review 106 (2001) S. 906-922.

110 Vgl. Joachim Fest, Der Führerbunker, in: Deutsche Erinnerungsorte (wie Anm. 109), Bd. 1, S. 122-137.

$111 \mathrm{Zu}$ transnationalen Erinnenungsorten vgl. Jacques Le Rider/Moritz Czäky/Monika Sommer ( $\mathrm{Hg}$.), Transnationale Gedächtnisorte in Zentraleuropa, Innsbruck 2002. 
blematische Erinnerung gepflegt wurde - eine monströse und irgendwie gefährlichverführerische Ideologie geformt wurde". ${ }^{112}$

Ganz generell lässt sich auf europäischer Ebene eine Konjunktur von Erinnerungsorten beobachten, was sich nicht nur in der Adaption des Konzeptes der "lieux de mémoire" von Nora auf andere Nationalstaaten wie Deutschland und Italien ausdrückt. ${ }^{113}$ Einerseits führt die Ausweitung dieses Konzeptes auf die europäische Ebene zur Differenzienung zwischen privaten und öffentlichen, lokalen, regionalen, nationalen und europäischen Erinnerungsorten. Gemeinsame europäische Erinnerungsorte können dabei auch in der Antike gefunden werden, worauf der Berliner Althistoriker Wilfried Nippel hinwies. ${ }^{114}$ Sie liegen aber auch in der neueren und neuesten Geschichte. Der Göttinger Historiker Manfred Hildermeier schlägt allein für Osteuropa die Eroberung von Moskau durch Napoleon 1812, die Schlach bei Stalingrad 1943 und den Militärputsch in Moskau von 1993 vor. Andererseits führt die Debatte um europäische Erinnerungsorte zur Frage nach einer gemeinsamen europäischen Erinnerungskultur, die weniger in gemeinsamen Orten als vielmehr in vergleichbaren Topoi der Erinnerung bestehe (Günter Lottes).

Dass Erinnerungsräume dennoch vor allem nationalen Grenzen folgen, zeigt die "Geschichtspolitik" (Edgar Wolfrum) der jüngsten Vergangenheit. ${ }^{115}$ Ein Beispiel hierfür ist der verstärkte geschichtspolitische Einsatz des Amselfeldes im Kosovo durch serbische Politiker wie Slobodan Milosevic. Der Ost-West-Konflikt hatte eine tendenzielle Transnationalisierung der Erinnerungsräume begünstigt. Dies galt sowohl für Westeuropa als auch für Osteuropa, wo der Antifaschismus als Gründungserzählung die nationalen Gründungsmythen überlagern sollte. In Westeuropa bildeten sich ebenfalls transnationale Mythen der Konsumkultur aus (Coca-Cola, Jeans, MTV). Der Zusammenbruch des Sowjet-Imperiums 1991 bedeutete hier eine Zäsur. Mit der Sowjetunion und ihren Satelliten-Regimen gingen auch die antifaschistischen Gründungserählungen neuer Gesellschaften, die aus den Ruinen des Zweiten Weltkriegs und dem Antifaschismus entstanden waren, zugrunde und nationale Mythen rückten wieder in den Vordergrund. Die nationale Erinnerung an eine Gründungsgeschichte im und nach dem Zweiten Weltkrieg trat hinter älteren und offensichtlich langlebigeren Erinnerungsorten zurück. ${ }^{116}$ Darauf macht ein Vergleich der Ausstellungen "Mythen der Nationen" aufmerksam, deren erste 1998 das Zeitalter der Nationalstaatsgründungen im 19. Jahrhundert und deren zweite 2004 die Erinnerungen an den Zweiten Weltkrieg und das Kriegsende mit einem Schwerpunkt auf Osteuropa thematisier-

112 So Gerd Krumeich, in: Deutsche Erinnerungsorte (wie Anm. 109), Bd. 3, S. 292.

113 Vgl. auch die italienische Adaption der "Lieux de memoire": Mario Isnenghi/Ersilia Alessandrone Perona ( $\mathrm{Hg}$.), I luoghi della memoria, 2 Bde., Rom 1996-1997; ders., La memoire divisée des llaliens, in: Hèrodole Revue de Geographie et de Géopolitique 89 (1998), S. 39-55; ders., Der Platz als Zentrum von Vaterland und Territorium, in: Quellen und Forschungen aus italienischen Archiven und Bibliatheken 83 (2003), S. 308-318. Vgl. auch die besonders komplexe österreichische Version der lieux de memoire: Emil Brix/Ernst Bruckmüler/Hannes Stekl (Hg.), Memoria Austriae, 3 Bde.,Wien 2004-2005.

114 Vgl. Willfied Nippel, Die Antike in der amerikanischen und französischen Revolution, in: Gianpaolo Urso (Hg.), Popolo e potere nel mondo antico, Pisa 2005, S. 259-269; Elke Stein-Hölkeskamp ( $\mathrm{Hg}$.$) , Erinnerungsorte der Antike: die römische Welt, München 2006$.

115 Zum Begriff, Geschichtspolitik' vgl. Edgar Wolfum, Geschichtspolitik in der Bundesrepublik Deutschland. Der Weg zur bundesrepublikanischen Exinnerung 1948-1990, Darmstadt 1999.

116 Tim Snyder nennt diesen Vorgang reconstruction $n^{n}$ V Vgl. Timothy Snyder, The Reconstruction of nations. Poland, Ukraine, Lithuania, Belarus, 1569-1999, New Haven 2003; Larry Wolff, Revising Eastern Europe: Memory and the nation in recent historiograph, in: The Journal of modern History $78(2006)$, S. $93-118$

296 I Neue Politische Literatur, Jg. 51 (2006) ten. ${ }^{117}$ Die Ausgangsbeobachtung der Mythenausstellung von 1998 war es, dass die Entstehung neuer Staaten mit einem verschärten Nationalismus einherging, der sich besonders in nationalen Mythen ausdrückte. Die Ausstellung versuchte, diese Mythen in einem "europäischen Panorama" nachzuzeichnen. Sie zeigte anschaulich, dass nationale Mythen aufgrund ihrer Strukturanalogien und Visualisierungsstrategien "außerordentlich ähnlich, wenn nicht sogar austauschbar" sind. ${ }^{18}$

Historiker sind nicht nur zertifizierende Mythenproduzenten, sie analysieren sie auch in steigendern Maße. Das Interesse der nationalismusgeschichtlichen Mythenforschung gilt in jüngster Zeit den Faktoren, die nationale Identität stiften, ihrem Timing, d. h. den Zeitpunkten ihrer Thematisierung, ihren Trägergruppen, Zielvorstellungen, Ideologien und Legitimationsabsichten, der Definition des Eigenen und des Fremden, den Methoden der massenwirksamen Propagierung von Mythen, ihrer Reichweite und Akzeptanz sowie dem Wandel ihrer populären Ausformung. ${ }^{119}$ Historiker sind dabei bisher noch nicht zu einer gemeinsamen Definition des Begriffes Mythos gekommen. Doch soviel düfte feststehen: "Der Mythos ist kein historisches Ereignis, sondem eine symbolisch wirksame semantische Struktur, die die permanenten Funktionen von Bestätigung, Legitimierung und Regulierung für gesellschaftliche Erhaltung und Reproduktion garantiert. Er erklärt die Existenz nicht, sondem deutet sie in der Figur von Ursprungsgeschichten." "120 Als Ursprungsgeschichten sind sie Wesensgeschichten, die nicht der kausalen Logik der Geschichtswissenschaft folgen. Sie fingieren nicht Geschichte, sondem versuchen sie zu begründen. In diesem Sinne gibt es Ursprungsmythen, Raummythen, Mythen von heiligen Königen, Kriegern und Helden, Bekräftigungsmythen, Abstammungsmythen, Kriegsmythen sowie Opfer-, Märtyrerund Auferstehungsmythen. Opfer und Märtyrer sind besonders populär, weil sie erlauben, aus vergangenen Niederlagen zukünftige Siege zu machen und so die Lebenden zum Kampf für die Nation verpflichten. Mythen erzeugten "vorgestellte Räume" und "Grenzen im Kopf" wie die Rheingrenze für Frankreich oder der Rhein als "vaterländischer Fluss" für Deutschland. ${ }^{121}$

Als gemeinsames Merkmal der nationalen Mythen tritt dabei hervor, dass Opfer, Leiden und Niederlagen häufig eine stärkere gemeinschaftsbildende Bedeutung haben als Siege

117 Vgl. Monika Flacke ( $\mathrm{Hg}$.), Mythen der Nationen - ein europäisches Panorama: eine Ausstellung des Deutschen Historischen Museums. Begleitband zur Ausstellung vom 20. März 1998 bis 9. Juni 1998. Berlin 1998; dies. (Hg.), Mythen der Nationen: 1945 - Arena der Erinnerungen: eine Ausstellung des Deutschen Historischen Museurns. Begleitbände zur Ausstellung 2. Oktober 2004 bis 27. Februar 2005, Mainz 2004.

118 Flacke (Hg.), Mythen der Nationen (wie Anm. 117), S. 20.

119 So: Hannes Stekl, Nationale Mythen. Die Slowakei und Osterreich im Vergleich - Einleitung, in: Beiträge zur historischen Sozialkunde 33 (2003) Nr. 4, S. 1. Vgl. zur Ausführung dieses Programms den dritten Band der Gießener Reihe "Studien zur Entwicklung des koilektiven Bewusstseins in der Neuzeit": Helmut Berding ( $\mathrm{Hg}$.$) , Mythos und Nation, Frankfurt am Main 1996, der in$ der Hauptsache Mythenbildungen in europäischen Nationalstaaten nachzeichnet. Ähnlich: Sima Godfrey/Frank Unger $(\mathrm{Hg}$.$) , The Shifting Foundations of Modern nation-states: realignments of$ belonging, Toronto 2004.

120 Eugen Kotte, Die Funktion historischer Mythen bei der Konstituienung europäischer Nationen. Ein Kommentar zur Ausstellung .Mythen der Nationen" des Deutschen Historischen Museums in Berlin in: Orbis Linguarum 12 (1999), S. 1-21, 4; ders., "Not to have ideologies, But to have one!" Die Gründungsgeschichte der USA in amerikanischen Schulgeschichtsbüchern aus dem Jahre 1958 bis 1985, Hannover 1997, S. 392f.

121 Zu den Strategien der Mythisierung der Nation vgl. Weichlein, Nationalbewegungen und Nationalismus in Europa (wie Anm. 9). S. 124-137.

Neue Politische Literatur, Jg. 51 (2006) I 
und Erfolge. In diesem Zusammenhang dürfte einer der Gründe liegen, weshalb die jüngste Entdeckung der Opferrolle von Deutschen im Zweiten Weltkrieg bei den Nachbam auf solche Irritationen stößt. ${ }^{122}$ Mythen umfassen indessen nicht nur Ursprungsgeschichten, sondem auch Bekräftigungsgeschichten nationaler Traditionen. Ihre wichtigsten dynamisierten Varianten waren Bildung und Fortschritt, die eine andauernde „Arbeit am nationalen Gedächtnis" bedeuteten. Anhand einer Geschichte der deutschen Bildungsidee stellte die Anglistin Aleida Assmann drei Formen der Arbeit am nationalen Gedächtnis heraus: die Wiederholung, die Überblendung und die Koppelung:

Historische Daten müssen, wenn sie aus dem Kontext des historischen Bewusstseins in den des nationalen Gedächtnisses übergehen, versinnbildlicht werden und zu festen Symbolen gerinnen. Auf drei soicher Gedächtnis-Strategien, die Geschichtsdaten in Erinnerungssymbole verwandeln, möchte ich hier kurz eingehen: 1. Wiederholung - die Erinnerung ist auf Wiederholung angewiesen; ein Beispiel dafür ist die organisierte Wiederkehr historischer Daten im Kalender der Gedenktage. [...] 2. Überblendung [...] die Ereignisse, die die Geschichtswissenschaft in einem chronologischen Genüst verkettet, überblenden sich im nationalen Gedächtnis. Ein Ereignis wird zur Folie des anderen und trägt zu seiner Stilisierung ins Monumentale bei. [...] 3. Koppelung - neben Wiederholung und Überblendung spielt die Koppelung von chronologisch entfernten Daten in der nationalen Mnemotechnik eine wichtige Rolle. [...] Der Sinn solcher Koppelung lässt sich mit einer glücklichen Formel von Arno Borst als ,identifikation des Futurs mit dem Perfekt' bezeichnen. Es geht darum, ein Ereignis der Vergangenheit aus seinem historischen Kontext herauszulösen und als Mythos in den Dienst eines politischen Ziels zu stellen. " ${ }^{123}$

Die Mythen scheinen die Denkmäler in ihrer forschungsstimulierenden Wirkung abgelöst zu haben. Die Denkmalswelle der frühen 1990er Jahre ist in der Nationalismusforschung Deutschlands weitgehend abgeebbt. Denkmäler, politische Feiem und Feste gehören mittlerweile zum festen Bestandteil der Nationalismusforschung. ${ }^{24}$ Ihre Ergebnisse werden weiter differenziert, neue Beispiele hinzugefügt. Die grundlegenden interpretationsmuster haben sich dabei aber kaum verändert. In der Zwischenzeit ist jedes einigermaßen bedeutende Denkmal erforscht. ${ }^{125}$ Denkmäler stehen, wie es 1995 Friedemann

$122 \mathrm{Vgl}$. Aleida Assmann, On the (in)compatability of guilt and suffering in German memory, in: German Life and Letters 59 (2006), S. 187-201

123 Aleida Assmann. Arbeit am nationalen Gedächtnis. Eine kurze Geschichte der deutschen Bildungsidee, Frankfurt am Main 1993, S. 52-54; vgl. dies., Vier Formen des Gedächtnisses, in: Erwägen Wissen Ethik 13 (2002), S. 183-190, S. 231-238 (Replik); und Arno Borst, Barbarossas Erwachen - zur Geschichte der deutschen Identität, in: Odo Marquard u. a. (Hg.), Idenlität, Mün-
chen 1979, S. 57.

124 Vgl. Hroch, Das Europa der Nationen (wie Anm. 9), S. 211-217 (Denkmäler), 217-227 (nationale Feiem).

125 Seit 1995 vgl. u. a.: Matthias Stickler, .... denn wo du bist, ist Deutschland“. Bismarckkult und Bismarckdenkmäler im Kaiserreich, in: Bernd Heidenseich $(\mathrm{Hg}$.). Bismarck und die Deutschen, Bertin 2005, S. 169-181; Reinhold P. Kuhnert, ,... die freudig ihr Leben für König und Vaterland hingaben. Das Bayreuther Reiterdenkmal des 6. Chevaulegers-Regiments (Kreß), in: Archiv für Geschichte von Oberfranken 85 (2005), S. 283-304; Natalja Konradova/Anna Ryleva, Helden und Opfer. Denkmäler in RuBland und Deutschland, in: Osteuropa 55 (2005), S. 347-366; Winfried Speitkamp, Zu Rezeption und Verständnis nationaler Denkmäler in Europa, in: Stadt Leipzig ( $\mathrm{Hg}$.), Wenter Kiel und Posen Kiel 2002 ; Jütat, Leipzig 2005, S. 78-84; Rudolf Jaworski $(\mathrm{Hg}$.$) . Denkmäler in$ Denkmälem in Deutschland nach den beiden Weltkriegen, in: Bruno ThoB (Hg.), Erster Weltkrieg -

298 I Neue Politische Literatur, Jg. 51 (2006)
Schmoll formulierte, für die ngelungene Implantierung des Prinzips Nation in das Identitätsgefüge des modernen Menschen“. Thre Entwicklung versinnbildlicht die Emanzipation des nationalstaallichen Gedankens von seinen spezifischen historischen Voraussetzungen, vor allem von der preußischen Monarchie. Die Nation erfuhr so eine Remythisienung: Aus dem Kaisemythos wurde eine Volkstumsideologie. ${ }^{126}$

Ein Beispiel dafür, dass die Forschungen zu nationalen Feiem lieb gewonnene Einsichten erschüttem können, ist Italien. Eine der wichtigsten Ursachen für den Erfolg des $\mathrm{Fa}$ schismus in Italien lag nach Wolfgang Schieder darin begründet, dass das Risorgimento nach 1860 mit seiner Nationsbildung gescheitert war. Eine Kultur des Nationalen, greifbar in populären Denkmälem, Feiem und Festen, habe es dort nicht gegeben. Die Mobilisierungswirkung des Ersten Weltkriegs und der Faschismus seit 1922 traten somit das Erbe einer gescheiterten nationalen Politik an und wirkten als zweite Nationsbildung. Mussolin selbst sprach vom Faschismus als dem zweiten und eigentlichen Risorgimento, das die Fehler von 1860 nicht noch einmal machte. ${ }^{127}$

Dieses Interpretationsmuster, das die historische Forschung zum Faschismus weitge hend dominierte, wird in jüngster Zeit in Zweifel gezogen. Manuel Borutta zeichnete die Kultur des Nationalen anhand der Feierlichkeiten zur Eroberung Roms durch italienische Truppen am 20. September 1870 und des 25jährigen Jubiläums 1895 nach. Von einem „improvisierten Charakter" der Feiem beim Einzug des Königs in Rom 1871 "ohne Punkt "und Schwung, ohne Größe und Majestät" kann heute keine Rede mehr sein. ${ }^{128}$ Die umfangreichen Feierlichkeiten zur Eroberung Roms bezogen alle sozialen Schichten ein und machten Anleihen beim Repertoire in der kulturellen Nationsbildung ihrer Zeit. ${ }^{129} 1870$ trat in den öffentlichen Feiern der Gegensatz zwischen der demokratischen Richtung Garibaldis, dem national gesonnenen Liberalismus und der staatsorientierten, piemontesisch orientierten Elite der "Destra" hervor. Dem Papst gegenüber rechtfertigte die Florentiner Regienng den Einmarsch in Rom sogar mit dem Argument, dem ${ }_{n}$ Papst und der italienischen Regie-

Zweiter Weltkrieg, Paderborn 2002, S. 711-728; Markus Dauß, Das Denkmal zwischen „historischem Jahrhundert" und "Ertebnisgesellschaft". Zum Bedeutungs- und Deutungswandel von Denkmälem während des 19. Jahrhunderts, in: Sozialwissenschaftliche Informationen 30 (2001) S. 81-88; Katharina Weigand, Kriegerdenkmäler: öffentliches Totengedenken zwischen MemoriaStiffung und Politik, in: Markwart Herzog $(\mathrm{Hg}$.), Totengedenken und Trauerkultur. Stuttgart 2001 S. 201-218; Annette Maas, Kriegerdenkmäler einer Grenzregion. Die Schlachtfelder um Metz und WeiBenburg/Wörth 1870/71-1918, in: Angelo Ara ( $\mathrm{Hg}$.), Grenzregionen im Zeitalter der Nationalismen. Bertin 1998, S. 285-300; Ries Roowaan, Nationaldenkmäler zwischen Geschichte und Kunstgeschichte, in: Archiv für Kulturgeschichte 78 (1996). S. 453-466; Martin Papenheim, "Trauer und Propaganda" - eine Failstudie zu Aussagen und Funktion von Kriegerdenkmälern, in Franz-Joseph Jakobi $(\mathrm{Hg}$.). Stadtgesellschaft im Wandel, Münster 1995, S. 421-482; affirmativ dagegen: Uirich Schlie, Die Nation erinnert sich. Die Denkmäler der Deutschen, München 2002.

126 So Friedemann Schmoll, Verewigte Nation. Studien zur Erimnerungskultur von Reich und Einzelstaat im württembergischen Denkmalskult des 19. Jahrhunderts, Stuttgart 1995, S. 15, S. 70 .

127 Vgl. u. a. Wolfgang Schieder, Das Deutschland Hitlers und das Italien Mussolinis. Zum Problem faschistischer Regimebildung, in: Gerhard Schulz $(\mathrm{Hg}$.$) , Die GroBe Krise der dreiBiger Jahre. Vom$ Niedergang der Weltwirtschaft zum Zweiten Weltkrieg, Göttingen 1985, S. 44-71.

128 So: Ferdinand Gregorovius, Römische Tagebücher 1852-1889, Hg. von Hanno-Walter Kruft/Markus Völkel, München 1991, S. 308 (2. Juli 1871)

129 Vgl. Umberto Levra, Fare gil italiani. Memoria e celebrazione del risorgimento, Turin 1992; Bruno Tobia. Una patria per gli Italiani: spari, itinerari, monumenti nell'Italia unita, 1870-1900, Rom 21998; Albert Russell Ascoli/Krystyna von Henneberg ( $\mathrm{Hg}$.), Making and Remaking Italy: The cultivation o national identity around the Risorgimento, Oxford 2001; Alberto

Neue Politische Literatur, Jg. 51 (2006) I 
rung Schutz vor einer kosmopolitischen Revolutionspartei zu gewähren". ${ }^{30}$ Die 25-JahrFeiem 1895 offenbarten einen staatszentrierten Blick auf die italienische Nation. Borutta kommt in diesem Zusammenhang zu einer Frühdatierung des nationalen Totenkultes und seiner symbolischen Praxis. Nicht erst der Erste Weltkrieg, sondern bereits das späte 19 Jahrhundert kannte einen nationalen Totenkult um die Opfer des Risorgimento und der Republiken von 1848/49. ${ }^{13 t}$ Borutta überstrapaziert seine Ergebnisse jedoch, wenn er aus der Teilnahme des Königs an einem Schieß̧wettbewerb den Übergang von einem sozial exklusiven Nationalismus der Eliten zu einem sozial inklusiven Nationalismus der Massen herauslesen will. Auch die "Entauratisierung" des Denkmals von Garibaldi durch die römische Bevölkerung 1895 spricht weniger für den Übergang zu einem Nationalismus der Massen, als vielmehr für den Unterschied zwischen einer sozialen und einer nationalen Festkultur.

Ein weiteres Feld der Denkmaisforschung ist der transnationale Vergleich, wie er von Helke Rausch für Paris, London und Berlin vorgenommen wurde. Rausch untersucht die Wirkung personenbezogener Kulffiguren auf das nationale Selbstverständnis zwischen 1848 und 1914.132 Gleichwohl besitzt der Vergleich nationaler Denkmalspolitiken in Hauptstädten seine methodischen Tücken. Eine gemeinsame Periodisierung dieses Zeitraumes fällt schwer, weil die Zäsur 1870 für Deutschland und Frankreich sehr wohl, für England dagegen weniger markant ist. Der Vergleich einzelner Phasen müsste im englischen Fall von anderen zeitlichen Einschnitten ausgehen. Noch wichtiger ist, dass hauptstädtische Denkmäler in föderalen Systemen anders beurteilt werden müssen als in zentralistischen Staaten. Es überrascht also nicht wirklich, dass die Denkmalspolitik in Berin, der Hauptstadt des föderalen Kaiserreiches, weitaus weniger aktiv war als in London oder $\mathrm{Pa}$ ris. Dennoch ergeben sich aus diesen Studien weiterführende Fragestellungen nach transnationalen Erinnerungs- und Symbolräumen. Die Nationalisierung der Erinnenung kann nicht die Definition des Untersuchungsgegenstandes beherrschen. Sie deutet als Prozessbegriff vielmehr auf die Intention der Nationalbewegungen und einen Mechanismus der kulturellen Nationsbildung hin. Der Nationalstaat konnte die transnationalen Erinnenungsund Symbolräume nie völlig ersetzen, was etwa an der Bedeutung von Religion, Kunst und Wissenschaft deutlich wird. Nicht nur der Sozialismus oder der katholische Ultramontanismus, sondern die meisten Erinnerungen und Symbole folgten transnationalen Erinnerungsräumen.

4. Die Grenzen des Konstruktivismus in der Nationalismusforschung

Die Karriere kulturgeschichtlicher Themen in der Nationalismusforschung seit den 1980er Jahren spiegelt die zunehmende Rezeption des Konstruktivismus in den Geschichts- und Gesellschaftswissenschaften wider. So innovativ die konstruktivistischen Fragestellungen

130 Borutta, Die Kultur des Nationalen (wie Arm. 105), S. 490.

131 Gegen Oliver Janz, Zwischen privater Trauer und öffentlichem Gedenken. Der bürgerliche Gefallenenkult in Italien während des Ersten Weltkriegs, in: Geschichte und Gesellschaft 28 (2002). S. 545-574.

132 Vgl. Helke Rausch, Kulttigur und Nation. Öffentliche Denkmäler in Paris, Berlin und London, 18481914. München 2006: dies.. Monumentale Personifizierung und kultische Inszenierung nationaler (dentitaten: nationale Denkmalfiguren in Paris und Berin (1870-1914), in: Hirschhausen/Leonhard (Hg.), Nationalismus in Europa (wie Anm. 14), S. 267-287; dies., Denkmalsymboliken in Paris, Nationalen?, in: Comparativ 14 (2004), S. 98-125.

300 I Neue Politische Literatur, Jg. 51 (2006) auf die Nationalismusforschung auch wirkten, nicht alles daran war neu. Bereits Kari W. Deutsch hatte 1969 Nationen als Gemeinschaften bezeichnet, die auf einem gemeinsamen Irrtum über ihre Herkunft beruhen und nur durch die Gegnerschaft zu ihren Nachbam geeint werden. ${ }^{133}$ Auch die Kritik am essentialistischen Verständnis der Nation ist nicht neu, sie reicht bis in die Debatten um Nation und Nationalität im 19. Jahrhundert zurück. Der Webersche Begriff der "gedachten Ordnung" artikulierte dies genauso wie der Gemeinsamkeitsglauben, der jeder Nation zugrunde liegt. "Nation als vorgestellte Gemeinschaft, Nationalgeschichte als Artefalt bedeutet im Kern: die Nation ist nichts Ewiges." Schon Emest Renan und Elias Canetti kritisierten die Ewigkeitsbehauptung der Nation scharf. ${ }^{134}$ Nicht ein intellektuelles Interesse an der Definition von Nation und Nationalität, sondern Machtkämpfe und Deutungsmonopole dominierten diese Debatten. Wer das Selbstverständnis einer Nation beschreiben konnte, hatte Zugriff auf ihre Ressourcen. Diese Einsicht ist seit den 1980er Jahren ins Zentrum der Aufmerksamkeit gerückt. Die essentialistische Behauptung der Nation kam spätestens mit der Europäisierung und Globalisierung abhanden. Seither ist es ein Gerneingut, dass Nationen imaginiert und Traditionen "invented" sind. Eines war indessen neu. In dem Maße, in dem die Geschichtswissenschaft Anthropologie und Soziaiwissenschaften rezipierte, veränderte sich ihr chronisches methodisches Handelsbilanzdefizit. Historische Arbeiten aus dem Umfeld der Nationalismusforschung wirken heute auf die Nachbardisziplinen zurück, wo von einem "historic tum in human sciences" gesprochen wird. ${ }^{135}$

Kritische Stimmen in der Nationalismusforschung heben hervor, dass die immer wieder angeführte Langlebigkeit des Nationalismus eine ausgeprägte Flexibilität des Konzeptes der Nation voraussetzt, die mit den bisherigen kulturgeschichtichen Methoden der Identitätsrekonstruktion nicht zu beschreiben sei. Um diese Langlebigkeit zu erklären, reicht es nicht aus, anti-essentialistisch den konstruktiven Charakter der Nation immer wieder hervorzuheben. Die in der Konstruktionsleistung des Nationalismus unterstellte lange Dauer verdeckt die der Nation innewohnende Flexibilität, die das eigentlich zu Erklärende ist. ${ }^{136}$ Ein Beispiel für diese Flexibilität ist der Stellenwert des Rassedenkens im modernen Nationalismus. Gerade die immanente Widersprüchlichkeit rassistischer Stereotypen war dabe von Vorteil: einerseits war die Nation auf immer und ewig gefährdet, andererseits musste sie deswegen aktiv geschützt und "gereinigt" werden. "Die Notwendigkeit ihrer Reinigung wirkte umso überzeugender, je deutlicher man ihre faktische Verunreinigung darstellte." Nationalistische Ideologie "präsentierte in der Vereinnahmung ethnischer Differenz und

133 AA group of people united by a common enor about their ancestry and common dislike of their neighbours." Karl W. Deutsch, Nationalism and its alternatives, New York 1969, S. 3.

134 Vgl. Langewiesche, Was heiBt , Ertindung der Nation'? (wie Anm. 39), S. 597.

135 "This transformation is historic in at least three senses: First it represents an epochal turn against the science of society, constituted at least in part in opposition to ,history' in the immediate pos World-War Two years. Second it involves a contentious and by nomens well-delined turn toward History, - as past, process, context, and so on, but not necessarily as a discipline, as a componen of intelleciual investigations across a wide variety of fields. Finally it is producing renewed inquiry into the construction in history of disciptinary discourses and investigators. Terrence J. MacDonald, In troduclion, in: ders. (Mg.), The historic lun in the human sciences, Ann Arbour 1996, S. 1-16, 1.

136 „Was unter den Strukturbedingungen der Moderne zu überleben und sich auf Daver zu stellen fähig ist, muss einen hohen Grad an Flexibilität, Anpassungsfähigkeit und immanenter Wandelbarkeit besizen. Gerade dies gerat aber aus dem Bick der Forschung, wo sich ithre Aummerksamkeit auf das nende , erst produzieren." Geulen, Die Metamorphose der Identität (wie Anm. 8), S. 358.

Neue Politische Literatur, Jg. 51 (2006) I 301 
kultureller Heterogenität auch das noch in Form einer ,beständigen Gefährdung' als Kontinuität, was ihren eigenen Ewigkeitsanspruch am meisten bedrohte: Kontingenz." "137

Die Nationalismusforschung hat die Leitbegriffe der "imagined comunities" und der "invention of tradition" inzwischen weiterentwickelt. Anderson hatte noch den Begriff der "imagined communities" durch eine spekulative Adaption eines Gedankens von Walter Benjamin plausibilisiert, blieb dabei aber vage. Die homogene, leere Zeit wurde erst durch die Imagination der Nation gefüllt. Dahinter stand die eher geschichtsphilosophische Beobachtung. dass im Mittelalter die Gleichzeitigkeit von verschiedenen zeitlichen Ebenen kein Problem darstellte. Hierhin passten die Kategorien Verheißung und Erfüllung. Diese Simultaneität der Zeiten gingen nach Walter Benjamin und Erich Auerbach vertoren und wurde durch die Vorstellung der Homogenität der einen und unendlich langen Zeit abgelöst:

„Den Platz des mittelalterlichen Denkens einer überzeitlichen Simultanität hat [...] eine Vorstellung von ,homogener und leerer Zeit' eingenommen, in der Gleichzeitigkeit sozusagen querliegt, die Zeit kreuzt. Gekennzeichnet ist sie nicht durch eine Figuration und Erfüllung, sondern durch zeitliche Deckung, messbar durch Uhr und Kalender. " ${ }^{138}$

So ertragreich dieser Gedanke der homogenen und leeren Zeit, die durch die geschichtliche Kausalität von vorher und nachher erst gefült wird, für die Historisierung nationalen Bewusstseins auch ist, so wenig spezifisch ist er. Auch der Raum kann als homogen und leer beschrieben werden. Durch die Nation wurde der Raum neu konstruiert und gefüllt. Die Ausbildung des französischen Nationalstaates begann mit der Etablierung von 80 Departements, deren Grenzen in keiner Weise auf gewachsene Loyalitäten Rücksicht nahmen. ${ }^{139}$

Eine ähnliche Ambivalenz fand sich bei Eric Hobsbawms Begriff der "invented tradition“ in dem er sowohl das Moment der bewussten Neu-Fabrikation als auch der Wiederentdeckung definitorisch stark macht. Damit wird das Theorem der erfundenen Tradition sowohl für konstruktivistische wie auch semikonstruktivistische Zugangsweisen anwendbar Hobsbawm lässt allerdings den methodischen Ot seines Leitbegriffs zwischen Konstruktion und Rekonstruktion letzlich offen. ${ }^{140}$ Tatsächlich bedeuten Imagination und "Invention" nicht, dass die Nation ins Belieben ihrer Konstrukteure gestellt ist.

137 Ebd., S. 372; ders. The final frontier ..." Heimat, Nation und Kolonie um 1900: Carl Peters, in: Bitthe Kundrus ( $\mathrm{Hg}$. ). Phantasiereiche (wie Anm. 1), S. 35-55. Mit der These, von den kolonialen Heiratsverboten mit den Einheimischen zu den Nürm. rechnet ab: Bithe Kundrus Von Windhoek nach Nümberg? Koloniale Mischehenverbote" und die nationalsozialistische Rassengesetzgebung, in: ebd., S.110-131

138 Anderson, Die Erfindung der Nation (wie Anm. 1), S. 32; vgl. Walter Benjamin, Illuminationen, Frankfurt am Main 1969, S. 276. MaBgebliche Anregungen verdankte Benedikt Anderson dem teraturwissenschaftlichen Standardwerk von Erich Auerbach, Mimesis, Dargestellte Wirklichkeit in der abendländischen Literatur, Tübingen ${ }^{10} 2001$ (zuerst 1946).
deratich

139 "Benedict Anderson argues that the modem idea of the nation would be impossible without a partular sense of temporality that accompanied the advance of capitalism: the conception of what he following Walter Benjamin, calls empty, homogeneous time' In reconstituting the ternitorial basis of the French nation, the revolutionaries where in effect enacting a new conception of empty, homogeneous space." William Sewell, The French Revolution and the Emergence of the Nation Form, in: Michael Morrison/Melinda Zook ( $\mathrm{Hg}$.), Revolutionary Currents: Transatlantic Ideology and Nationbuilding, 1688-1821, Lanham 2004, S. 91-125, 103.

140 Zu den methodischen Problemen einer Vermittlung zwischen Konstruktivismus und objektiver Hermeneutik vgl. Alfons Bora, Konstruktion und Rekonstruktion. Zum Verhältnis von Systemtheorie und objektiver Hermeneutik, in: Gebhard Busch/Siegfried J. Schmidt ( $\mathrm{Hg}$.), Konstruktivismus und Sozialtheorie, Frankiurt am Main 1993, S. 282-330.

302 I Neue Politische Literatur, Jg. 51 (2006)
-So wenig es die Nation an sich gibt, so wenig läßt sich ein reines Erfinden endlicher Subjekte imaginieren. [...] Denn im Akt des Erfindens oder in sonstigen intellektuellen Konstruktionsprozessen sind die imaginierenden Subjekte unausweichlich auf Ressourcen bezogen, die ihren Konstruktionsleistungen vorausliegen." ${ }^{141}$

Der wahrscheinlich wichtigste Erkenntnisgewinn des Konstruktivismus in der Nationalismusforschung ist die Absage an jede Form des historischen Determinismus, der eine notwendige Entwicklungslinie hin zu nationaler Identität und zum Nationalstaat unterstellt. Nationen und Nationalstaaten sind nicht das notwendige Ergebnis der Geschichte, sondem das Ergebnis spezifischer Entscheidungen, Haltungen und Institutionen, die eng mit Weltbildem verflochten sind. Für den methodischen Standpunkt des Konstruktivismus ist die Entstehung von Nationen und Nationalstaaten mithin kontingent.

Die Einsicht in die Kontingenz und die Differenz alles Nationalen erklärt noch nicht, warum fast alle Staaten Nationalstaaten sind. Die Modemisierungstheorie hatte diese auffällige Parallelität, wenn nicht Strukturkongruenz zwischen so vielen modernen Staaten systemisch mit gleichgenchteten Herausforderungen erklärt. Es wird eine Aufgabe der zukünftigen Forschung sein, zwischen den kulturgeschichtlichen (re-)konstruktivistischen Einsichten und dem Erkenntnisgewinn der Modernisierungsgeschichte in der Nationalismusforschung zu vermitteln, um einen Rückfall hinter die Einsichten der Modernisierungstheorie zu vermeiden. Wie von der postnationalen Konstellation in Europa (Habermas) darf man von der zurecht über die Modemisienungstheorie hinausgehenden Nationalismusforschung erwarten, dass sie die Einsichten ihres überwundenen Antipoden nicht unterbietet.

Aber: who invented invention? Die Erfindung von Traditionen ist, anders als Eric Hobsbawm annahm, kein Proprium der modernen Massengesellschaft, sondem reicht weit in die Frühe Neuzeit zurück, weshalb Autoren wie Andreas Suter und Reinhard Stauber die Formulierung umkehrten und von einer "Tradition der Ertindung" sprachen. ${ }^{142}$ In Frankreich dominierte bereits im Ancien Régime eine Tradition der Diskontinuität. Schon die absolutistischen Institutionen setzten sich scharf von der Vergangenheit ab. Seit Ludwig XIV. wurden die institutionellen Keme für jede Vermittlung mit der Vergangenheit zerschlagen. Die Revolutionäre von 1789 standen mit ihrer Politisierung der Nation gegen die absolutistische Vergangenheit dennoch in deren Fußspuren. Absolutismus und Revolution teilten die Tradition der Diskontinuität. Dagegen herrschte in der Schweiz die Tradition der Kontinuität vor. Schweizer Eliten griffen über einen langen Zeitraum auf die mittelalterliche Emanzipation von Habsburg (1291 bzw. 1307) und die spätmittelalterliche Loslösung vom Reich zurück. Beide Ereignisse galten ihnen als Ausdruck eines berechtigten Freiheitsstrebens. Bereits in der Frühen Neuzeit verfestigte sich diese Tradition institutionell. Im 19. Jahrhundert wurde sie als "Regeneration" der alten Freiheiten semantisch in die Nationalstaatsgründung eingespeist. Deutschland stellte einen Zwitter zwischen den beiden Traditionen der Erfindung und der Kontinuität dar. Einerseits galt die politische Diskontinuität

141 Friedrich Wihelm Graf, Die Nation - von Gott "erfunden"? Kritische Randinotizen zum Theologiebedart der historischen Nationalismustorschung, in. ders, Die Wiederkehr der Götter. Religion in der modernen Kultur, München 2004, S. 102-132, $116 \mathrm{f}$.

$142 \mathrm{Vgl.}$ Andreas Suter, Nationalstaat und die, Tradition der Erfindung'. Vergleichende Überlegungen, in: Geschichte und Gesellschaft 25 (1999), S. 480-503 (= Der Nationalstaat und die "Tradition der Ertindung" - Die Schweiz, Frankreich und Deutschland im Vergleich, in: von Hirschhausen/Leonhard ( $\mathrm{Hg}$.). Nationalismen in Europa (wie Anm. 14), S. 68-95)

Neue Politische Literatur, Jg. 51 (2006) I 303 
zum Deutschen Bund und zum Alten Reich, andererseits die kulturelle, und immer mehr auch die völkische Kontinuität als Nationsargument. ${ }^{143}$

Eine weitere Schwachstelle eines überzogenen Konstruktivismus, der mehr der Bestätigung einer metageschichtlichen Theorie zuarbeitet als der Analyse von Nation, Nationalismus und Nationalstaat, besteht in dern Umstand, dass er dem ldentitätsbegriff verbunden bleibt und seine Leistungsfähigkeit vor allem in Identitätsdiskursen erhält. Mindestens ebenso wichtig ist indessen die Erforschung der integrativen Seite des Nationalismus. Heinz-Gerhard Haupt und Charlotte Tacke haben die Bedeutung der Integration in der Nationalismusforschung gegen deren identitätslogische Verkürung verteidigt. ${ }^{144}$ Die Untersuchung der Integration richtet sich auf andere historische Gegenstände: die Ausweitung und die Verdichtung sozialer Kommunikation, die Vereinheitlichung des Rechts, das Wahlrecht und den Sozialstaat. Mehrere Studien haben das nationsbildende Potenzial von Post und Verkehr herausgearbeitet. Auch die Nationalisierung des Rechts zieht allmählich das interesse der Historiker auf sich. ${ }^{145}$

Lutz Niethammer meldete jüngst gravierende Zweifel am Nutzen des ideologieträchtigen und zur Reifizierung neigenden Identitätsbegriffes gerade auch für die Nationalismusforschung an. ${ }^{166}$ Dennoch wird man auf ihn in der Nationsforschung schon deshalb nicht verzichten können, weil Identitätsbehauptungen dazu dienen, Relationen zwischen Individuen und Kollektiven herzustellen, ihrerseits also einen integrativen Sinn besitzen. Dies wird am deutlichsten in dem von Alois Hahn geprägten Begriff der "partizipativen Identität", dessen analytisches Potential für die Nationalismusforschung noch lange nicht gehoben ist. Hahn unterscheidet biographische von partizipativer Identität.

„Während die partizipative Identität auf die Beziehung zu anderen und auf bestimmte soziale Konstruktionen zurückgreift, bestimmt sich die biographische Identität durch die Beziehung des Individuums zu sich selbst und durch die im Laufe der eigenen Biographie erworbenen Eigenschaften und Erfahnungen. Wir können auch von einer selbstreferentiellen und einer fremdreferentiellen Bestimmung von Identität sprechen, immer

143 Vgl. hierzu Guy P. Marchal, Nationalgeschichten in Vergleich. Das Mittelalter als Identitätsfolie in Frankreich, Deutschland und der Schweiz, in: Schweizerisches Landesmuseum $(\mathrm{Hg}$.$) , Die Erfin-$ dung der Schweiz. Bildentwürfe einer Nation 1848-1998, Zürich 1998, S. 146-157.

144 Vgl. Heinz-Gerhard Haupt/Charlotte Tacke, Die Kultur des Nationalen. Sozial- und kulturgeschichtliche Ansätze bei der Erforschung des europäischen Nationalismus im 19. und 20. Jahrhundert, in: Wolfgang Hardtwig/Hans-Uirich Wehler $(\mathrm{Hg}$.), Kulturgeschichte heute, Göttingen 1996,

S. $255-283$.

45 Zu Nationsbildung und sozialer Kommunikation vgl. Siegfried Weichlein. Nation und Region. Integrationsprozesse im Bismarckreich, Düsseldorf 22006; Andreas Helmedach, Das Verkehrssystem als Modemisierungsfaktor. Straßen, Post, Fuhrwesen und Reisen nach Triest und Fiume vom Beginn des 18. Jahrhunderts bis zum Eisenbahnzeitaller, München 2002 sowie ais Problemskizze: Jurgen Kocka, Das Problem der Nation in der deutschen Geschichte, in: ders., Geschichte und Autklärtung, Göttingen 1989, S. 82-100; zur Integration durch Recht und Staatsbürgerschaft Dieter Gosewinkel, Einburgern und Ausschließen. Die Nationalisierung der Staatsangehörigkeit vom Deutschen Bund bis zur Bundesrepublik Deutschland, Göttingen 2001; Argast, Staatsbürgerschaft und Nation (wie Anm. 1); zu Nationsblidung und Wahlrecht vgl. die Pionierstudie von Margaret L. Anderson, Practicing Democracy. Elections and political culture in Imperial Germany, Princeton 2000; Rofung And poltischen Realilät der Reichstaglfreiheit im Kaiserreich. Zur Parlamentarischen Wahlprü-

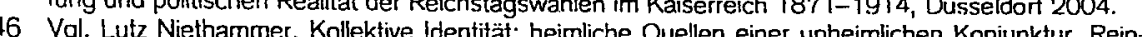
bek 2000; ders Konjunkturen und Kot. heimliche Quellen einer unheimilchen Konjunktur, Reinbek 2000; ders., " Konjunkturen und Konkurrenzen kollektiver Identitäli. Ideologie, Infrastruktur un Gedächtnis in der Zeitgeschichte*, in: PROKLA. Zeilschrift für kritische Sozialwissenschaft 24
(1994), Heft 96, S. 378-399.

304 I Neue Politische Literatur, Jg. 51 (2006) mitbedenkend, dass Selbstreferenz nicht ohne Fremdreferenz und Fremdreferenz nicht ohne Selbstreferenz möglich ist." ${ }^{147}$

Partizipativ sind soziale Identitäten, in denen individuelle auf kollektive Selbstbeschreibungen zurückgreifen, an ihnen also teilhaben. Partizipative Identitäten sind nie uniform, sondern greifen immer auf mehrere symbolische und semantische Plattformen von bestehenden Gruppen in einer Gesellschaft zurück. Über partizipative Identität schließen sich Individuen bestimmten Gruppen an, von anderen aber gleichzeitig aus. Identität wird somit nicht holistisch und im affirmativen Nachvolizug der Akteure verstanden, auch durch Inklusion und Exklusion.

Während der Identitätsbegriff Nation und Nationalismus vomehmlich als Deutungsformationen sieht, liegt der Vorteil des Integrationsbegriffs darin, Erfahrungen und Institutionen miteinander zu vermitteln. So bildeten etwa das Verwaltungs- oder das Wahlrecht den staatsrechtlichen Raum alltagsweltlich ab und organisierten Wahmehmung und Teilhabe am nationalen Erfahrungsraum. Um sich indessen das Kategoriengerüst der Akteure und Eliten mit ihrer Grundannahme eines sich homogenisierenden Resonanzkörpers der Politik nicht zu eigen zu machen, bedarf es der Analyse sowohl des Bewusstseins als auch der Erwartungshaltungen, die sich auf diesen Erfahrungsraum beziehen. Der Nationalstaat ist mithin beides: Erfahrungsraum und Identifikationsobjekt.

Der Leitbegriff der integration in der modemen Nationalismusforschung hat verschiedene Bedeutungsebenen. Integration kann sowohl Systemintegration als auch Sozialintegration bedeuten. Nationen und Nationalstaaten waren das Resultat dieser beiden gleichzeitigen historischen Prozesse. "Während beim Problem der sozialen Integration die geordneten oder konfliktgeladenen Beziehungen der Handelnden eines sozialen Systems zur Debatte stehen, drehte es sich beim Problem der Systemintegration um die geordneten oder konfliktgeladenen Beziehungen zwischen den Teilen eines sozialen Systems." ${ }^{148}$ Die Systeme Nation und Nationalstaat standen seit der Französischen Revolution als Modelle bereit, die politische Herrschaft neu legitimierten und organisierten. Die Geschichte der Nationalbewegungen in Europa ist damit auch die Geschichte der Rezeption, der Aneignung und der Abwandlung dieses Systemmodells. Nationsbildung als Systemintegration bezieht sich auf dieses vorgegebene Modell und fragt nach der Koordination der Ebenen und Institutionen des Nationalstaats. Erfolgreich konnte diese Systemintegration aber nur dort werden, wo auch die soziale Integration Fortschritte machte. Ein Gewinn an sozialer Zusammengehörigkeit unter dem Leitbild der gemeinsamen Nation trieb die Systemintegration in den Nationalstaat entscheidend voran. Nationale Integration als soziale Integration ist durch neue nationale Wissensformen und kulturelle Repräsentationen bestimmt. Diese Formen der Sozialintegration beziehen Identitätsangebote mit ein. Man wird also Identität

147 Cornelia Bohn/Alois Hahn, Selbstbeschreibung und Selbstthematisierung. Facetten der Identität in der modemen Gesellschaft, in: Herbert Willems/Alois Hahn ( $\mathrm{Hg}$.). Identität und Moderne. Frankfurt am Main 1999, S. 33-61, 38; ders.. "Partizipative" Identitäten, in: Herfried Münkler $(\mathrm{Hg}$.), Furch und Faszination: Facetten der Fremdheit, Berlin 1997, S. 115-158: ders., Identität, Nation und das Problem der Fremdheit in soziologischer Sicht, In: Fernuniversität Hagen $(\mathrm{Hg}$.$) , Reader: Strukture$ und theoretische Konzepte zum Kulturtourismus. Kultur-Tourismus-Management, Hagen 1997,
S. 221-254.

148 David Lockwood. Sozialc Integration und Systemintegration, in: Wolfgang Zapf ( $\mathrm{Hg}$.). Theorien des sozialen Wandels, Köln 1970. S. 124-137, 125: vgl. Richard Münch, Elemente einer Theorie de Lebenswelten. Der schwierige Weg in die Weltgesellschaft, Frankfurt am Main 1998, S. 27-67.

Neue Politische Literatur, Jg. 51 (2006) I 
und Integration in der Nationalismusforschung letztlich nicht gegeneinander ausspielen können. ${ }^{149}$

\section{Religion und Nation}

Zu einem zentralen Forschungsfeld der neuesten Kulturgeschichte der Nation und des $\mathrm{Na}$ tionalismus wurde das Verhältnis von Religion und Nation. ${ }^{150}$ Man kann geradezu von einer Explosion der Studien zu Religion und besonders zum Katholizismus sprechen. ${ }^{151}$ Dass Religion und Nation in einer engen Austauschbeziehung stehen, ist nach einer zwanzigjährigen Forschungsgeschichte allgemein deutlich. Michael Geyer wies darauf hin, dass nationale und religiöse Bewegungen vergleichbare Ursprünge haben. Die Nation bildet in dieser Sicht keine Alternative zur Religion, sondern eigentlich ihre Fortsetzung mit anderen Mitteln. ${ }^{152}$ Es ist daher in der Zwischenzeit zu einem Gemeinplatz geworden, dass die Nation religiöse Inhalte und Rituale aufgreift. Die Kriegsbereitschaft des kleinen Mannes in den Weltkriegen hing, wie Benjamin Ziemann ausgeführt hal, mit der Usurpation religiöser Rituale und Glaubensinhalte durch die deutsche Nation - und man mag hinzufügen, ebenso der französischen, italienischen und anderer Nationen und Nationalitäten - zusammen. ${ }^{153}$

"Die Frage ist allerdings, wer hier wen okkupiert." $\$ 54$ Modernisierungsgeschichtlich sieht die Sache immer noch einfach aus: Die Nation beerbt die Religion, die der Säkularisierung anheim fiel. Nachdem die Säkularisierungstheorie selbst in die Kritik geraten ist, rückte Mi-

149 Vgl. Weichlein, Nationalbewegungen und Nationalismus in Europa (wie Anm. 9), S. 5.

50 Vgi. den Forschungsbericht von Ralph Schattkowsky, Kirche und Nation im 19. Jahrhundert. Ein Forschungsbericht unier besonderer Benïcksichtigung des preuBischen Ostens, in: Zeitschrift fü Ostmitteleuropa-Forschung 54 (2005), S. 527-563. Uber den Religionsbegriff, der dabei zugrunde gelegt werden sollte, besteht bisher keine Einigkeit. Vgl. Gunther Wenz, Religion. Aspekte ihres Begriffs und ihrer Theorie in der Neuzeit, Göttingen 2005; Falk Wagner, Was ist Religion? Studien

1 zu ihrem Begriff und Thema in Geschichte und Gegenwart, Gütersloh 1986.

$151 \mathrm{Vgl}$. Olaf Blaschke $(\mathrm{Hg}$.). Konfessionen im Konflikt. Deutschtand zwischen 1800 und 1970: ein zweites konfessionelles Zeitalter, Göttingen 2002; Stefan Laube, Fest, Religion und Erinnerung. Konfessionelles Gedächtnis in Bayern von 1804 bis 1917, München 1999; Helmut W. Smith ( $\mathrm{Hg}$.) Kolestants, Catholics and Jews in Germany, 1800-1914, Oxford 2001. Den Konflikt zwischen den Kirchen und den Nationalstaaten des 19. Jahhunderts vergleicht auf europäischer Ebene: Christopher Clant Wolfram Kaiser ( $\mathrm{Hg}$.), Culture Wars. Secular-Catholic Conflict in 19th century Europe, Gross. Ges. century Gemany. Ann Arbor 2004; vgl. allgemein Adrian Hastings, The Construction of Nationhood, Elhnicity, Religion and Nationalism, Cambridge 1997; Marcel Gauchet, The Disenchantmen

152. Wo eine frühere Generation von Historiken, Princeton 1997.

religiöser Oriente Generallon von Historkern einen Prozess der Verwellichung, der Abschwächung Forschun eine Sehnsucht bensführung überging [ ] Dass die modern in die Suche nach einer bedeutungsgesätligten Le Gütem gehörte wird k. I. I Dass die moderne Nation zu diesen sinn- und gemeinschaftsstiftenden eine unbewältigte eine unbewaltigle Geschichte. Eine einführende Betrachtung, in: Geyer/Lehmann (Hg.), Religion

53 Vgl. Benjumin Zienann, Front und (wie Anm. 29), S. 11-32, 20.

1997; ders. Katholische Religiosität und die Bändliche Kriegserfahrung im südlichen Bayern, Essen ger in der deutschen Armee 1914-1918, in: Jahrbuch für historische Friedensforschung 6 (1997),
S. 116-136.

Reigion und Nation - eine unbewältigte Geschichte (wie Anm. 152), S. 22

\section{I Neue Politische Literatur, Jg. 51 (2006)}

chael Geyer den umgekehrten Vorgang der religiösen Durchdringung der Nation in den Vordergrund. Beide Sichtweisen sollen im Folgenden entfaltet werden.

a. Nation für Religion

Von Religion ist in den Meisternamativen der neueren Nationalismusforschung nicht die Rede. Während sie für Emest Gellner gar keine Rolle spielt, wird die religiöse Erzählgemeinschaft für Benedict Anderson von der nationalen abgelöst. Eric Hobsbawm sieht zwar den Faktor Religion, schätzt ihn jedoch nicht sehr hoch für die Entstehung des modernen $\mathrm{Na}$ tionalismus ein. ${ }^{155}$ Hier dürfte sich ein erheblicher Unterschied zwischen dem kulturgeschichtlichen Paradigma und den immer wieder gerühmten Klassikertexten der kulturgeschichtlichen Nationalismusforschung auftun. Während Religion in der Kulturgeschichte immer ihren Platz hatte, beerbte die Nation nach Ansicht der Nationalismusforschung die Religion. Darin stimmen Anderson, Hobsbawm, und Gellner überein. Thomas Nipperdey, der ansonsten den Stellenwert der Religion gerade betonte, liefert den locus classicus für diese Herangehensweise:

In der Epoche des politischen Glaubens gewinnt Nation so einen religiösen Zug, religiöse Prädikate - Ewigkeit und erfültte Zukunft, Heiligkeit, Brüderlichkeit, Opfer, Martyrium - werden mit ihr verbunden. Das Religiöse wird im Nationalen säkularisiert, das Säkulare sakralisiert." 156

Wenn die Nation die weltbildgebende und -orientierende Funktion der Religion übernimmt, wird sie zur Ersatzreligion. Dieses Deutungsmuster formulierte Josef Roth pointiert in seinem Roman "Radetzkymarsch" von 1932 in Bezug auf die Habsburger Doppelmonarchie vor dem Ersten Weltkrieg: "Man glaubt nicht mehr an Gott. Die neue Religion ist der Nationalismus. Die Völker gehen nicht mehr in die Kirche. Sie geh'n in nationale Vereine." 157 Zumeist wird diese Sichtweise noch mit einem Zitat des römischen Kardinal Antonelli belegt, dem nach der Entscheidung für einen kleindeutschen Nationalstaat unter Ausschluss des katholischen Österreich in der Schlacht bei Königgrätz am 3. Juli 1866 der Satz zugeschrieben wird: „Casca il Mondo!"158

155 NNeither (religion or ethnicity) can be legitimately identified with the modern nationalism that passes as their lineal extension, because they had or have no necessary relation with the unit of territoral political organization which is a crucial criterion of what we understand as a ,nation' today." Eric Hobsbawm, Nations and Nationalism since 1780, Cambridge 1990, S. 47 (Hervorhebung im Original).

156 Thomas Nipperdey, Deutsche Geschichte 1800-1866. Bürgerwelt und starker Staat, München 1983, S. 300.

157 Josef Roth, Radetzkymarsch (1932), in: Werke Bd. 5, hg. von Fritz Hackert, Köln 1989, S. 290. Zit. in: Heinz-Gerhard HaupV'Dieter Langewiesche, Nation und Religion zur Einführung, in: dies. (Hg.), Nation und Religion in der deutschen Geschichte (wie Anm. 23), S. 11-29, 11.

158 Einen sehr frühen Beleg für diesen dem Kardinalstaatssekretär Giacomo Antonelli nachgesagten Satz liefert Kurd von Schlözer, von 1864 bis 1869 preuBischer Legationssekretär in Rom. Am 19. Oktober 1866 schreibt er: AAls [... M Monsignore Berardi am 4. Juli abends dem kranken Antonelli die Nachricht von Sadowa brachte, rief die Eminenz zitternd aus: .Casca il mondo!" (Kurd von Schlözer. Römische Briefe, Stuttgart 1912, Nachdruck 1924, S. 250.) Der Zeitraum zwischen dem angeblichen Ereignis und der Niederschrift - interessanterweise sind gerade aus dem Juli 1866 keine Briefe des preuBischen Diplomaten hinterlassen - sowie die Formulierung lassen jedoch an der historischen Verbürgtheit dieser Aussage zweifeln. Antonelli selbst hat später bestritten, diesen Satz je gesagt zu haben (vgl. Rudolf Lill, Geschichte Italiens vom 16. Jahrhundert bis zu den Anfängen des Faschismus, Darmstadt ${ }^{4} 1988$, S. 189 sowie Adam Wandruszka, Schicksalsjahr 1866,
Graz, Köln, Wien 1966, S. 13.). Dennoch taucht das plakative Zitat meist unkommentiert in vielen

Neue Politische Literatur, Jg. 51 (2006) / 307 
In der Literatur wurde dieses Phänomen als "politische Religion" bezeichnet. Diesen Begriff hatte Eric Voegelin in den 1930er Jahren in die Politikwissenschaft eingebracht. Emilio Gentile benutzt ihn zur Analyse des italienischen Faschismus, deutsche Historiker für den Nationalsozialismus. Besonders Gentile legte nicht nur auf die "Dogmen"-Struktur des Faschismus Wert, sondern auch auf seine Riten und symbolischen Praktiken. ${ }^{159}$ Der Nationalismus wurde als "politische Religion" interpretiert, weil er auf zentrale Elemente der christlich-jüdischen Tradition zurückgriff, sie aber gleichzeitig profanierte. Dazu gehörten die Verheißung menschlicher Kontingenzbewältigung im Diesseits, das Versprechen unfehlbarer Weltdeutung bis zum Opfertad für die Nation als höchstem Wert, ein Deutungsmonopol gegenüber allen anderen sozialen oder konfessionellen Wertesystemen sowie klare Grenzen ethnischer und sprachlich-kultureller Vergemeinschaftung zwischen nationaler in-group und out-group (Hans-Ulich Wehler). Die daraus resultierenden nationalreligiösen Bilder basieren auf den Vorstellungen des auserwählten Volkes, der nationalen Heilsgemeinschaft, der brüderlich-egalitären Heilsgenossenschaft sowie einem manichäischen Weltbild, das mit Überhöhungen und Dämonisierungen arbeitet. Der Begriff der "politischen Religion" dient dem Verständnis für die religiöse Dimension in politischen Diktaturen. ${ }^{160}$ Diese Dimension ist keine Eigenheit des 20. Jahrhunderts. Sie ließ sich vielmehr schon in der Französischen Revolution beobachten, die bei allem Antiklerikalismus dennoch auf der Zivilreligion des höchsten Wesens und einer zivilreligiösen Grundienng der Nation insistierte. Dennoch stehen der "Politischen Religion" als analytischem Leitbegriff für die Nationalismusforschung Bedenken entgegen. Haben politische Religionen ein instrumentelles Verhältnis zur Symbolressource Religion oder haben sie einen substantiell religiösen Charakter mit Transzendenzbezug? ${ }^{i 61}$ einschlägigen Werken auf oder ist sogar titelgebend (Emil Franzel, 1866. II mondo casca. Das Ende
des Alten Europa, Wien, München 1968). Meist fehlt jedoch eine genaue Quellenangabe oder das Zes Alten Europa, Wien, München 1968). Meist fehlt jedach eine genaue Quellenangabe oder das schichte" als "Kommentar des Papstes" (Nipperdey, Deutsche Geschichte (wie Anm. 156), S. 786). Für diesen Hinweis danke ich Patricia Hertel, M.A. Damit teilt das Antonelli zugeschriebene Zitat
Funter das Schicksal des berühmten Diktums von Massimo d'Azeglio "Fatta l'italia, bisogna fare gli Italiani", das in dieser Form von d'Azeglio nie gefallen ist. Zur Überieferungsgeschichte des angeblichen d'Azeglio Zitates vgl. Franz J. Baver, Nation und Maderne im geeinten Italien (1861-1915), in: S. $16-30,16$.

59 Vgl. Eric Voegelin, Die politischen Religionen, hg. von Peter J. Spitz, München 1993; Emilio Gentie, Die Sakralisierung der Politik, in: Hans Maier $(\mathrm{Hg}$.), Wege in die Gewalt. Die modernen politiSchen Religionen, Frankfurt a. M. 2000, S. 166-182; ders.. Politics as religion, Princeton 2006. Als schichte, Bd. 3, München 1995, S. 942f, ders. Nationalismus (wier, Deutsche Gesellschaftsgetionalismusgeschichtichen Gebrauch von ., ders., Nationalismus (wie Anm. 9), S. 27-35. Zum nasches Gemeinschaftsideal als Politische Religion. Zum Vereinsnationalismus der Sänger, Schützen

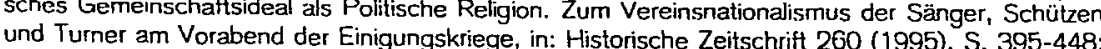
Michael Burleigh, Sacred Causes. Religion and Politics from Zeitschrift 260 (1995), S. 395-448; London 2006; weitere Belege bei Klimó, Das Ende der Nationalismusforschung (wie Anm. 104) kritisch auch: Wolfgang Hardwwig, Political Religion in Modem Germany: reflections on nationalism, Socialism, and National Socialism, in: Bulletin des GHI Washington 28 (2001), S. 3-36. 160 Vgl. Hans Maier ( $\mathrm{Hg}$.), „Totalitarismus" und "Poitische Religionen". Konzepte des Diktaturvergleichs,
3 Bände, Paderborn 1996ff.

161 Vgl. Georg Pfleiderer/Ekkehard W. Stegemann ( $\mathrm{Hg}$.), Politische Religion. Geschichte und Gegenwart eines Problemfeldes, Zürich 2004. Kritisch insbesondere zur Anwend Geschichte und Gegengion" auf den Nationalsozialismus: Hans Günter Hockerts, War der Nationalsozialismus eine politische Religion? Über Chancen und Grenzen eines Erklänungsmodells, in: Klaus Hildcbrand politiZwischen Politik und Religion. Studien zur Entstehung. Existenz und Wirkung des Totalitarismus, München 2003, S. 45-71.

308 I Neue Politische Literatur, Jg. 51 (2006)
Die Übemahme religiöser Elemente macht den Nationalismus noch nicht zu einer postreligiösen Religion. Dagegen spricht zum einen das begriffliche Verständnis einer Religion ohne Transzendenzbezug. Dabei häufen sich gerade die Beispiele dafür, dass die $\mathrm{Na}$ tionskonstrukteure sich von einem genuin religiösen Bewusstsein mit Transzendenzbezug leiten ließen. Friedrich W. Graf kehrt die Blickrichtung sogar um und liest die religiöse Bedeutungsebene des Nationalismus als Teil einer Geschichte der Rechristianisierung.

"Die Durchsetzung des Nationalismus läßt sich nicht einfach unter .Dechristianisierung' subsumieren. Sie kann auch als eine Erfolgsgeschichte der ,Rechristianisierung' gelesen werden. [...] Die individuellen Produzenten solcher neuen Auslegungen waren tief davon überzeugt, gegenüber einem dogmatisch petrifizierten, nur noch für eine relativ kleine Klientel plausiblen Kirchenchristentum den originären Intentionen der biblischen Überlieferung oder der Wahrheit des Glaubens zu neuer Durchsetzung zu verhelfen. [...] Immer ging es ihnen darum, das Eingebundensein des Individuums in die Nation zu einer zutiefst innerlichen, Lebenssinn erschließenden moralischen Selbstbindung zu sakralisieren; der Dienst an der eigenen Nation gewann so einen religiösen Verpflichtungsgehalt." ${ }^{162}$

Zum anderen aber unterstellt "Politische Religion" einen Unterschied zwischen politischer und nicht-politischer Religion im Zeitalter des Nationalismus. Dabei wirkte Religion selbst unmittelbar politisch. Erst unter dem Dogma der Säkularisierung wurde es sinnvoll, von Religion "als solcher" zu sprechen und sie von "Politischer Religion" zu unterscheiden. Die Grenzen der Säkularisienung, wie sie in den letzten Jahren deutlich wurden, zeigten damit auch die Schwächen des Begriffs "Politische Religion" auf. ${ }^{163}$ Den Nationalismus als Ersatzreligion oder politische Religion zu bezeichnen, ist nur dann sinnvoll, wenn man Modernisierung und Säkularisierung engführt und wenn die Nation die Religion in ihrer Bedeutung ablöst. Damit hängt die begriffliche Vorentscheidung zusammen, von Religionen als modemisienungsresistenten Einheiten auszugehen, was wiederum von der religionsoziologischen und historischen Forschung seit längerem bezweifelt wird. Schon weil die Religion selbst ein Faktor der Modernisierung war, liegt ihre Nähe zu anderen Modernisierungsinstrumenten nahe. ${ }^{164}$

Dabei können die sinnvollen Gehalte des Begriffs der "Politischen Religion" durch den Begriff der "politisierten Religion" zum Ausdruck gebracht werden. Dass Religion politisiert werden kann, macht den Nationalismus noch nicht zur Politischen Religion. „Die Besetzung des politischen Raumes durch religiöse Sprache impliziert im Gegenzug eine Politisienung des Religiösen, in der die Religion sich selbst zum Instrument des politischen Machtkampfes darbietet oder als solches funktionalisiert wird." " 65 Aber auch in diesem Begriff bleibt

162 Friedrich Wilhelm Graf, ,Dechristianisierung'. Zur Problemgeschichte eines kulturgeschichtlichen Topos, in: ders., Die Wiederkehr der Götter. Religion in der modemen Kultur, München 2004 S. 69-101, 99 .

163 Vgl. Hockerts, War der Nationalsozialismus eine politische Religion? (wie Anm. 161), S. 4571 .

164 Vgl. Michael N. Ebertz, "Ein Haus von Glorie schauet ..." Modernisierungsprozess der römischkatholischen Kirche im 19. Jahrhundert, in: Wolfgang Schieder $(\mathrm{Hg}$.), Religion und Gesellschaft im 19. Jahrhundert, Stuttgart 1993, S. 62-85; ders., Herrschaft in der Kirche. Hierarchie, Tradition und Charisma im 19. Jahrhundert, in: Karl Gabriel/Franz-Xaver Kaufmann ( $\mathrm{Hg}$.$) , Zur Soziologie des$ Katholizismus, Mainz 1980, S. 89-111.

165 Heiner Bielefeldt/Wilhelm Heitmeyer, Einleitung: Politisierte Religion in der Moderne, in: dies. (Hg.), furt a M 1998 S. 1133,15 V Jl Juan Linz, Der religïse Gebrauch der Politik und/oder der poli-

Neue Politische Literatur, Jg. 51 (2006) I

309 
letzlich noch unklar, wer wen politisiert oder gar instrumentalisiert: die Religion die Politik oder die Politik die Religion. Diese Aporie führt schlieBlich zur Grundsatzfrage, was die Geschichts- und Sozialwissenschaften unter Religion verstehen: Ist sie ein gesellschaftlicher Strukturbegriff wie Politik und Kultur, bezeichnet sie ein Segment innerhalb der Kultur, ist sie ein Funktionsbegriff oder ist sie ein Substanzbegriff? Angemessener als es in den Begriffen Ersatzreligion und politische Religion zum Ausdruck kommt, erscheint es vieimehr, davon auszugehen, dass Nationen das religiöse Weltbild ebenso ergänzen können wie umgekehrt Religionen das nationale Weltbild untermauern und verfestigen können. Indem die Nation das religiöse Weltbild ergänzte, stabilisierte diese wiederum das nationale Lager. ${ }^{166}$

\section{b. Religion als Nation}

Von einer durchgängigen Säkularisierung modemer Gesellschaften kann nicht mehr die Rede sein. Dies liegt zum einen am Vordringen religiöser Fundamentalismen seit den 1980 er Jahren. Zum anderen aber hat die Literatur herausgearbeitet, dass auch zuvor von einem säkularen Normalweg modemer Staaten nur ausnahmsweise und unter besonderen Bedingungen gesprochen werden kann. An die Stelle der Säkularisierung trat der ständige Gestaltwandel der Religion, beziehungsweise die Transformation der Religion ins Religiöse, "the emancipation of the religious from the religion" (John Dewey). ${ }^{157}$

Der amerikanische Sozialwissenschaftler Talal Asad hat auf die politische Funktion hingewiesen, die die Säkularisienungsthese im Nationalstaat erfült und "die darauf hinausläuft, dass ohne einen Rückgang von religiöser Autorität in Staat und Gesellschaft das öffentliche Leben in einer modernen Zivilgesellschaft und in einem demokratischen Staat nicht hätte entstehen können". Asad brachte diese Beobachtung auf den Nenner, „dass die Formation des Säkularen immer ein politisches Programm sei, dessen hauptsächliches Ziel die Überwindung der Religion als gesellschaftsordnende Kraft und ihre Substitution durch eine im geregelten Verfahren konstituierte Herrschaftsordnung sei". 168 Säkularisierung ist damił zum einen keine allgemeine Kategorie zur Beschreibung aller modemen Gesellschaften, sondern ein partieller Prozess in bestimmten Staaten, ohne auf andere Länder übertragen werden zu können. Zum anderen stellt sie nicht nur eine analytische Kategorie, sondern in erster Linie eine Intention historischer Akteure dar, die zum politischen Pro-

tische Gebrauch der Religion. Ersatzideologie gegen Ersat,religion, in: Maier (Hg.), „Totalitanismus" tische Gebrauch der Religion. Ersatzideologie gegen Ersatreligion,
und "Politische Religionen" (wie Anm. 160), Bd. 1, S. 129-154.

166 So vor allem: Peter Walkenhorst, Nationalismus als npolitische Religion"? Zur religiösen Dimension nationalistischer Ideologie im Kaiserreich, in: Blaschke/Kuhlemann $(\mathrm{Hg}$.$) , Religion im Kaiserreich$ (wie Anm. 60), S. 503-529. Kritisch ebenfalls: Frank-Michael Kuhlemann, Pastorennationalismus in Deutschland im 19. Jahrhundert - Befunde und Perspektiven der Forschung, in: Haupt/Langewiesche ( $\mathrm{Hg}$.). Nation und Religion in der deutschen Geschichte (wie Anm. 23), S. 548-586; Laurence Cole. Nationale identität eines nauserwählten Volkes": zur Bedeutung des Herz-Jesu-Kultes rence Cole. Nationale identität eines „auserwählten Volkes": zur Bedeutung des Hen
unter der deutschsprachigen Bevölkerung Tirols 1859-1896, in: ebd., S. 480-515.

167 John Dewey, A common faith (1934), The later Works, 1925-1953, vol. 9: 1933-1934, Hg. Jo Ann Boydston, A common larth (1934), The later Works, 1925-1953, vol. 9: 1933-1934, Hg. Jo Ann Boydston, Carbondale 1989, S. 1-58, 19, 45. Zur Debatte um den Säkularisierungsbegriff vgl. Europa Lehmann ( $\mathrm{Hg}$.), Säkularisierung, Dechristianisierung, Rechristianisierung im neuzeitlichen Europa. Bilanzen und Perspektiven der Forschung, Göttingen 1997; John Bruce ( $\mathrm{Hg}$.$) , Religion and$ Modernisation. Sociologists and Historians debate the secularization thesis, Oxford 1992; William $\mathrm{H}$.

8 So Gos u.a. ( H. ), The Secularizalion Debale, Lanham 2000.

Formations of the und Nation - eine unbewalligle Geschichte (wie Anm. 152), S. 14; Talal Asad, modernity, Stanford 2003; José Casanova, Public religions in the modern World, Chicago 1994

310 I Neue Politische Literatur, Jg. 51 (2006) gramm erhoben wurde. Die neuere Soziologie schränkt die Säkularisierung erheblich ein und spricht von der "Religionsproduktivität der Moderne" (Franz Xaver Kaufmann). ${ }^{169}$ Der Münchener Theologe und Historiker Friedrich Wilhelm Graf beschrieb die Zeit um 1900 als eine äuBerst religionsproduktive Zeit". ${ }^{170}$ Die Reversibilität der Säkularisienung wird auch in den neueren Titeln wie "Rückkehr der Religionen" (Martin Riesebrodt) oder "Die Wiederkehr der Götter" (Graf) ausgedrückt. Diese Formeln sind jedoch umstritten, weil unklar bleibt, ob es sich um die Vitalität von Religionen als institutionalisierten Deutungs- und Sozialformationen handelt oder ob diese Ausdrücke den Transformationsprozess von Religionen in das Religiöse anzeigen. ${ }^{171}$ In jedem Fall wirkte sich die religiöse Komposition einer Geselischaft massiv auf die Konstruktion nationaler Identität aus, und zwar nicht über ihre Abwesenheit und die Suche nach Funktionsäquivalenten, sondern vielmehr über ihre Anwesenheit und direkte Wirkung:

"Die nationalpolitische Bedeutung religiöser bzw. konfessioneller Einstellungen schwand keineswegs im Prozess der Säkularisierung. Es entstanden keine a-religiösen Gesellschaften, als sich das Religiöse im 19. und 20. Jahrhundert stärker vom öffentlichen in den privaten Bereich verlagerte und mehr Menschen als zuvor Religiosität außerhalb kirchiicher Institutionen zu leben suchten. Die religiöse Pluralität nahm vielmehr zu, als die Religionsmärkte der modemen Geselischaften sich der Dominanz etablierter Kirchen entzogen." 172

Es regen sich daher Zweifel an der These von der Nation als Religionsersatz. Im Wesentlichen stehen sich zwei Auffassungen gegenüber, eine vermittelnde und eine, die die Nation genuin religiös verortet. Hans-Ulrich Wehler argumentiert, dass die Nation die Religion sowohl verdrängen als auch partiell mit ihr koexistieren kann. Dagegen geht Wolfgang Reinhard davon aus, dass der moderne europäische Staat im Kern christlich geprägt ist und dass er selbst in seiner säkularisierten Variante noch einen religiösen Charakter behalte. Nation und Religion scheinen sich also wechselseitig zu stärken und nicht zu schwächen. "Traditionelle Formen des Einsatzes von Religion zur Lenkung der Gesellschaft [werden] im Zeitalter des Nationalismus noch einmal dynamisier $\left[t^{3}{ }^{4}{ }^{173}\right.$ Der Osteuropa-Historiker Rudolf Jaworski geht von der "Überlagerung" religiöser und nationaler Bindungen aus, nicht von der Ablösung durch die Nation. ${ }^{174}$ Der Tübinger Soziologe Bernd Estel sieht im Dualismus von Wesensgleichheit und Dissens die "grundsätzliche Spannung zwischen Nation und Religion". Menschen partizipieren sowohl an der Religion als auch an der Nation. Wahrschein-

169 Vgl. Franz-Xaver Kaufmann, Religion und Modernität. Sozialwissenschaftliche Perspektiven, Tübin-

170 Friedrich Wilhelm Graf, Alter Geist und neuer Mensch. Religiöse Zukunftsenwartungen um 1900, in: ders., Die Wiederkehr der Götter (wie Anm. 141), S. 133-178.

$171 \mathrm{Vgl}$. Martin Riesebrodt. Die Rückkehr der Religionen. Fundamentalismus und der „Kampf der Kulturen", München 22001; Graf, Die Wiederkehr der Götter (wie Anm. 141).

172 Dieter Langewiesche/Heinz-Gerhard Haupt, Einleitung, in: dies. (Hg.). Nation und Religion in Europa (wie Anm. 1). S. 11-23, 13; vgl. Hartmut Lehmann, Jenseits der Säkularisierungsthese: Religion im Prozess der Säkularisienung, in: Manfred Jakubowski-Tiessen ( $\mathrm{Hg}$.), Religion zwischen Kunst und Politik, Göttingen 2004, S. 178-190.

173 Vgl. Wollgang Reinhard, Geschichte der Staatsgewalt. Eine vergleichende Verfassungsgeschichte Europas von den Anfängen bis zur Gegenwart, München 22000; Gerd Krumeich/Hartmut Lehmann, Nation, Religion und Gewalt: zur Einführung, in: dies. (Hg.). "Golt mit uns". Nation, Religion und Gewalt im 19. und frühen 20. Jahrhundert, Göttingen 2000. S. 1-6, 2, 4.

$174 \mathrm{Vgl.} \mathrm{Rudolf}$ Jaworski, Konfession als Faktor nationaler Identifikationsprozesse in Ostmitteleuropa im rele Codes, Innsbruck 2001, S. 131-147, 133.

Neue Politische Literatur, Jg. 51 (2006) I 311 
licher als der Konflikt zwischen Religion und Nation sei daher die harmonische Verbundenheit von Religiosität und ausgeprägtem Nationalbewusstsein". ${ }^{175}$ "Daraus erklärt sich, dass Historiker heute im Unterschied zum älteren "secular nationalism" von "religious nationalism" (Peter van der Veer), von „pious nationalism" oder vom "religiös imprägnierten Nationalismus" (Gangolf Hübinger) sprechen. ${ }^{176}$ Diese Begriffe stellen Tiefenstrukturen im Verhältnis zwischen Religion und Nationalismus fest. Empirisch durchgeführt wurden sie indessen vor allem in Asien und Afrika, kaum dagegen anhand europäischer Gesellschaften. Vor allem für das gegenwärtige Indien und für die islamischen Staaten hat sich der Begriff des "religious nationalism" eingebürgert. In den europäischen Gesellschaften ist das Verhältnis zwischen Religion und Nation kaum direkt, sondern vermittelt. Hierzu liegen drei divergierende interprelationsvorschläge vor:

a) Der erste behauptet, dass spezifische Konstellationen darüber entscheiden, ob und wie sich Nation und Religion vermählen. Lucian Hölscher hat in einer begriffsgeschichtlichen Untersuchung des religiösen Konfliktfeldes mehrere Typen unterschieden und zeigt dass die Rolle der Religion in den verschiedenen Gesellschaften entscheidend von ihren semantischen Oppositionen, ihrem "framing" abhängt. Während in Deutschland über Religion im Zusammenhang des Verhältnisses von Staat und Kirche gesprochen wird, ist dieses Oppositionspaar in Frankreich fast unbekannt. Hier dominiert die laizistische Tradition, die dem Staat "le culte" gegenüberstellt und nicht "'église" oder "la religion". In England wiederum dominierte der semantische Gegensatz zwischen hochkirchlicher church" und dissentierender "chapel". ${ }^{177}$ Diese semantischen Oppositionen wirken sich auf das Verhältnis der religiösen Gruppen zu den Nationalbewegungen und Nationalstaaten aus.

b) Friedrich Wilhelm Graf nimmt eine vermittelnde Position ein und weist die Säkularisierungsthese entschieden zurück. Er hält jedoch fest, dass die politische Ethik der. Nation säkular ist und sich im Ansatz von der religiösen Ethik unterscheidet, welche den Verpflichtungsgehalt des Handelns von seinen Folgen und Prämien trennt. ${ }^{178}$

"Die Nation [dagegen] prämiert Erfolge und ahndet Misserfolge. Ihre säkulare Ethik ist

im Gegensatz zur religiösen erfolgsabhängig. [...] Dauerhaftes Versagen des von ihr

175 Bernd Estel, Nation/Nationalismus, in: Hubert Cancik (u. a.), Handbuch religionswissenschaftliche Grundbegriffe, Bd. 4, Stuttgart 1998, S. 212-219.

176 Vgl. Peter van der Veer, Religious nalionalism. Hindus and Muslims in India, Berkeley 1994, Mak Juergensmeyer. The new cold war? Religious nationalsm contonts the secular stat, Beker 1994; Roger Friedland, Religious nationalism nationalism confronts the secular state, Berkeley nual review of Sociology 27 (2001). S. 125-152; Be problem of collective representation, in: AnUnderstanding the Consequences of a Complex Relationship in: Ethnicities $3(2003), 2$ Nationalism: Gangolf Hübinger, Sakralisierung der Nation und Formen dis tantismus, in: Krumesh/

177 Vgl. Lucian Holscher

gemeinschaftung in Europa Göttingen 2007: ders Krche. Sprachliche Konzepte religiöser VerModem Germany in Europa, Gottingen 2007; ders., Semantic Structures of Religious Change in Europe 1750-2000, Cambridge 2003, S. 184-200; ders., Religion im Wandel: Von Begriffen des religiösen Wandels zum Wandel religiöser Begriffe, in: Wilhelm Gräb $(\mathrm{Hg}$.), Religion als Thema des Theologie. Geschichte, Standpunkte und Perspeldiven theologischer Religionskritik und Religionsbegründung, Gütersloh 1999, S. 45-62.

178 „Die Besonderheit von hochentwickelten religiösen - im Unterschied zu rein innerwelttichen, säkularen - Ethiken liegt jedoch darin, dass der ethische Verpflichtungsgehalt nicht erfolostberogen definiert wird: das Handeln und die Prämien des Handelns lassen sich entkoppeln. Religiöse Ethik ist dann erfolgsunabhängig. Der Fromme folgt dem Gebot nicht um des Erfolges willen, sondem handelt allein mit der Intention, dem absolut bindenden Gotteswillen Genüge zu tun." Graf, Die Nation von Gott "erfunden"? (wie Anm. 141), S. 112.

312 I Neue Politische Literatur, Jg. 51 (2006) verheißenen diesseitigen Glücks kann sich die säkulare Wertidee Nation nicht lange leisten."

Dennoch gilt die Nation hier nicht als Ersatzreligion, sondem als Gestalt genuin religiöser Deutungs- und Mobilisierungsprozesse, ablesbar nicht zuletzt an der Bedeutung der Nation in den theologischen Diskursen um 1800 und um 1900.

Die erfolgszentrierte Sicht auf die säkulare Nation behält ihre Aussagekraft vor allem für Deutschland, findet jedoch an katholischen Staaten wie Polen und irland ihre Grenzen. Hier überlebten nationale Vorstellungen trotz einer langen Leidensgeschichte und ständigen fremdstaatlichen Dementis ihrer Nationalität. ${ }^{179}$ Der katholische Blick auf die Nation betonte stärker die Kontinuität zur Christentumsgeschichte und sah die Nation im Christentum selbst begründet. ${ }^{180}$ Letztlich verweist diese erfolgszentrierte Sicht der Nation damit auch auf die Unterschiede innerhalb der nationalen Ethiken, die offensichtlich gar nicht so säkular waren wie theoretisch oft angenommen.

c) Der britische Historiker Adrian Hastings formulierte in seinem Buch "The Construction of Nationhood" (1997) die schärfste Absage an die Nation als säkulare Ersatzreligion. Für ihn sind Nationen im Kem durch Religion entstanden und geprägt, was sich in seiner Chronologie des Nationalen niederschlägt. Hastings plaziert die katholische Version einer im Christentum begründeten Nation im mittelaltertichen Spanien in der Auseinandersetzung mit dem Islam. Deutschland war für ihn wegen der tiefen konfessionellen Spaltung und des Mangels eines großen Gegners eher ein Sonderfall mit einer schwachen religiösen Identität. Die Begründung der Nation aus dem Christentum setzte zumeist auf den alttestamentlich inspirierten Auserwählungsgedanken. Der Erwählungsgedanke war in Deutschland konfessionell gebrochen. Die Stärke des protestantisch-theologischen Diskurses legt die Vermutung nahe, dass England eine biblische, Deutschland dagegen eine theologische Nation war. ${ }^{181}$ Hastings sieht in Nationen nicht moderne, sondem sehr alte Gebilde, die bereits im Mittelalter durch die Übersetzung der Bibel in die Landessprache entstanden waren. Durch seine Frühdatierung von Nation und nationaler Identität ebnete Hastings die Epochenzäsur der Französischen Revolution genauso ein wie die begrifflichen Unterschiede zwischen Patriotismus und Nationalismus. ${ }^{182}$ Weiterführend war dagegen Hastings' Katalog von sieben Kriterien, die für die Prägung nationaler Vorstellungen durch die christlichen Religionen typisch waren. Seine Typisierung eignet sich, um die beziehungsreiche Geschichte von $\mathrm{Na}$ tion und Religion zu ordnen. Nicht alle Punkte sind bisher in der gleichen Dichte bearbeitet; einige kehren in anderer Ausdrucksweise wieder:

179 Heinz-Gerhard Haupt/Dieter Langewiesche, Nation und Religion- zur Einführung, in: dies. (Hg.) Nation und Religion in der deutschen Geschichte (wie Anm. 23), S. 11-29, 14; vgl. Rudolf Stöber, Die erfolgverührte Nation. Deutschlands öffentliche Stimmungen 1866 bis 1945, Stuttgart 1998.

180 So Geyer, Religion und Nation - eine unbewältigte Geschichte (wie Anm. 152), S. 26.

181 Ebd. Auf die Bedeutung des protestantisch-theologischen Diskurses für die Konstruktion der Nation

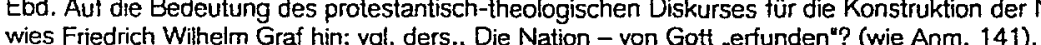

82 Dafür ist Hastings in den Rezensionen mehrfach gescholten worden. Vgl. Steven Groszy, Religion, ethnicity and nationalism: the uncertain perennialism of Adrian Hastings, in: Nations and nationalism
9 (2003), S. 7-13; Anthony D. Smith, Adrian Hastings on nations and nationalism, in: ebd., S. 2528. 
1. Sanctifying the starting point or shaping and canonizing origins and the discovery of a unique national destiny

Religiöse Ursprungsgeschichten der Nation überhöhen deren Entstehung im Sinne einer Teilnahme an der Heilsgeschichte, nicht nur der Weltgeschichte. Ein Beispiel dafür stellt der Bonifatiuskult der deutschen Katholiken dar, der im 19. Jahrhundert aufblühte und von Propagandisten wie lgnaz Döllinger und dem 1849 gegründeten Bonifatiusverein vorangetrieben - mythenstrategisch die nationale Einstellung der deutschen Katholiken von derjenigen der Protestanten absetzen sollte. Bonifatius und sein Kult heiligten bei den Zentennarfeiem von 1855 und 1905 die Entstehung der deutschen Nation im Bunde mit dem römischen Papst und nicht wie im Hermann-Mythos gegen das Römische Reich. Deutsch an Deutschland war für die Bonifatiusverehrer seine christliche Prägung, die man konsequentenweise mit den Missionsreisen des päpstlichen Legaten Wynfrit-Bonifatius zu Beginn des achten Jahrhunderts ansetzte. ${ }^{183}$ Ähnliche mythenstrategische Vereinnahmungen erfuhren in Frankreich die Figuren Chlodwigs oder Jeanne d'Arcs. ${ }^{184}$ Beide antworteten auf die republikanische "Heiligsprechung" der Revolution. Die Ausstellung "Mythen der Nationen" präsentierte 1998 ebenfalls zahtreiche Beispiele für solche geheiligten Ursprungsmythen, vor allem in der Form von "Heiligen Königen" (Piastenlegende, König Stephan in Ungarn, König Wenzel in Böhmen). 185

Die bekannteste Form der religiösen Aufwertung nationaler Ursprünge ist der Erwählung- oder Auserwählungsgedanke. In großer Nähe zum alttestamentlichen Selbstverständnis Israels sahen sich modeme Nationen geme als das zur Erlösung und Rettung der Welt ausersehene "neue Israel", die auserwählle Nation, "the chosen nation" oder als "First new nation" (USA). ${ }^{186}$ Besonders deutlich ist dies in England, worauf Hastings hinweist. ${ }^{187}$ Der englische Frühnationalismus ist ohne diese "chosenness" kaum vorzustellen. Conor Cruise O'Brien ordnete die religiöse Aufwertung oder Selbstüberhöhung der Nation in drei Stufen: Die Enwählung der "chosen people" durch Gott geschah nur auf Zeit; sie war ständig zu erneuern, nie auf Dauer und konnte jederzeit widerrufen werden. Erst die "holy nation " konnte sicher sein, auf Dauer erwählt zu sein Gchosen people with tenure"). Nun kam zur Erwählung in der Vergangenheit ein Auftrag für die Zukunft hinzu. Eric Hobsbawm führte hierfür im Anschluss an Michael Chemiavskys "Tsar and People" die Beispiele "Heiliges Russland", "Heiliges Irland" und "Heiliges Land Tirol" an. Mit der Nation verband sich jetzt der Gedanke

183 Vgl. Siegfried Weichlein, Der Apostel der Deutschen. Die konfessionspolitische Konstruktion des Bonifatius im 19. Jahshundert, in: Blaschke ( $\mathrm{Hg}$. ), Konfessionen im Konflikt (wie Anm. 151) S. 155-179; ders., Bonifatius als politischer Heiliger im 19. und 20. Jahrhundert, in: Michael Imhof/Gregor $\mathrm{K}$. Stasch ( $\mathrm{Hg}$.), Bonifatius. Vom angelsächsischen Missionar zum Apostel der Deutschen, Fulda 2004, S. 219-234.

$184 \mathrm{Vgl}$. Mollenhauer, Symbolkämpfe um die Nation (wie Anm. 48).

Vgl. Monika Flacke ( $\mathrm{Hg}$.), Mythen der Nationen - ein europäisches Panorama: eine Ausstellung des Deutschen Historischen Museums. Begleitband zur Ausstellung vom 20. Mär 1998 bis 9. Jun 1998. Berlin 1998, S. 298-301, S. 504-508, S. 534-540 (zu Piast, Przemysl. Stephan); Christoph Augustynowicz, Piast - ein Begriff zwischen politischen Programmen und historischen Traditionen in: Osterreichische Osthefte 43 (2001), S. 333-351. Zum Stephanskult: Klimó, Nation, Konfession, Geschichte (wie Anm. 1), S. 92-130, 244-288; ders., St. Stephen's Day. Politics and Religion in 20th-Century Hungary, in: East Central Europe 26 (1999), S. 15-31.

$186 \mathrm{Vgt}$. hierzu besonders Anthony D. Smilh, Chosen peoples. Sacred sources of national identity, Oxford 2003

187 Vgl. hierzu vor allem: Herbert Grabes, Elect Nation: Der Fundierungsmythos englischer Identität in der frühen Neuzeit, in: Berding (Hg.), Mythos und Nation (wie Anm. 44), S. 84-103.

\section{I Neue Politische Literatur, Jg. 51 (2006)}

der Sendung. Gänzlich unüberbietbar durch alle anderen Erwählungen wurde die Nation in der vergöttlichten Nation, der "deified nation", die keine Instanz mehr über sich kannte. ${ }^{188}$

\section{The mythologization and commemoration of great threats to national identity}

Die religiöse Interpretation der Gründung und der Gründungsfiguren setzte sich fort in der religiös-mythischen Lesart der Gefahren für die Nation, welche zumeist aus Kriegen und Schlachten enwuchsen. Religiös überhöhte Schlachten fassten mythenkonstruktiv einen langen Prozess in der zweiwertigen Logik eines Kampfes zusammen und kommunizierten das Ergebnis von Machtkämpfen erfolgreich. "In retrospect a large process became simplistically symbolised in public memory by a single event or hero figure calculated best to reinforce a special identity." 189 Beispiele hierfür sind der englische "gunpowder plot" genauso wie die Schlacht auf dem Amselfeld oder Jeanne d'Arc.

Eine besondere Wirkung spielten religiöse Denkmuster in der nationalen Erinnerung von Leidens- und Unterdrückungserfahrungen. Im religiösen Symboispeicher wurden diese Konstruktionselemente nationaler Identität konserviert und geheiligt. Ein Beispiel hierfür sind vor allem der irische und der polnische Nationalismus, wo der Opfergedanke national interpretiert wurde. Nach Adam Mickiewicz war Polen der "Christus unter den Völkern". Durch sein Leiden sollte es die anderen europäischen Völker erlösen. ${ }^{190}$ Die genuine Kompetenz der Religion, auf Erfahrungen des Leidens zu antworten, verband sich hier engstens mit der Konstruktion nationaler Gemeinsamkeit.

3. The social role of the clergy

Die Rolle des Klerus für die Nationalbewegungen harrt noch immer ihrer Erforschung Während protestantische Pfarrer Gegenstand der Bürgertumsforschung waren, ist die Rolle des katholischen Klerus für die europäischen Nationalbewegungen erst in Umrissen sichtbar. So teilte einerseits der Klerus mit der römischen Kirchenleitung einen strammen ultramontanen, gegenrevolutionären und antinationalen Standpunkt. Ideologisch stand er daher in keiner Weise den Nationalbewegungen nahe. Seiner sozialen Stellung nach war der katholische Klerus jedoch oft lokal eingebunden und artikulierte die politische Haltung seine Klientel. Kam hier ein starker äußerer Gegner - wie in Spanien Napoleon - hinzu, konnte der Klerus auch einen nationalen Standpunkt vertreten. ${ }^{191}$

Lediglich für Osteuropa ist bisher die Rolle des Klenus in den Nationalbewegungen untersucht worden. In den gemischt-religiösen und multiethnischen Gesellschaften Osteuropas übemahm der niedere Klerus die Interessen seiner kirchlichen Klientel auch in nationalen Angelegenheiten. Ricarda Vulpius hat den Klenus der Ukraine, Martin Schulze Wessel

188 Vgl. Conor Cruise O'Brien, God Land: Refiections on religion and nationalism, Cambridge Harvard 1988; Montsersat Guibernau/John Hutchinson ( $\mathrm{Hg}$.). History and National Destiny. Ethnosymbo1988: Montserrat Guibernau/Joh

189 Hastings, Construction of Nationhood (wie Anm. 151), S. 191

190 Vgl. u.a. aus der umfangreichen Literatur: Kimberly Cowell-Meyers, Religion and politics in the nineVgl. U.a. aus der umfangreichen Literatur: Kimberly Cowell-Meyers, Reigion and politics in the nine-
teenth century: the party faithful in lreland and Germany, Westport 2002; Stephan Scholz, Der deutsche Katholizismus und Polen (1830-1849): Identitätsbildung zwischen konfessioneller Solidarität und antirevolutionärer Abgrenzung, Osnabrück 2005; Jim Bork, Neither German nor Pole: Ca-

tholicism and National Indifference in a Central European Borderland, 1890-1922, Ann Arbor 2007.
Niceto Blázquez, El national clericalismo Vasco, Madrid 2004; Kevin Collins, Catholic clergy and the Celtic revival in Ireland, 1848-1916. Dublin 2002 
denjenigen der Tschechoslowakei, Böhmens und Mährens und Christian Pletzing denjenigen Polens untersucht. ${ }^{192}$ Der Klerus nahm in diesen Nationalbewegungen eine ambivalente Rolle ein. Einerseits nämlich ging für den Klerus durchweg die nationale vor der konfessionellen Identität, was im Falle der polnischen Katholiken auf dem deutschen Reichsgebiet die Trennung von den deutschen Katholiken und deren Zentrumspartei bedeutete. Der polnische Klenus verhielt sich pragmatisch zur ,Organischen Arbeit', also dem Aufbau eigener polnischer gesellschaftlicher und wirtschaftlicher Strukturen. In eine ähnliche Richtung deuten die Ergebnisse Schulze Wessels für Böhmen, die ihn zu der Frage führen, ob in ethnisch segmentierten Gesellschaften nicht die Ethnizität gegenüber der Konfession den Ausschlag gegeben habe. Ist die Religion die Zurechnungseinheit für ihre Motivation oder nicht eher ihre soziale Lage oder ihre Ethnizität? Wenn der polnische Klerus die nationale Identität über die konfessionelle stellte, dann relativiert dies die Bedeutung der Konfession. Martin Schulze Wessel fragte denn auch zugespitzt, ob in ethnisch segmentierten Gesellschaften tatsächlich Konfessionalität oder nicht doch eher Ethnizität epochenprägende Bedeutung eriange. ${ }^{193}$ Letztlich würden diese Befunde den Stellenwert des Faktors Konfession in den Nationalbewegungen relativieren.

Allerdings ging der Klerus auch in Polen nur so lange mit der Nationalbewegung, wie die Interessen der Kirche davon nicht tangiert wurden. Stand er in der Sprachenfrage, schon um hier die Glaubwürdigkeit nicht einzubüßen, noch Seite an Seite mit seinen Gemeinden, so zeigte der Klenus gegenüber dem entwickelten Nationalismus doch zunehmend Abstoßungsreaktionen. Besonders in Polen häuften sich im späten 19. Jahrhundert die Konflikte zwischen Klerikern und Nationalisten. Entscheidend ist es hier, die Ebenen und Institutionen im Verhältnis von Klerus und Nationalismus auseinander zuhaiten. Religiöse Begründungen für nationales Engagement können nicht mit dem Verhalten der Amtskirche gleichgesetz werden. Auch die Reichweite der verbreiteten nationalen Losung der "Gefährdung des Glaubens" blieb beschränkt. 1848 machten sich nur westpreußische, nicht aber die anderen polnischen Adligen diese Parole zu eigen. Erieichtert wurde die $\mathrm{Zu}$ sammenarbeit dort, wo die Ziele der Kirche und der Nationalbewegung deckungsgleich waren. ${ }^{194}$

\section{The production of the vemacular literature}

Religion wirkt sich nach Hastings am stärksten auf die Nationenbildung durch Bibelübersetzungen und die Konstruktion von Nationalsprachen aus. Die Übersetzungen der Bibel in die jeweilige Landessprache stellen für ihn, wie bereits erwähnt, den Beginn des Nationalbewusstseins dar, den er zumeist auf das Mittelalter zurückverlegt. Die Kirchen werden so

192 Vgl. Martin Schuize Wessel, Revolution und religiöser Dissens. Der römisch-katholische und russisch-orthodoxe Klerus als Träger religiösen Wandels in den böhmischen Ländern brw. in Russland 1848-1922. Habilschrift Universität Halle 2001; Christian Pletzing, Vom Völkerfrühling zum nationalen Konflikt. Deutscher und polnischer Nationalismus in Ost- und Westpreußen 1830-1871. Wiesbaden 2003; Ricarda Vulpius, Ukrainische Nation und zwei Konfessionen. Der Klerus und die ukrainische Frage 1861-1921, in: Jahrbücher für Geschichte Osteuropas 49 (200t), N.F., S. 240 256: dies., Nationalisierung der Religion: Russifizienungspolititk und ukrainische Nationsbildung 1860-1920. Wiesbaden 2005 .

193 Vgl. Martin Schulze Wessel, Das 19. Jahrhundert als „Zweites konfessioneiles Zeitalter"? Thesen zur Religionsgeschichte der böhmischen Länder, in: Geschichte und Gesellschaft 27 (2001), 5. 514-530, 519. Zur Diskussion um den Ethnonationalismus in Europa vgi. Urs Altermatt, Das Fanal von Sarajewo. Ethnonationalismus in Europa, Zürich 1996.

194 Vgl. Schaltkowsky, Kirche und Nation im 19. Jahrhundert (wie Anm. 150), S. 552

316 I Neue Politische Literatur, Jg. 51 (2006) zum genuinen Träger des Nationalbewusstseins. Auch im 19. Jahrhundert finden sich hiertür Beispiele. Die ukrainische Nationalbewegung, von den Russen bis dahin als .Kieinrussen" bezeichnet, wurde entscheidend durch die 1861 angefertigle Bibelübersetzung in die Landessprache beeinflusst. Moskau erkannte darin eine Gefahr und untersagte den Druck, sah es sich doch selbst als Schutzmacht der "Slavia orthodoxa". Die Wiederzulassung der ukrainischen Bibelübersetzung wurde zur zentralen Forderung des ukrainischen Klerus, der sich darüber an die Nationalbewegung annäherte. ${ }^{195}$ Nach der Oktoberrevolution von 1917 forderte die ukrainische Nationalbewegung "Los von Petrograd", Geistliche nahmen diesen Ruf auf und riefen "Los von Moskau". ${ }^{196}$ Bei der Nationsproduktivität der Bibelübersetzung liegt ein religiöser Vergleich zum Islam nahe. Zu fragen ist, ob der Umstand, dass die islamische Theologie keine Übersetzung in die Landessprachen kennt, das andere Verhältnis zur Nationenbildung erklären kann. Der Koran ist Gottes Wort, wohingegen die Bibel Gottes Wort wiedergibt, erzählt, also selbst Interpretation ist und daher für weitere Interpretationen offen bleibt. Diese Interpretationsoffenheit der Bibel scheint sich über weite Strecken der neuesten und allemeuesten Geschichte stark vom muslimischen Verständnis heiliger Texte zu unterscheiden; als Grundlage für genuin nationales Selbstbewusstsein kam der Koran kaum in Frage.

\section{The provision of a biblical model for the nation}

Die Sprache der Nationalisten und ihre Selbstdeutungen sind voll von religiös-biblischer Sprache. Der Auserwählungsgedanke wurde bereits erwähnt. Hierzu gehören auch die jesajanische "Stadt auf dem Berg", die für die Völker leuchtet und sie anzieht Vereinigte Staaten), die Wiedergeburt und „anagenisis", mit der die Griechen 1822 die "Wiedergeburt des altes Hellas" feierten, oder das namengebende Risorgimento in Italien und der Kreuzestod Christi, der der polnischen Selbstdeutung eines "Christus unter den Völkem" zugrunde lag. Am folgenreichsten dürfte aber der nationale Messianismus sein. Er richtete sich als nationales Sendungsbewusstsein auf die Zukunft und knüpfte an die altisraelitische Tradition sowie an das Neue Testament an.

Klaus Schreiner hat den Bedeutungs- und Funktionswandel des Messianismus in mehreren Studien untersucht. ${ }^{197}$ Das theologisch-politische Deutungsmuster, einer Nation ein von Gott gewolltes Schicksal zuzuschreiben, reichte bis ins Mittelalter zurück. Nach 1918 gewann der nationale Messianismus weiter an Bedeutung, gab er doch ultimative Antworten auf die nach der Kriegsniederlage drängende Sinnfrage der deutschen Nation. Ein Beispiel dafür war der protestantische Theologe Wilhelm Stapel. Er befand, "das deut-

195 Vgl. Vulpius, Nationalisienung der Religion (wie Anm. 192); dies., Ukrainische Nation und zwei Konfessionen (wie Anm. 192).

196 Vgl. Vulpius, Nationalisierung der Religion, (wie Anm. 192), S. 379

197 Vgl. Klaus Schreiner, Politischer Messianismus, Führergedanke und Führererwartung in der Weimarer Republik, in: Manfred Hetlling u. a. (Hg.), Was ist Gesellschaftsgeschichte? Positionen, Themen, Analysen München 1991, S. 237-247; ders., Messianismus. Bedeutungs- und Funktionswandel eines heilsgeschichtlichen Denk- und Handlungsmusters, in: Klaus Hildebrand (Hg) Zwischen Poltitik und Religion (wie Anm. 161), S. 1-44; ders., Reichsbegriffe und Romgedanken. Leitbilder politischer Kultur in der Weimarer Republik, in: Wolfgang Lange/Norbert Schnitzler ( $\mathrm{Hg}$ ) Deutsche italomanie in Kunst, Wissenschaft und Politik, München 2000, S. 137-177; ders. Wann kommt der Retter Deutschlands?": Formen und Funktionen von politischem Messianismus in der Weimarer Republik, in: Saeculum 49 (1998), S. 107-160; Klaus Hornung, Politischer Messianismus: Jacob Talmon und die Genesis der totalitären Diktaturen, in: Zeitschrift für Politik $47(2000)$ S. 131-172; Hans-Ulrich Wehler, Nationalismus (wie Anm. 9), S. 281.

Neue Politische Literałur, Jg. 51 (2006) I 317 
sche Volk [...] sei kraft des ihm von Gott eingeprägten Nomos ein ,imperiales Volk'. Als solches sei es zur Bildung eines übernationalen Reiches berufen, in dem ihm die politische Führung zukomme." "198 Die religiöse Aufwertung des nationalen Weges eines Volkes stand in Weimar in besonders starkem Kontrast zur gefühlten Gegenwart. Der politische Messianismus überbrückte in der Weimarer Republik vor allem diese Gräben. Das Ergebnis war eine politisch-endzeitliche Aufwertung der Führer- und Retter-Vorstellung. Der Führer stellte den politischen Messias dar und sollte aus der nationalen Misere herausführen. Die Sehnsucht nach dem Einen, der alles wendet, rückte ins Zentrum der politischen Vorstellungswelt. Die Bewohner Fallingbostels in der Lüneburger Heide weihten 1922 ihr Gefallenendenkmal mit den Worten ein: „Wann kommt der Retter Deutschlands? Wann kommt die Zeit, in der ein starker Mann wie Bismarck das Reich auf's neue schmiedet und aller Feinde zum Trotz Deutschland zu altem Ruhm erhebt?" Diese national-religiös aufgeladene Vorstellungswelt bereitete den Boden für Hitler in der deutschen Gesellschaft, aber auch innerhalb der NSDAP, wo sich Goebbels zum Künder des Hitlerschen Messiasbewußtseins machte. Der nationale Messianismus und Führergedanke blieb indessen nicht au Deutschland beschränkt. Auch die italienischen Faschisten sahen in Mussolini "il Salvatore d'Italia" oder "il Messia della Patria" und sprachen vom "messianismo mussoliniano". ${ }^{199}$ Beispiele wie diese belegen die "Funktionalisierung des Religiösen in politischer Absicht durch anpassungsfähige Pfarrer, Prediger und Theologen auf der einen, [die] Instrumentalisierung religiöser Vorstellungen, Metaphem und Begriffe durch die Wortführer politischer Bewegungen und Parteien auf der anderen Seite. ${ }^{\text {200 }}$

6. The autocephalous national church

Anders als im ultramontanen Katholizismus mit seiner strengen Romorientierung bildeten die autokephalen Kirchen des Protestantismus und der Orthodoxie institutionelle Voraussetzungen für ein Nationalbewusstsein. Im Katholizismus scheiterten die nationalkirchlichen Versuche des Febronianismus und des Wessenbergianismus, auch wenn sie in Teilen traditionsbildend wirkten. Die Autokephalie der Kirchen wirkte sich vor allem in den Reichen Osteuropas auf die Nationalbewegungen aus. Beispiele hierfür sind die serbische Orthodoxie und die ukrainische orthodoxe Kirche. Aber auch in Finnland verdichtete sich in der lutherischen Kirche die Nationalbewegung. ${ }^{201}$

Was Hastings freilich nicht erwähnt: Der intrinsische Zusammenhang von Religion und Nation wird beim Antisemitismus ebenfalls deutlich. So trieb der christliche Erwählungsgedanke der Nation den Ausschluss der Juden aus der Nation voran: "Wenn die Juden das Volk waren, das die Deutschen unter protestantischer Führung werden wollten, dann konnten sie [sc. die Juden] schwerlich als integraler Bestandteil der Nation begriffen werden. "202 Auch ihr Versuch, sich dem deutschen "Volk" als ethnisch-religiöser jüdischer

198 Zit. in Schreiner, Messianismus (wie Anm. 197), S. 24

199 Zit. in ebd., S. 29.

200 So das Resümee von Schreiner in ebd., S. 41.

201 Neben den Arbeiten von Ricarda Vulpius vgl. Ann Urbar/Serhy Yserhy, The nation's clothes: Constructing a Ukrainian high culture in the Russian empire, 1860-1900, in: Jahrbucher fur Geschichte Osteuropas 49 (2001), N.F., S. 230-239; Snyder, S. 105-132; Teuvo Lartila $(\mathrm{Hg}$.), Nationalism and Orthodoxy. Two thematic studies on national ideologies and their interaction with the church, Helsinki 2004 .

202 So Geyer, Religion und Nation - eine unbewältigte Geschichte (wie Anm. 152). S. 25; Nir.olaus Buschmann, Auferstehung der Nation? Konfession und Nationalismus vor der Reichsgründung in

318 I Neue Politische Literatur, Jg. 51 (2006)
Stamm", einzugliedem, scheiterte an dem von nationaltheologischen Gruppen vorangetriebenen Antisemitismus. Die antisemitische Spannungslinie erwies sich zumindest in de deutschen Nationalbewegung stärker als die Spannungen zwischen den Konfessionen.

c. Konfessionalisierung der Nation?

Die Nähe religiöser und nationaler identitätskonstruktionen hat Historiker zur These der "Konfessionalisierung der Nation" geführt. In den gemischtkonfessionellen Gesellschaften Mitteleuropas korrespondierte die nationale Entgrenzung der religiösen Selbstverständigung zur Inanspruchnahme der Nation durch die Konfessionen. Die Mehrkonfessionalität von europäischen und außereuropäischen Gesellschaften wurde für die auf Homogenität angelegte Ordnungsidee der Nation zum Problem. Aber auch konfessionell homogene Geseitschaften wie Frankreich oder Italien kannten konfessionelle Lesarten nationaler Identität Die Konfessionalisierung der Nation schien also nicht auf gemischtkonfessionelle Gesellschaften beschränikt zu sein. ${ }^{203}$

Für das protestantische Bürgertum wird die These der Konfessionalisierung der Nation seit längerem vertreten. Dessen theologische Aufladung des deutschen Nationalgedankens geschah mittels dreier Vorstellungen: erstens durch das auserwählte Volk, zweitens durch die jedem Volk wesensmäßig eigene Religiosität, wie sie sich in den lutherischen Chorälen und der Musik Johann S. Bachs auszudrücken schien und die die Rückkehr eines verweltlichten Volkes zu seinem Gott garantierte. Hinzu kam drittens ein übergreifendes Sittengesetz, das die Lebensführung auch jenseits der kirchlichen Gemeinschaft anleitete. ${ }^{204}$ Religionen boten den Konstrukteuren der modemen Nation einen "reich gefüllten Symbolspeicher", den diese nutzten, um die Nation mit der "Aura einer [...] schon immer gegebenen Substanz" zu umgeben. Nicht nur die deutsche Nation erhielt so einen religiösen Mehrwert. 205

Heinz-Gerhard Haupt und Dieter Langewiesche gehen in zwei Tagungsbänden der Bedeutung von Religion in der deutschen und in anderen europäischen Nationalbewegungen nach. ${ }^{206}$ Im Mittelpunkt stehen die Fragen nach der Nationalisierung der Religion und der

der Debatte jüdischer, protesfantischer und katholischer Kreise, in: Haupt/Langewiesche ( $\mathrm{Hg}$.). Nation und Religion in der deutschen Geschichte (wie Anm. 23), S. 333-388. Vgl. ebenso Till van Rahden, Germans of the Jewish Stamm. Visions of Community between Nationalism and Particularism, 1850 to 1933, in: Mark Roseman/Nils Riemer/Neil Gregor (Hg.), German History from the Margins, 1800 to the Present, Bloomington and Indianapolis 2005, S. 27-48.

$203 \mathrm{Vgl}$. dazu die Einleitungen in: HaupV/Langewiesche $(\mathrm{Hg}$.), Nation und Religion in der deutschen Geschichte (wie Anm 23); dies. ( $\mathrm{Hg}$.), Nationen und Religionen in Europa (wie Anm. 1); Schattkowsky, Kirche und Nation im 19. Jahrhundert (wie Anm. 150)

204 Vgl. Geyer, Religion und Nation - eine unbewältigte Geschichte (wie Arm. 152), S. 25; Graf, Die Nation - von Gott ,erfunden"? (wie Anm. 141), S. 116-129; Hartmut Lehmann, The Germans as a chosen people. Old testament themes in German Nationalism, in: German Studies Review 14 (1991). S. 261-274; ders., God our old ally. The chosen people theme in late 19th century German nationalism, in: ders. William R. Hutchinson $(\mathrm{Hg}$.$) , Many are chosen. Divine election and Western$ nationalism. Minneapolis 1994, S. 85-108.

205 Haupt/Langewiesche, Nation und Religion zur Einführung, in: dies., Nation und Religion in der deutschen Geschichte (wie Anm. 23), S. 17; Graf, Die Nation von Gott "erfunden"? (wie Anm. 141), S. 314.

206 Vgl. Heinz-Gerhard Haupt/Dieter Langewiesche ( $\mathrm{Hg}$.), Nation und Religion in der deutschen Geschichle (wie Anm. 23); dies. ( $\mathrm{Hg}$.), Nation und Retigion in Europa (wie Anm. 1). Vgl. hierzu auch die weiteren vergleichend angelegten Bände: Geyer/Lehmann $(\mathrm{Hg}$.). Religion und Nation (wie Anm. 29); Krumeich/Lehmann ( $\mathrm{Hg}$.). "Gott mit uns" (wie Anm. 173).

Neue Politische Literatur, Jg. 51 (2006) I 319 
Sakralisierung der Nation. Die Ergebnisse dieses Bandes differenzieren die ältere These der Konfessionalisienung der Nation erheblich. In gemischtkonfessionellen Gesellschaften der Konje Konfessionalisierung auf eine Gegenkonfessionalisienung. Konfessionalisienungsstieß jede Konfessionalisierung auf eifolgreich, blieben intention und waren gerade nicht soversuche waren immer nur relativ erfolgreich, blieben litenlion un waften Südeuropas stieß ziale Realität. In den konfessionell homogenen National

ch die Konfessionalisierung außerdem am Laizismus. ${ }^{20}$ zu diesem Themenfeld sein

Wie gewinnbringend der begriffsgeschichtliche Zugang zu diesem Themenfeld sein kann, zeigt Willibald Steinmetz. Er zeichnet anhand einer Begriffsgeschichte der Nation in den Konfessionellen Lexika die Phasen, Verwerfungen und Widerstände gegen die Konfesden konfession Nation nach. ${ }^{208}$ Die Spannbreite der Bedeutungen von Nation sionalisierung der deutschen Nation nach. ${ }^{2}$ Die Spann groß. Besonders im Katholizismus blieb allen Homogenisienungstendenzen zum Trotz sehr groß. Besonderf im Katholizisnus war bis zur Mitte des 19. Jahmunderts umstritten, was dieser Begrif bezeichnen solle. War die Nation Teil einer religiös verstanden Geschichte oder bildete sie ihr Gegenstuck? Widersprach die Nation dem Transnationalismus des Ultramontanismus? Auch unter konWidersprach die servativen und Iiberalen Protestanten wansorstellungen fessionelle Polemik gegen die jeweils andere Konfession und hre Lexikon sprach von einahmen gegen Ende des 19. Jahrhunderts zu. Ein protestantsches Lexkon sprach von einer chinesischen Mauer, die der Ultramontanismus um den katholischen Volkstell gelegt ner chinesisch habe und der ihn von Kirche, der jeder nationalen Einhegung entgegenstand. Der Erste universalen Beruf der Kirche, der jeder nationalen Eho konfessionalisierten NationsbeWeltkrieg bildete hier die große Zäsur. Er veranderte die konfessionalsiertischen griffe und näherte sie einander an. Nach 1918 werteten die deutschen kalholischen Lexka die Nation aus genuin religiösen Gründen auf. Der Aufstieg des Volksbegriffes erleichterte die Nation aus genuin religiosen Grunden ation jetzt nicht mehr protestantisch dominiert war. diese Annäherung, weil die deutsche Nation jetzt nicht mehr protestanlisch dom von keiner Gleichzeitig bewirkte er den definitiven Ausschluss der Juden, wogegen sich von këkisch. Dazu Seite auch nur der leiseste Widerstand erhob. Juden galten jetzt als fremdvökisch. Dazu verschärte sich der inneriüdische Streit, ob man überhaupt noch Teil der deutschen Nation verschartte sich der innenudische Start ausschloss. Ihre Selbstbeschreibung innerhalb der bleiben wollte, die die Juden derart ausschloss. Ihro Selbstamm, und bildete damit die deutschen Nation schwankte zwischen Religion, Nation und Starnm, und bildete damal ab. Ihre Debatvölkische Wendung der konfessionellen Definitionsversuche noch einmal ab. Ihre Debattenbeiträge erhielten keine Antwort mehr. Für den Syndikus des Jüdischen Zentralvereins in München Wemer Cahnmann waren Juden "nicht einzuordnen in die allgemeine Terminologie von, Nation' und ,Nicht-Nation'".209

(n) Andere Autoren setzen die semantische und ideolgisch. Frank Becker und andere seden deutschen "Normalnationalismus" bereits vor 1914 an. Frank Becker und andere sehen im Abflauen des Kulturkampfs die wesentliche Zäsur und betonen die Bereitschaft katholischer Mittelschichten, am withelminischen Nationalgefühl teilzuhaben. ${ }^{210}$ In die gleiche Richtung zielen die Befunde Dieter Langewiesches zur Geschichte des Akademischen Bo-

207 Vgl. Wolfram Kaiser, Clericalism - that is our enemy!' European anticlericalism and the culture Vgl. Wolfram Kaiser, ,Cleicals (wie Anm. 151), S. 47-76. wars, in: ders./Christopher Clark (Hg.). Culture Wars (we Anm.

(1830-1940), in:

209 Vgl. Willibald Sleinmet, Die Nation in kontessionellen Lex deutschen Geschichte (wie Anm. 23), Haupt/Langewwesche ( $\mathrm{Hg}$.), Nation und Religion in Stamm: Zum Wandel der Selbstdefinition unter S. 217-292; Michael Brenner, Religion, Nation und Stamm: Zumann, Judentum und Volksgemein deutschen Juden, in: ebd., S. S87-695.

10 schall, in. Der Morgen 2 (1) Kaupt/Lange Vgl. Frank Becker, Kontessionelle Nationsbider im Deutschen Kaiser. 23), S. 389-418.

390 I Neure Politische Literatur, Jg. 51 (2006) nifatiusvereins vor 1914, der für gebildete Katholiken wie kaum ein anderer Verein die Ver einbarkeit von Nation und Religion verkörperte. Immer breitere katholische Schichten be kamen Zugang zum nationalen Gedankengut, ohne dass dadurch die protestantische Deu tungshoheit gebrochen oder auch nur gefährdet wurde. Der Nationalismus stieg auf dies Weise von den Höhen der politischen Propaganda in den Altag hinab. Er veralltäglichtı sich, wurde "banal nationalism" (Michael Billig). Der Normalnationalismus war erschwinglicl für jedermann. ${ }^{211}$

Die nationskonfessionellen Stereotypen des nationalen Protestantismus und des na tionsskeptischen Katholizismus bestimmten lange Zeit die Nationalismusforschung. Metho disch barg diese Herangehensweise die Gefahr in sich, nationalistische Stereotypen au den Quellen in die Darstellung hinein zu verlängem und zu analytischen Größen zu machen Die neuere Literatur bestätigt zwar die zahlreichen Versuche zur Konfessionalisierung de Nation, beurteilt ihren Erfolg jedoch sehr viel skeptischer als früher. Seit mehreren Jahre setzte ein Revisionismus in der Literatur zu Konfessionalisierung und Nation auf mindesten fünf verschiedenen Ebenen ein:212

a. Ein erster Einwand lautet, dass die These der ${ }_{n}$ Konfessionalisierung der Nation" de jüdischen Beitrag zur deutschen kulturellen Nationsbildung nicht beachtet. Der verstorben Leipziger Kirchenhistoriker Kurt Nowak wandte sich bereits 1993 gegen diese Begrifflich keit, weil an der Kultumation nicht nur Protestanten und Katholiken, sondern vor allem aucl Juden mitwirkten. Dazu gehörten etwa die Komponisten Felix Mendelsohn, Gustav Mahle und Giacomo Meyerbeer. Juden konfessionalisierten die Nation aber gerade nicht. Im jüdi schen Bildungsbürgertum herrschte vielmehr eine enge Verbindung zwischen Universalis mus und Nationalismus vor. ${ }^{213}$

b. Die zweite Kritik betrifft die Reichweite der Konfessionalisierungsthese, die oft über schätzt werde. Bis in den Vormärz hinein hatte die Nation einen überkonfessionellen Cha rakter. Der Bikonfessionalismus zeigte sich in der kulturgeschichtlichen und nich staallichen Lesart der Nation, die in beiden Nationen vorherrschte. Der "Apostel der Deut schen" Bonifatius war bis in die 1840er Jahre Gemeingut beider Konfessionen, bis er ge gen Luther und die Reformation zur Geltung gebracht wurde. Bis dahin war er nicht der rö mische Legat, sondern der monotheistische Tugendprediger im griechischen Philosophen mantel, wie ihn das Fuldaer Bonifatius-Denkmal darstellte. ${ }^{214}$ Auch für die Schweiz arbeite Oliver Zimmer heraus, dass die Nationskonzeptionen in den beiden Großkirchen sich se den 1870er Jahren bis zum Jubiläumsjahr 1891 einander annäherten. ${ }^{215}$ Die konfessionell Lesart der Nation konnte also nur unter bestimmten Konstellationen und dann auch nur fü einen bestimmten Zeitraum eine relative Deutungshoheit für ihre Klientel beanspruchen. Fü

211 Michael Billig, Banal nationalism, London 1995

212 Zur neueren Debatte um Nutzen und Nachteil der analytischen Vorstellung der Konfessionalisierun der Nation vgl. Stefan Plaggenborg, Konfessionalisierung in Osteuropa im 17. Jahrhundert. Zu Reichweite eines Forschungskonzeptes, in: Bohemia 44 (2003). S. 3-29.

213 Vgl. Ulrich Sieg, Bekenntnis zu nationalen und universalen Werten. Jüdische Philosophen im Deut schen Kaiserreich, in: Historische Zeilschrift 263 (1996), S. 609-639; Kurt Nowasophen im Deu Schen Kaiserreich, in: Historische Zeilschrift 263 (1996), S. 609-639; Kurt Nowak, Konfession un lessen u. a. ( $\mathrm{Hg}$.), Europa fordert die Christen. Zur Problematik von Nation und Konfession, Re gensburg 1993, S. 24-51.

214 Vgl. Weichlein, Apostel der Deutschen (wie Anm. 183). Zum bikonfessionellen Hintergrund der fru hen Nationsvorstellungen vgl. auch Schattkowsky (wie Anm. 150), S. 540.

215 Vgl. Oliver Zimmer, A Contested Nation. History, Memory and Nationalism in Swilzerland, 1761 1891, New York 2003, S.164ff. 
Deutschland hat Georg Schmidt die lange Tradition der Mehrkonfessionalität des Alten Reiches herausgearbeitet. ${ }^{216}$

c. Für Frank-Michael Kuhlemann und Nikolaus Buschmann konnten diese Versuche, die Nation zu konfessionalisieren, nie auch nur die Mehrheit der jeweiligen Konfessionsgedie Nation zür kich gewinnen, geschweige denn allumfassend werden. Die Konfessionalisienossen für sich gewinnen, geschweige denn allumen Unterschiede in den Konfessionen zu rung der Nation war eher dazu angetan, die intemen Unterschiede in den Kotionsvorstellunverdecken. Kuhlemann zeigt dies vornehmlich fur die protestantischen Nationsvorstellungen. Er arbeitet die verschiedenen Versuche heraus, die Nation mit konfessionellen Gehalten zu füllen. Aber auch er meldet Zweifel an der Reichweite dieser Versuche an. Dieter Langewiesche verstärkte diese Zweifel in seiner Darstellung des scheitemden Versuches, Langewion protestantische bügenliche Nationalhelden we Ludwig Unland und Freiken zum deutschen nisieren. ${ }^{217}$ Nikolaus Buschmann differenziert die Haltung der Katholiken zum deutschen Nationaistaat. Er räumt mit dem Stereotyp auf, dass die deutschen Katholiken einen nationalen Standpunkt gehabt hätten, dessen StoBrichtung gegen die Liberalen zielte. Tatsächlich kann der Standpunkt der Ultras nicht verallgemeinert werden, und schon gar nicht für lich kann der Standpul bürgerliche Schichten, worauf bereits Thomas Mergel hingewiesen hatte. Der nalionalpolitsche Konflikt zwischen Katholiken und Protestanten war immer nuf partiell und auf be-
stimmte Gruppen im Katholizismus beschränkt.218

d. Hinzu kommt, dass religiöse Argumente für die Nation und die Konfessionalisierung nicht Hand in Hand gehen, wie die Untersuchung des böhmischen Jan-Hus-Kult von Martin Schulze Wessel zeigt. Zwar wurde der Kult um den 1416 in Konstanz als Ketzer vertin Schulze Wessel zeigt. Zwar wurde der Kull un den 1416 in Konstanz als Ketzer verbrannten Reformator zu einem zentralen religiosen Topos der tschechischen Nationalbewegung im Kampf gegen Wien. Aber er diente gerade nicht der Konfessionalisierung der gung im Laizismus und dem Ausschluss der tschechischen Nallon, sotis Weltkrieg von Rom abgespaltene und kurzzeitig erfolgreiche tschechoslowakische Kirche. Entscheidend ist, ob die konfessionell gedeutete Nation mit einer positiven oder einer negativen Identität einherging. Der Hus-Kult grenzte sich negativ gegen Katholiken und Wien galiven lde $a b$ und blieb daher bedeutungsolfen fur lazistische Nation viel integrativere Wenzel-Kult der Hus-Kult stark nachließ und der für die Slowaken sehr viel integralivere Wenzel-Kult zunahm, brach sich die religiöse Konstruktion der Nation jedoch an der ethnischen und
sprachlichen Komposition der tschechischen Gesellschaft. ${ }^{219}$

216 Vgl. Georg Schmidt, Die frühneuzeitliche ldee "deutsche Nation": Mehrkonfessionalität und säkulare Werte, in: Haup

217 Vg. Frank-Michael Kuhlemann, Konfessionalisierung der Nation. Deutschland im 19. Und frühen 20. Hahter 20. Jahrhundert, S. 27-63; Dieter Langewiesche, Vom Schettem burgeriche Friedrich Ludwig Jahn, in: Historische Zeitschrits 278 (20̈sischen Krieges von 1870/71, Paderborn 2004 .

218 Nikolaus Buschmann, Auferstehung der Nation? Konfession und Nationalismus vor der Reichsgründung in der Date jüdischer, protestantischer und katholischer Kreise, in: Haupt/Langewiesch dung in der Debatte Judisch in der deutschen Geschichte (wie Anm. 23), S. 333-388; ders., Einkrei(Hg.). Nation und Religon cift. Die öfentliche Deutung von Krieg und Nation in Deutschland 1850 sung und Waflenbruderschatt. Die öfentliche Deutung Klasse und Konfession. Katholisches Bürgertum im Rheinland 1794-1914, Göttingen 1994.

219 Martin Schulze Wessel, Die Konfessionalisienung der tschechischen Nation, in: Haupt/Langewiesche $(\mathrm{Hg}$.), Nation und Religion in Europa (wie Anm. 1), S. 135-149; ders., Historismus und

322 I Neue Politische Literatur, Jg. 51 (2006) e. Schließlich wurden auch begriffsgeschichtlich Bedenken gegen die Konfessionalisierungsthese formuliert. Lucian Hölscher arbeitete heraus, dass der Konfessionsbegriff als Fremdbezeichnung im frühen 19. Jahrhundert entstand. Konfessionalismus und "engel konfessioneller Standpunkt" waren Vorwürfe im innerprotestantischen Disput zwischen Liberalen und Orthodoxen. In allen Kirchen - auch im Judentum - setzten sich in den innerreligiösen Deutungskämpfen des 19. Jahnunderts die konservativen Positionen durch. Ir diesem Zusammenhang ist der Konfessionsbegriff zu sehen. Erst von hier aus wurde er ir das 16. und 17. Jahrhundert zurück projiziert Anders als es die These vom zweiten konfessionellen Zeitalter" (Olaf Blaschke) unterstellt, entstammt der Konfessionsbegriff selbs dem so bezeichneten "konfessionellen Zeitalter" und kann nur bedingt analytisch an es herangetragen werden, wenn er begrifflich davon sauber getrennt wird. 220

Nimmt man diese Einwände gegen die Konfessionalisierungsthese zusammen, so folg daraus: Die Bedeutung der Religion für die Nation kann nicht umstandslos auf die Konfessionen übertragen werden. Konfessionen zielen mit der Konfessionalisierung der Nation vo allem nach innen und suchen einen Meinungsdruck und größere Homogenität zu erzeugen. Tatsächlich näherten sich die Konfessionen gegen Ende des 19. Jahrhunderts an das nationale Denken durch den gemeinsamen Antisozialismus an. Beispiele dafür sind vor allem Deutschland und Italien, weniger dagegen Frankreich, wo im Katholizismus der Antirepublikanismus und damit eine mentale Reserve gegen den republikanischen Nationalismus dominierte. ${ }^{221}$ Aber auch die Entwicklung in Polen unterstützte nur teilweise die Konfessionalisierungsthese. Vor 1871 zeichnete sich im polnischen Klerus die Tendenz ab, die nationale polnische Identität über die konfessionelle zu stellen, damit aber den Bruch mit den deutschen Katholiken zu riskieren.222

Eine weitere offene Frage ist, ob der Laizismus tatsächlich selbst eine systemische Alternative zu allen Formen religiöser Aneignung der Nation darstellte oder ob er eine eigene neue Konfession neben den etablierten Großkirchen bildete. War der Laizismus ein Teil der konfessionellen Landschaft oder entzog er sich ihr? Mit Blick auf die französischen Verhältnisse charakterisierte Marcel Gauchet das Verhältnis von Religion und Laizismus als "antagonisme de l'obstination religieuse et de l'ambition läque" und lässt die Frage damit in der Schwebe. ${ }^{223}$ Tatsächlich aber besaßen der Laizismus und der Antiklerikalismus "eigene Symbole und Rituale, ein spezifisches Menschen- und Geschichtsbild und einen weltanschaulich bestimmten Entwurf der gesellschaftlichen Entwicklung". Diesen Strukturanalo-

konkurrierende kirchliche und konfessionelle Geschichtsdeutungen in Ostmittel- und Osteuropa zwischen den Weltkriegen, in: Zeitschrift für Geschichtswissenschaft 50 (2002). S. 141-154.

220 Vgl. Lucian Höischer: Konfessionspolitik in Deutschland zwischen Glaubensstreit und Koexistenz, in ders. $(\mathrm{Hg}$.): Baupläne der sichtbaren Kirche (wie Anm. 177), S. 11-52; Olaf Blaschke, Das 19. Jahrhundert: Ein Zweites Konfessionelles Zeitalter? in: Geschichte und Gesellschaft 26 (2000) S. 38-75.

221 Vgl. Daniel Mollenhauer, Symbolkämpfe um die Nation. Katholiken und Laizisten in Frankreich (1871-1914), in: Haupt/Langewiesche (Hg.), Nation und Religion in Europa (wie Anm. 1), S. 202230

222 Literatur zu Polen in: Schattkowsky, Kirche und Nation im 19. Jahrhundert (wie Anm. 150), S. 548563; Jaworski, Konfession als Faktor nationaler Identifikationsprozesse (wie Anm. 174); Dariusz Aleksandrovicz, Katholische Religion und Nationalismus in Mittelosteuropa, in: Kart Acham ( $\mathrm{Hg}$. ). Kontinuitäten und Brüche in der Mitte Europas. Lebenslagen und Situationsdeutungen in Zentraleuropa um 1900 und um 2000, Wien 2003, S. 93-118.

223 Marcel Gauchet, La religion dans la démocratie, Paris 1998, S. 10; Haupt/Langewiesche, Einleitung, in: dies. (Hg.), Nation und Religion in Europa (wie Anm. 1), S. 17 
gien auf der expressiven Seite stehen freilich gravierende Gegensätze in der Ideologie gegenüber 224 Die institutionellen und ideellen Beziehungen zwischen dem Laizismus und dem Nationalismus sind ein Desiderat der Forschung.

N. Nation, Territorialität und Region

Studien zu Regionalismus und Nationalismus, zur Vereinbarkeit von regionaler und nationaler ldentität nahmen in den letzten Jahren stark zu. ${ }^{225}$ Hierbei spielte einmal die generelle Konjunktur des Regionalismus eine wichtige Rolle, aber auch das kulturgeschichtliche interesse an der Identitätspolitik auf verschiedenen politischen Ebenen. Eine Grundüberzeugung zum Verhältnis von Nation und Region prägt die Literatur der letzten Jahre: der konstruktive Charakter der Region. Auch diese ist eine "imagined community" und lebt von "invented traditions". ${ }^{226}$ Die Imagination und kulturelle Konstruktion beziehen sich nicht nur auf die Nation, sondern auch auf die Region und die Kommunen und ihren Kommunalismus. Wenn sich die Imagination und Erfindung aber auf mehrere Ebenen bezieht, wie verhalten sich dann diese "imagined communities" zueinander? Welche Modelle organisieren ihr Verhälthis zueinander: Teil und Ganzes, Wir und die anderen, Inklusion und Exklusion, oben und unten, die Parität, der Proporz oder der Parteienwettbewerb?227

Die Region zu definieren hat sich in der Vergangenheit als mühsames Geschäft erwie sen. Dabei hat es sich als besonders schwieng herausgestellt, das Verhältnis zwischen verstaallichen Regionen und ihrer kulturellen Konstruktion zu bestimmen, da hier von einem Wechselverhältnis ausgegangen werden muss. Der Region eine eindeutige ldentität zuzuordnen erwies sich als eine selbstgestellte methodische Falle wie die Reduktion auf politische oder kulturelle Praxen. Weder empirisch noch theoretisch läßt sich die Kohärenz solcher Identität darlegen. Das führte Rogers Brubaker dazu, Regionen zu ndiskursiven Kon-

224 Zum Verhältnis des Laizismus zum Nationalismus vgl. Mollenhauer. Symbolkämpfe um die Nation (wie Anm. 221); Kaiser, ,Clericalism - that is our enemy!' (wie Anm. 207); Bernhard Plé, Die sakralen Grundlagen der laizistischen Republik Frankreichs. Zur Liturgie der aufgeklärten Bürgerschaft in der dritten Republik, in: Archiv für Kulturgeschichte 87 (2005), S. 373-395.

$225 \mathrm{Vgl}$. Nancy R. Reagin, Recent work on German national Identity: Regional? Imperial? Gendered? Imaginary?, in: Central European History 37 (2004), S. 273-289.

$226 \mathrm{Vgl}$. Detlef Briesen/Rüdiger Gans, Regionale Identifikation als, Invention of Tradition'. Wer hat und warum wurde eigentlich im 19. Jahrhundert das Siegerland erfunden, in: Berichte zur deutschen Landeskunde 66 (1992). S. 61-73. Zum Konstruktcharakter von Regionalität vgl. Thomas Küster, "Regionale identität" als Forschungsproblem. Konzepte und Methoden im Kontext der modernen Regionalgeschichte, in: Westrälische Forschungen 52 (2002), S. 1-44, 22; Fiender/Plau/Schmidt, Regionale Identität zwischen Konstruktion und Wirklichkeit (wie Anm. 1). Zum Forschungsstand vgl Maiken Umbach, Nation and region, in: Timothy Baycroft/Mark Hewitson $(\mathrm{Hg}$.$) , What is a nation?$ Europe 1789-1914. Oxford 2006, S. 63-80; Peter Weichhart, Die Region - Chimäre, Artefakt oder Strukturprinzip soziajer Systeme?, in: Gerhard Brunn $(\mathrm{Hg}$.), Region und Regionsbildung in Europa: Konzeptionen der Forschung und empirische Befunde, Baden-Baden 1996, S. 25-43; Anssi Paasi, Place and region: regional worlds and words, in: Progress in Human Geography 26 (2002), S. 802812; ders., Region and place: regional identity in question, in: Progress in Human Geography 27 (2003), S. 475-485; ders., Place and Region: looking through the Prism of Scale, in: Progress in Human Geography 28 (2004), S. 536-547; ders., Bounded spaces in the mobile World: deconstructing, regional identity', in: Tijdschrift voor Economische et Sociale Geografie 93 (2002), S. $137-148$

227 Den Parteienwettbewerb als Konfiliktregulierungsmechanismus macht Gerhard Lehmbruch besonders stark. Vgl. Gerhard Lehmbruch, Parteienwettbewerb im Bundesstaat. Regelsysteme und Spannungslagen im Institutionengefüge der Bundesrepublik Deutschland, Opladen ${ }^{2} 1998$.

$324 I$ Neue Politische Literatur, Jg. 51 (2006) zepten "zu erklären, die von ihren Akteuren gebraucht werden, um Ansprüche (claims) durchzusetzen. Begriffe wie Region und Nation wären dann „frames", um Ansprüche zu artikulieren. Andere sehen in der Region die "Verdolmetschung des Nationalen" (Confino) oder auch ein "diskursives Refugium" vor dem Hintergrund eines rasanten Modemisierungsprozesses. Regionen indes analog zu Nationen als kleine Nationen oder Nationen im Wartestand zu begreifen, sie also als zur Nation strukturanaloge soziale Einheiten zu sehen, würde bedeuten, die theoretische Entwicklung der Nationskonzepte und ihrer methodischen Umsetzung noch einmal zu durchlaufen, kurz: das Ei der Identität und der Integration noch einmal zu erfinden - mit allen Schwierigkeiten. ${ }^{228}$ Aus der Sicht der Nationalismusforschung ist vielmehr entscheidend, wie sich das Verhältnis zwischen Nation und Region staltete: konkurrierend oder komplementär? Für beides findet sich reiches empirisches Material. Die Nationalismusforschung sollte diese Befunde systematisch interpretieren.

Aushandiungsprozesse und Beziehungsgeschichte

Die Heimatidee war eine Weise, den Ort der Region im Nationalstaat zu bestimmen. Sie schrieb dem Nationalen lokale Eigentümlichkeiten, Heterogenität und Differenz zu und wirkte ihrerseits auf die Regionsbildung zurück. ${ }^{229}$ Sie verband kognitiv und emotional verschiedene Ebenen und Akteure der Nationsbildung miteinander: „Der Prozess des kognitiven Kartierens ist [...] verantwortlich dafür, dass emotionale und mentale Ordnungsraster entstehen, die dem Raum ,innere Logik' und den Menschen Identifikationsmöglichkeiten ,bis hin zum Heimatgefühl' verleihen."230 Die bahnbrechenden Studien von Alon Confino und Celia Applegate haben diesen doppelten Vorgang, die Region der Nation, aber auch das Nationale dem Regionalen einzuschreiben, für Württemberg bzw. für die linksrheinische Pfalz nachgezeichnet. ${ }^{231}$ "Die Imagination einer abstrakten, ewigen deutschen Gemeinschaft" ließ Heimal schließlich zu einem, sowohl lokalen als auch nationalen Symbol" werden." 232 Hinter diesem Symbol stand der Anspruch, Region und Nation miteinander zu ver-

228 Vgl. Rogers Brubaker, Rethinking nationhood: nation as an institutionalized form, practical category, contingent event, in: ders., Nationalism refraimed. Nationhood and the national question in the new Europe, Cambridge 1996, S. 13-22. Diese Konzepte werden diskutiert in: Ther/Sundhaussen (Hg.), Regionale Bewegungen und Regionalismen (wie Anm. 1). Vgl. Mühler/Opp, Region und Na-

"Heimal betrifft die Beziehung zwischen Ort und Ich. Sie symbolisiert das AuBen, dass das ich nich wirklich betreten, in dem es sich aber spiegeln kann. Sie erhebt somit den Anspruch, dem modernen Menschen eine subjektzentrierte Eigen- und Umwelterfahrung, einen Standori, dem moderRolf Petri, Deutsche Heimat 1850-1950, in: Comparativ 11 (2001), H.1, S. 77-127, 79; Vgl. auch allgemein: David Morley/Kevin Robbins, No Place like Heimat: Images of Home(land) in Eunopean Kultur, in: New Formation 12 (1990), S. 1-23.

230 Kuster, "Regionale Identität" als Forschungsproblem (wie Anm. 226), S. 22

Vgi. Alon Confino, The Nation as a Local Metaphor. Württemberg, Imperial Germany and National Memory, 1871-1918, Chapel Hill North Carolina UP 1997; ders, Die Nation als lotab Metapher: Heimat, nationale Zugehörigkeit und das Deutsche Reich 1871-1918, in: Zeitschrift für Goschichtswissenschaft 44 (1996), S. 421-435; ders., Localness and nationhood, in: Bullefin des Deutschen Historischen Instituts London 23 (2001), S. 7-27; Celia Applegate, A Nation of Provinces (wie Anm. 89), dies., Heimat and the varieties of regional History, in: Central European Hisfory $33(2000)$. S. 109-117

232 Danny Trom, Natur und nationale Identität. Der Streit um den Schutz der, Natur" um die Jahrhundertwende in Deutschland und Frankreich, in: Etienne François u. a. ( $\mathrm{Hg}$.), Nation und Emotion Deutschland und Frankreich im Vergleich: 19. und 20. Jahrhundert, Göttingen 1995, S. 147-167, 162: vgl. Katharina Weigand ( $\mathrm{Hg}$.), Heimat. Konstanten und Wandel im 19./20. Jahrhundert: Vorsteliungen und Wirklichkeiten, München 1997.

Neue Politische Literatur, Jg. 51 (2006) 
binden. Doch allzu oft ersetzte der Heimatgedanke nur den regionalen Konflikt durch einen 列 modernisierungsgeschichtilichen, wie die ultranationäls sie zu den Deutungsformationen, die in der Weimarer Republik bewies. das Ende des deutschen Nationalstaates 1945 uberlebten. Heimat dise ${ }^{234}$ Jan Palmowsi hat für die Geschichte im Nationalsozialismus und als Trost in der Krise. ${ }^{234}$ Jan Palmowski hat fur die Geschich der DDR aufgezeigt, dass die semantische und soziale integrationsfigur der Handem auch nur für das Deutsche Kaiserreich und die Weimarer Republik gegollen hat, sondem auch nur fur das5, als der Nationsbegriff bis in seinen Kern hinein kontaminiert schien, gleichsam nach 1945, als der Nationsbegrif bis in seinen Kem konnte. Die DDR kannte eine lange und eine Ausfallbürgschaft für die Nation übemehmen

Was für Deutschland die Semantik der Heimatidee war, war für Frankreich die VorstelWas Verhältnis von regionaler und nationaler Identität. lung der npetile patre. Sie regullerte dä lange Zeit als reaitypischer Zentralstaat gesehen In Frankreich, das in der Forschung uber lange Zu, die die Rolle des Lokalen und des Regiowurde, nehmen in jüngster Zeit Forschungen zu, die die Rolle despte sich so immer mehr als nalen in der Nationsbildung herausarbeiten. Zentralismus entpuppte sich so immer meschreiein Mythos der Nationalisten, weniger jedoch als eine analytische Kategorie zur Beschrei-

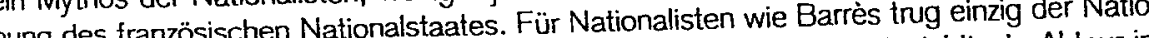
bung des französischen Nationalstaates. Für Nationalsten wich der einzige und wichtigste Akteur im nalstaat historische Bedeutung. Er war aus ihrer Sicht der einzige und wevolution, die wie die öffentlichen Leben, Träger des Fortschritts und Verkorpenung der Revolution, die weruch des Nation eins und unteilbar schien. Alles Lokale und Regionale stand daher im Genuch des reaktionären Provinzialismus, der Anhänglichkeit an die Aristokratie, des Legitimismus und der Konterrevolution. Diese Sichtweise geriet seit den 1960er Jahren in die Kritik. Im Jahr 2000 konnte der Soziologe Alain Bourdin auch fur Frankreich behaupten "The regionalen Brechuntriumphs. ${ }^{236}$ Besonders die Arbeiten zum Bicentennaire arbeitelen die regionalen Brech in gen und Einflüsse im Revolutionsgedenken heraus. Hier entstand ein Bild der Diversitat im Gedenken, wie es bei Pierre Noras "Lieux de memoire" und seiner Beschre

homogenen Frankreichs der Erinnerungsorte gerade nicht zum Vorschein kam.

Was für die sozialen Praktiken des Revolutionsgedenkens galt, traf auch aut die Vorstellung der Nation zu. Sie wurde regional unterschiedlich angeeignet. Anne-Manie Thiesse und Jean-François Chanet arbeiteten die Diskursgeschichte der npetite patie "und de Geschichte der sie unterstützenden Institutionen heraus. Das "engere und das weitere land" bildete eine lebensweltlich verbreitete Semantik, die Region und Nation miteinande

33 Vgl. Willi Oberkrome, Schutzwalli Heimat. Themenschwerpunkte und weltanschauliche Prämissen gl. Wint Oberkome, "Schutzwall Heimat. Themenschungen 52 (2002), S. 185-203; ders., "Geder Westalentage 1920-1933, in: Westfalische Forschungen 52 (20 Heimatideologie in der ersten sundes Land - gesundes Volk. Deulsche Landschaftreschichte und Agrarsoziologie 53 (2005),

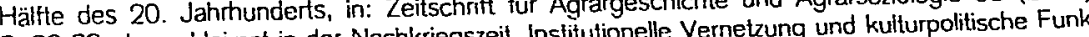
S. 26-39; ders.. Heimat in der Nachkriegszell. Inshuliter tionen des westfälischen Heimatbundes in der Hartung, Konservative Zivilisationskritik und regionale schungen 47 (1997. S. 153-200, Win Heimatbewegung 1895 bis 1919. Hannover 1991. Identitäl am Beispiel der niedersächsischen Heimalbewegung

$234 \mathrm{Vgl}$. Thomas Schaarschmidt, Regionalkultur und Diktalur. Sachsische

mat-Propaganda im Dritten Reich und in der SBZDDR, Koln 2004.

235 Vgl. Jan Palmowski, Deutschland bis in die DDR - Heimat: building an east german haton. S. 365 construction of a socialist "Heimat, $1945-1961$, in. Cental Erühen Jahren der DDR, in: Aus Politik 400: Michael Lemke, Nalionalismus und Patriotismus in den fruhthen Jahren der Identitäl in der Diklatur und Zeitgeschichte 50 (2000), S. 11-20. Den umgekionalkultur und Diktatur (wie Anm. 234).

zu rekonstruieren, geht: Thomas Schaarschmidt, Reg
Alain Bourdin, La question locale, Paris 2000, S. 10.

326 I Neue Politische Literatur, Jg. 51 (2006) verband. ${ }^{237}$ Diese Vorstellung war sogar auf der politischen Linken verbreitet. Institutionen, in denen regionales Bewusstsein konstruiert und tradiert wurde, waren die ethnologischen Museen, Ausstellungen und der frühe Tourismus. ${ }^{238}$ Kulturelle und regionale Diversität sland auch im Zentrum der Vermarktung des weithin bekannten Michelin". 239 Auch die lokalen Geschichtsvereine, die im 19. Jahrhundert entstanden und sich besonders mit dem Mittelalter beschäftigten, konzentrierten sich auf Fragen der regionalen Geschichte und Tradition. Auf allen diesen Ebenen kann von einer wechselseitigen ninterpenetration" des Nationalen und des Regionalen gesprochen werden. ${ }^{240}$ Bereits 1846 wies der Pariser republikanische Schriftsteller Aristide Guilbert den Anspruch Michelets, der den Lokalismus in Frankreich vemichten wollte, zurück: "It is not Paris that absorbs the provinces, (but) the provcinces that appropriate Paris (and) renew their spirit through repeated immigrations." 241

Für Italien galt im Prinzip Ähnliches. Der Unterschied war, dass die Kommunen hier die Rolle der Regionen im Aushandlungsprozess des modernen Nationalstaates einnahmen. Die subnationalen Einheiten waren also kleinteiliger. Rolf Petri und Mario Isnenghi beschrieben die Bedeutung "kleiner Räume" für die nationale Imagination Italiens. Die italienische Nation fand ihren Ausdruck und ihre alltägliche Anschauung auch in den "kleinen Räumen" und im öffentlich zugänglichen Platz, der der Inszenierung der Nation genauso diente wie ihrer kommunikativen Verdichtung:

"Region, Paese/paesi und piccole patrie wurden zum emotionalen Verindungsstück des Einzelnen zur Nation und bildeten damit einen Kembereich für die. zeittypische Ver-

237 Stéphane Gerson, Une France locale: The local past in recent French scholarship, in: French Historical Studies 26 (2003), S. 539-559; vgl. Alban Bensa/Daniel Fabre ( $\mathrm{Hg}$.$) , Une histoire a soi. F-$ gurations du passé et localités, Paris 2001; Patrick Marcia, Le bicentennaire de la Revolution française: pratiques sociales d'une commemoration, Paris 2000; Anne-Marie Thiesse, Ils apprenaient la France: L'exaltation des régions dans la discourse patriotique, Paris 1997; dies., La création des identités nationales: Europe XVille - XXe siècle, Paris 1999; dies., Des fictions créatrices: les identités nationales, in: Romantisme: Revue du dix-huitieme siècle 30 (2000), Bd.110, S. 5362; Jean-François Chanet, L'école républicaine et les petites patries, Paris 1996; Les petites patries dans ia France républicaine, Jean Jaurès cahies trimestriels, Sonderheft 152, Paris 1999; Pirn den Boer. History as a profession. The study of the History of France, 1818-1914, Ubers. Arnold J. Pomerans, Princeton 1998; Odile Parsis-Barubé ( $\mathrm{Hg}$.). Les representations du Moyen Âge au $\mathrm{XIXe}$ siecle dans les anciens Pays-Bas français et leurs contins picaros. Essai d'historiographie comparée, 2 Bde..Villeneuve d'Ascq 1999; François Gritlet, Naissance de la Normandie: Genèse et épanoissement d'une image regionale en France, 1750-1850, Caen 2000; Caroline Ford, Creating the nation in provincial France: religion and political identity in Brittany. Princeton 1993; Maurice Auguhthon, Conscience nationale et conscience regionale en France de 1815 à nos jours, in: ders. Histoire vagabonde, 3 Bde., Paris 1988, Bd. 2. S. 144-174.

238 Zum Einfluss des Tourismus auf das Verhälthis von Region und Nation vgl. Ellen Futlough, „Une leçon des choses". Tourist, empire, and the nation in interwar France, in: French Historical Studies 25 (2002), S. 441-474.

239 Vgl. Steven L. Harp, Marketing Michelin: Advertising and Cultural Identity in 20th Century France. Baltimore 2001 .

$240 \mathrm{Vgl}$. Stuart Woolf/Heinz-Gerhard Haupt/Michael Müller, Introduction, in: dies. (Hg.). Regional and National identities in Europe in the 19th and 20th centuries, The Hague 1998, S. $5 f$

241 L'llustration 7. Nr. 162, 4.4.1846, S.78, zit. in: Gerson, Une France locale (wie Anm. 237), S. 557 ; $\mathrm{Vgl}$. Aristide Guilbert $(\mathrm{Hg}$.), Histoire des villes de France, avec une introduction générale pour chaque province, 6 Bde., Paris, 1844-48. Zum Zusammenhang vgl. Stéphane Gerson, Town, Nation or Humanity? Festive Delineations of Place and Past in Northern France, ca. 1825-1865, in: Journal of Modern History 72 (2000), S. 628-682; ders., La représentation historique du "pays", entre l'état et la société civile, in: Romantisme 30 (2000), S. 39-51: ders., Parisian litterateurs, provincial joumeys and the construction of national unity in posi-revolutionary france, in: Past and Pre-
sent 151 (1996), S. 141-174. 
räumlichung sozialer und politischer Prozesse. Man könnte sagen, die Dörfer, Städte und Regionen konstruierten und gestalteten die Nation in dem Maße, in dem die Nation die Dörfer, Städte und Regionen (zum Teil neu) konstruiert und (um)gestaltet. ${ }^{242}$

Die Schwäche des "affetto regionale" wurde kompensiert durch die Stärke der italienischen Kommunen, was bis hin zu dem Diktum reichte, Italien bestehe eigentlich aus 100 Städten. ${ }^{243}$ Insofem übernahm in Italien die lokale Identität die Funktion der regionalen Identität in Deutschland. Der tief sitzende "campanilismo" drückte sich nicht nur politisch aus, sondern auch im Stolz auf kulturelle und sprachliche Eigenheiten: „Genauso wie die Annahme einer Nationalsprache nicht automatisch zum Verlust des Dialekts, sondern zur Ausbildung differenzierter Sprachpraktiken führt, hat die Annahme einer nationalen Identität historisch mit vielfältigen Zugehörigkeitsinhalten koexistiert: Gruppen-, Regional- und Ortszugehörigkeit." 244

Die neuere Forschung hat damit für mehrere Staaten zwei Grundannahmen nachhaltig erschültert, die die Nationalismusforschung bis in die jüngste Zeit durchzogen:

1. Das Verhältnis von Region und Nation kann modemisienungstheoretisch nicht mehr als dasjenige von Zentrum und Peripherie verstanden werden. Generationen von Modernisierungstheoretikem, allen voran der nonwegische Soziologe Stein Rokkan, hatten die Region auf die Seite der Peripherie gesteilt. Im Zentrum standen der Nationalstaat, seine Institutionen und Eliten. ${ }^{245}$ Das Modell von Zentrum und Peripherie ordnete der Region eine passive und reaktive, dem Zentrum des Nationalstaats dagegen eine aktive Rolle zu. Dies spiegelt indessen mehr die Intentionen der Nationalisten, weniger den historischen Prozess. Selbst wenn sie damit erfolgreich waren wie im Fall der ${ }_{n}$ cultural peripherization of Flanders" durch die französisch sprechenden wallonischen Eliten in Belgien hieß dies nicht, dass die Flamen passives Objekt der wallonischen Politik gewesen sind. ${ }^{246}$ Nationalismusforscher wie Josep Fradera arbeiteten heraus, dass das, was man im spanischen Fall etwa lange Zeit als Peripherie bezeichnet hatte, kein „Objekt staatlicher Nationalisierungspolitiken

242 Rolf Petri, Die ,kleinen Räume der Nation', in: Quellen und Forschungen aus italienischen Archiven und Bibliotheken 83 (2003), S. 288-307, 291; vgl. Mario Isnenghi, Der Platz als Zentrum von Vatertand und Territorium, in: ebd., S. 308-318; Stefano Cavazza/Reinhard Johler ( $\mathrm{Hg}$.), Identitż e culture regionali. Germania e Italia a confronto, Forle 1995, S. 14-16.

243 Zum "campanilismo" vgl. Woif D. Gruner, Italien zwischen Revolution und Nationalstaatsgründung

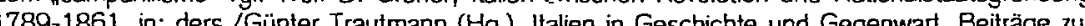
deutschen und europäischen Geschichte, Bd. 6. Hamburg 1991, S. 105-155.

244 So: Francesco Benigno, Naxionalismi e regionalismi. Frontiere identity e spazio politico nell'Europa del XX secolo, in: Meridiana 13 (1992), S. 217-223, 219; llaria Porciani, Lokale Identität-nationale del XX secolo, in: Meridiana 13 (1992), S. 217-223, 219; llaria Porciani, Lokale Identität-nationale
ldentilät. Die Konstruktion einer doppelten Zugehörigkeit in: Oliver Janz/Pierangelo Schiera/Hannes Sigrist $(\mathrm{Hg}$.). Zentralismus und Föderalismus im 19 und 20 . Jahthundert: Deutschland ra/Hannes Sigrist $(\mathrm{Hg}$.). Zentralismus und Föderalismus im 19. Und 20. Jahthundert: Deutschland und ltalien im Vergleich, Berlin 2000, S. 103-133; Adrian Lyttelton, Shifting identities: Nation, region and city, in: Carl Ley ( $\mathrm{Hg}$.), Italian Regionalism. History, Identity and Politics, Oxford 1996 , Föderalismus in ltalien vgl. auch Anne Bruch, Italien auf dem Weg zum Nationalstaat. Giuseppe Ferraris Vorstellungen einer föderal-demokratischen Ordnung. Hamburg 2005; Daniel Ziblatt Structuring the State. The formation of Italy and Germany and the puzzle of federalism, Princeton 2006; ders.. Rethinking the Origins of Federalism: Puzzle. Theory and Evidence from 19th century 2006; ders. Rethinking the Origins of Federalis
Europe, in: World Poiltics 57 (2004), S. 70-98.

245 Vgl. Stein Rokkan, Staat, Nation und Demokratie in Europa. Die Theorie Stein Rokkans aus seine gesammelten Werken rekonstruiert und eingeleitet von Peter Flora. Übers. Elisabeth Fix, Frankfurt a. M. 2000 .

246 Vgl. Celia Applegate, A Europe of Regions: Reflections on the historiography of sub-national places in modern times, in: American Historical Review 104 (1999), S. 1157-1 182. [war], sondem ein ebenbürtiger Akteur, der für das nationale Bekenntnis allerdings in de Regel eine, eigene Sprache' finden musste "247

An die Stelle der Dichotomie von Zentrum und Peripherie sind auf der Analyseebent Aushandlungsprozesse, Aneignungsprozesse und Transferprozesse getreten, die von eine wechselseitigen Beeinflussung ausgehen und die gleichzeitige Konstitution der modemer Nation und der modernen Region betonen. Die Region war im Nationalstaat eine ander Einheit als vor ihm. Sie wurde vom Rand ins Zentrum der Darstellung der Nationalstaatsbildung geholt. Für Historiker ist die Region nicht der Gegenbegriff zu einer nationalen Zentrale, sondem zunehmend eine Begleiterscheinung der Nation. Die Komplementarität überwiegt die Konkurrenz. Sozialgeschichtlich lief das Mitwirken bürgerticher Eliten an der Ide der Nation im 19. Jahrhundert fast immer über eine Identifizienung mit der Region. Die Provinz und die Region waren das "zzweite Vaterland". ${ }^{248}$

2. Der Grund dafür ist, dass die Region nicht mehr auf die Seite der Modernitätsskepsis beziehungsweise -verweigerung gestellt werden kann. Alles Regionale trug innerhalb des Paradigmas der Modernisierung den Beigeschmack des Antimodemen. Dieser Topos kommt indessen selbst aus nationalistischen Quellen. Die Regionsbildung in Verwaltung Schule und Infrastruktur folgte genauso wie die Nationsbildung modemen Mustem. Nach 1871 modernisierten sich die deutschen Einzelstaaten in Verwaltung, Kommunalordnungen und Schulordnungen schon deshalb gründlich, um dem Modemisierungsdruck des nationalen Gesetzgebers etwas entgegensetzen zu können. ${ }^{249}$ Die Dichotomie der antimodemen Region und der modemen Nation, die lange Zeit die Forschung leiteten, wird sich damit fü die Analyse nicht halten lassen.250

Für die Interpretation der empirischen Ergebnisse zum Verhältnis von Region und Nation wurden stattdessen mehrere theoretische Modelle vorgeschlagen:

a. Zum Beispiel empfiehlt es sich, diese Befunde durch eine Beziehungsgeschichte von Region und Nation zu erklären. Eigenschaften entstehen durch Relationen, nicht als Aus-

247 So: Sören Brinkmann, Der Stolz der Provinzen (wie Anm. 1), S. 19; Josep Fradera, Regionalist and Nalionalism. Catalo und Regions

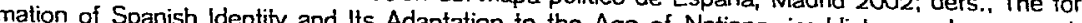

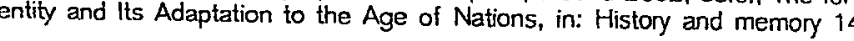

248 Vgl. Küster, „Regionale Identitäat" als Forschungsproblem (wie Anm. 226), S. 24; Jürgen Reulecke, Regionalgeschichte heute. Chancen und Grenzen regionalgeschichtlicher Betrachiungsweise in de Heft 7 (1998), S. 141. Gehard. Bestandsaufnahme und Perspektiven, in: IFER, Interregiones, tionen zur Raumentwicklung Heft 11/1993, S. 739-749, 740; Rüdiger und regionale Identität. Fin Kett Kantions, ind Informationen zurt. Ein Konzept der Moderne als Forschungsfeld der Geschichtswissenschaft, als Konstrukt. Historiographiegeschichtliche S. 781-792, 782f.; Bernd Schönemann, Die Region Blätter für deutsche Landeseschichte 135 (1999) und geschichtsdidaktische Reflexionen, in: Gans, Regionale Identifikation als Invention (19), S. 153-187, 169; Detlef Briesen/Rüdiger 19. Jahrthundert das Siegertand erfunden on S. $61-73,67,70$.

249 Vgl Weichlein Nation und Region (wie Anm, 145), S. 245-285, 371. Simone Lissig/Kan Hentich Pahl/James N. Retallack (Hg.) Modernisierung und Region im withimone Lässig/Kart Heinrich len, Wahirecht und Politische Kultur. Bislefeld nalen Selbstverwaltung im 19. Jahrinundert, in: Der Staat 35 (1996), Zur Entwicklung der kommu-

250 Damit selt kalismus (wie Anm. 90); ders., Nation - Region - Stadt (wie Anm. 90). 
fluss eines vorbestimmten Wesens. ${ }^{251}$ Beziehungsgeschichte betrifft nicht nur das Verhält-

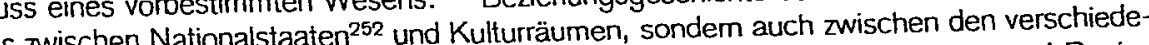
nis zwischen Nationalstaaten ${ }^{252}$ und Kulturraumen, sondem auch zwischen den verschiedenen Ebenen innerhalb eines sozialen Gebildes wie dem Nationalstaat. Nation und Region würden sich dann in einem ständigen Beziehungsgetlecht und beiderseiligen Aushandlungsprozessen befinden. Sowohl die nationale als

icht auf den passiven Objektstatus reduziert. ${ }^{253}$ (Helmut W. Smith, Mary Louise Pratt) die-

b. Die Region kann auch als "Kontaktzone" (Helmut W. Smith, Mary Louise Pratt) dieser Beziehungsgeschichte verstanden werden, in der Aushandlungsprozesse stattinden. Mary Louise Pratt definierte Kontaktzonen als n'ozialraume, in den, oft im Rahmen höchst Kulturen aufeinandertreffen, kollidieren und miteinander ningen, of asymmetrischer Beziehungen der Herrschaft und Unterordnung ". ${ }^{254}$ Die Region ist in diesem Sinne mehr das Ergebnis und weniger der Akteur in einer Beziehungsgeschichte zwischen privaten und öffentlichen, gesamt-, teil-, aber auch über- und außerstaatlichen Akteuren in dieser Kontaktzone. Dahinter steht ein bestimmtes Verständnis von sozialen Gebilden, das auf Nationen und Regionen angewandt werden kann. 1989 definierten die Herbilden, das auf Nationen und Regionen angewandt werden kann. Giog dind hicht Gebild ausgeber der "Annales" soziale Gebilde wie die Region: "Soziale Gebilde sind nicht Gebilde die mit Eigenschaften ausgestattet sind, sondern vielmehr sich ändernde Beziehungsgeflechte innerhalb sich ständig anpassender Konfigurationen, "255

c. Sett man dies voraus, dann gilt für die soziale Einheit Region auch, dass sie wie die c. Settt man des vorus, dann gilt fur die soial Einheit Regon auch, dass segionen Nation ein Produkt der Kommunikation, genauer der sozialen Kommunikation ist. Regionen können als Kommunikationsräume verstanden werden, die sich durch spezifische Prozesse, Institutionen, Märkte von anderen Kommunikationsräumen abgrenzen. Die regionale Of fention und reproduziert. In ihr artikulieren enche Ordnungsmodelle und soziale sich Identitäsvorstellungen, Grundungsme Rollen. „Kommunikation konstituiert über ihr Beziehungsgefüge historisch relevante Raume, wenn ihre nach innen gerichtete Interaktion deutlich dichter ausfält als die nach außen gerichtete." 256

251 Vgl. Weichlein, Nation und Region (wie Anm. 145), S. 13. Jörg K. Hoensch/Hans Lemberg ( $\mathrm{Hg}$.), Begegnung und Konflikt (wie Anm. 1).

0533 . Zu Beziehungsgeschichle vgl. Osterhangel, (wie Anm. 34).

254 Vgl. dazu Helmut W. Smith, Lokalgeschichte. Überlegungen zu Möglichkeiten und Grenzen eines Genre, in 1918. in. Iravel writing and transculturation, London 1992, S. 4.

Smith Lokalgeschichte (wie Anm. 254), S. 243.

( gl. Rolf KieBling, Kommunkalion und Reglon Kon 2001 (Fonum Suevicum Bd. 4). S. 11-39, 11. 11: Wolfgang $E$. J. Weber, Die Bldung 307 . gum theoretischen Hintergrund in der Nationalismushistorischen Perspeklve, in. Aur Rezeption forschung: Karl W. Deutsch, Nationallsm an K. Deutschs Modell der Nationswerdung und sein von Kar W. Deutsch vi. Than Beitrag für die historische Nalionallsmusforschung, $N$. Evalsmustheorien, München 1994, S. 127 nationalen Bewustsens in 144; Othin Jant forschung?, in: Mantred Bobrowsky/Wolfgang R. Langenbucher (Higtions in History: an initial theogeschichte, Munchen 1987, S. 5-13.

I Neue Politische Literatur, 51 (2006)
Die generelle Perspektive der Beziehung, des Transfers, der Aushandlung, des Kontakts und der Kommunikation auf Nations- und Regionsbildung ist auch deshalb von Vorteis, weil sie heute mit Blick auf den moralisch und geschichtspolitisch aufgeladenen Europabegriff einer Essentialisienung entgegenwirkt. "Die sich daraus ergebende Thematisierung der Raumvorstellungen. Transferprozesse und Transaktionen könnte sich für eine Analyse der wechselnden Identitätsbilder und Zusammenhänge quer durch Europa als außerordentlich fruchtbar erweisen "257 Die wechselnden Identitätsbilder beziehen sich nämlich sowohl aut die Region und die Nation als auch auf Europa. Historiker, zumal solche für europäische Geschichte, neigen dazu, zu Erfindern einer neuen Tradition zu werden, die im Grunde die Nationsbilder auf eine höhere Ebene transponieren.

Territorialität

Die neuesten kulturgeschichtlichen Arbeiten haben Nation und Region gerade nicht mehr ais territoriale Begriffe interpretiert. An die Stelle traditioneller Interpretationsmuster der Konkurrenz wie Ablösung und Ersetzung setzten Alon Confino und Celia Applegate Adaption, Vermittlung und Aneignung von Nation und Region. Dabei droht indessen die territoriale Dimension zu sehr in den Hintergrund zu treten. Gerade sie ist aber durch den nspatial turn $^{\prime \prime}$ in der Geschichtswissenschaft in der Nationalismus- und Regionalismusforschung stärker ins Bewusstsein getreten. Die Herausforderung für die Nationalismusforschung besteht darin, dass der spatial turn" den „cultural tum" nicht nückgängig macht, sondem vielmehr ergänzt. Die oft gebrauchte Formulierung "sense of place" macht diesen Zusammenhang sprachlich sinnfällig. ${ }^{258}$ Territorialität und Territorialisierung sind analytische Kategorien, die nicht zur Affirmation erfunden wurden. ${ }^{259}$

Einen Zugang hierzu bieten die Berechtigungstitel wie die Staatsbürgerschaft. Wir sind gewohnt, Anspruchsberechtigungen wie die Staatsbürgerschaft (citizenship) auf den Nationalstaat zu beziehen. ${ }^{260}$ Daneben und lange Zeit in gleicher Bedeutung standen jedoch Berechtigungstitel, die von subnationalen politischen Einheiten wie den Einzelstaaten oder den Kommunen ausgestellt wurden. ${ }^{261}$ Diese Berechtigungen waren noch nicht strikt territorial vereinheitlicht. Sie konnten sich vielmehr überlagem. Die Nationalstaatsbildung trieb die territoriale Schließung dieser Berechtigungen voran. Fortan sollte der Nationalstaat der

257 Konrad Jarausch, Zeitgeschichte zwischen Nation und Europa. Eine transnationale Herausforderung, in: Aus Politik und Zeitgeschichte Nr. 39, 20.9.2004, S. 9; vgl. Wilfried Loth, Die Mehrschichtigkeit der Identitätsbildung in Europa. Nationale, regionale und europäische Identität im Wandel, in: Ralf Elm (Hg.), Europäische Identität (wie Anm. 1), S. 93-109.

258 Vgl. David Blackbourn, A Sense of Place. New Directions in German History, German Historical institute London, The 1998 Annual Lecture, London 1999.

259 Zum spatial turn vgl. Andreas Dix, "Cultural turn" und "spatial turn“. Neue Berührungsebenen von Geographie und Geschichtswissenschaft, in: Geographische Zeitschrift 93 (2005), S. 2-5; Axel Gotthard. Raum und Identität in der frühen Neuzeit. Eine Problemskize, in: Sefik Alp Bahadir/Peter Ackermann $(\mathrm{Hg}$.), Kultur und Region im Zeichen der Globalisienung. Wohin treiben die Regionalkulturen?, Neustadt an der Aisch 2000, S. 335-368.

260 Vgl. hierzu den Forschungsüberblick bei: Dieter Gosewinkel, Staatsbürgerschaft und Staatsangehörigkeit, in: Geschichte und Gesellschaft 21 (1995), S. 533-556.

261 Vgl. Andreas Fahrmair, Nineteenth-century German citizenship: a reconsideration, in: Historical Journal 40 (1997), S. 721-52; ders., Governments and Forgers: Passports in Nineteenth-Century Europe, in: Jane Kaplan/John Torpey $(\mathrm{Hg}$.) , Documenting Individual Identity: The Development of State Practices in the Modern World, Princeton 2001, S. 218-234; ders., Passports and the Status of Aliens, in: Martin Geyer/Johannes Paulmann $(\mathrm{Hg}$.), The Mechanics of Internationalism. Culture, Society and Politics from the 1840s to the First World War, Oxford 2001, S. 93-119.

Neue Politische Literatur, Jg. 51 (2006) I 
ausschlieBliche Adressat für die Berechtigungen und Ansprüche seiner Bürger sein. Dies setzte die territoriale Schließung voraus. Exakt demarkierte Grenzen stellten die Voraussetzungen für die weitere Demokratisierung und den Aufbau des nationalen Wohlfahrtstaates zungen fur ${ }^{262}$

Der territorialen Schließung nach außen sollte im Sinne des Liberalismus eine durchgängig konstitutionalisierte vertikale Institutionenordnung im Innem entsprechen: Auf die Gemeinde- und Kreisordnung sollte die Provinzialordnung aufbauen, darüber soltten dann Landesverfassungen und schließlich die Reichsverfassung stehen. In der napoieonischen Zeit blieb diese Vorstellung ein Torso, die nicht über die preußische Städteordnung des Freiherm von Stein hinauskam. Erreicht wurde sie erst gegen Ende des 19. Jahrhunderts mit der Konstitutionalisienung des Reiches und den Provinzial- und Gemeindeordnungen. ${ }^{26}$ Die Staatsbürgerschaft trug und ergänzte diese Ordnung. Bis 1913 war sie als Bundesindigenat, danach als Reichsstaatsbürgerschaft organisiert. Die Berechtigungen deutscher Nationszugehöriger ergaben sich bis 1913 aus ihrer Zugehörigkeit zum einzelstaatlichen Verband. Freizügigkeit, demokratisches Wahlrecht und wohlfahrtsstaatliche Berechtigung bezogen sich auf das Territorium des Deutschen Reiches, die sich daraus ergebenden Ansprüche wurden an das Reich gerichtet. Dieter Gosewinkel arbeitete in seiner Habilitationsschrift heraus, dass die Organisation der Staatsbürgerschaft in Deutschland nicht - wie Rogers Brubaker dies vorgeschlagen hatte ${ }^{264}$ - den Nationsstereotypen von Willensnation und Kultumation, von ius soli und ius sanguinis folgte, sondem vielmehr in der Tradition de staatlichen Bearbeitung massenhafter Migration stand. Die Pointe seiner Studie ist es, dass vor dem Hintergnund der Massenmigration die Staatsangehörigkeit gemäß des Abstammungsprinzips eine modemisierende Funktion gegenüber dem älteren Territorialprinzip (ius soli) hatte. 265

"Westem societies, at least, made territoriality the basis for collective political action for about three centuries. Nonetheless, alternatives for political organization existed before territoriality and sovereignty became such obsessive preoccupations." Territonalität bildete im Zeitalter der Nationalstaatsbildung die Voraussetzung für staatliche Souveränität. „Territoriality, in effect, was the material condition for sovereignty; it was the underlying political ressource, usually uncommented on because it was so fundamental." Die großen Konflikte

262 Vgl. Habermas, Der europäische Nationalstaat (wie Anm. 6)

263 Vgl. Paul Nolle, Repräsentation und Gnundbesilz. Die kreisstandische Verfassung Preußens im 19 Jahrhundert, in: Klaus Tenfelde/Hans-Ulrich Wehler $(\mathrm{Hg}$.$) , Wege zur Geschichte des Bürgerturns.$ Vierzehn Beiträge, Göttingen 1994, S. 78-10

264 Vgl. Rogers Brubaker, Staats-Bürger. Deutschland und Frankreich im historischen Vergleich. Hamburg 1994 (Original: Citizenship and nationhood in France and Germany, Havard University Press 1992).

265 Vgl. Dieter Gosewinkel, Einbürgem und Ausschließen (wie Anm. 145); ders., Die Staatsangehörig keit als Institution des Nationalstaates. Zur Entstehung des Reichs- und Staatsangehörígkeitsgesezes von 1913, in: Rolf Grawert u. a. ( $\mathrm{Hg}$.), Offene Staatlichkeit. FS Böckenförde, Berlin 1995, S. 359-378; ders., "Unerwünschte Elemente" - Eirwanderung und Einbürgerung der Juden in Deutschland 1848-1933, in: Tel Aviver Jahrbuch für deutsche Geschichte 27 (1998), S. 71-106; ders., Untertanschaft, Staatsbürgerschaft, Nationalität. Konzepte der Zugehörigkeit im Zeitalter des Nationalstaats: Anmerkungen zur Begriffsgeschichte in Deutschland. Frankreich, England und den USA, in: Berliner Journal für Soziologie 8 (1998), S. 507-522; Eli Nathans, The politics of citizenship in Germany: ethnicity, utility and nationalism, Oxford 2004; Olivier Trevisiol, Die Einbürgerungspraxis im Deutschen Reich 1871-1945, Göttingen 2006; Regula Argast, Staatsbürgerschaft und Nation (wie Anm. 1); dies., Schweizer Staatsbürgerschaft und gouvernementale Herrschaft 1848-1920. Foucaults Konzept der liberalen Gouvernementalität in der Analyse der Staatsbürger-
schaft, in: Schweizer Zeitschrift für Geschichte 53 (2003), S. 396-409. zwischen den Nationalstaaten im 20. Jahrhundert wurden zwar über politische Werte wie Demokratie und Diktatur, Autokratie und Totalitarismus geführt In der politischen Praxis bedeutete dies jedoch einen Kampf um die Regulierung eines Raumes ${ }^{266}$ Territorialität begründete in der Regel eine Tendenz zur Vereinheitlichung, wie sie sowohl in Demokratien als auch in Diktaturen gefunden werden konnte. Sie bedeutete, dass immer nur ein Gesetzgeber über einen Raum einen Jurisdiktionsanspruch erheben konnte. ${ }^{267}$ Damit begründete sie auch die Deckungsgleichheit verschiedener Räume, wie sie für den Nationaistaat kennzeichnend waren: Der soziale Raum, der Wirtschaftsraum und der politische Entscheidungsraum bezogen sich auf die gleiche Raumgröße und garantierten damit die soziale und gesellschaftliche Regulierungsfähigkeit des Gesamtstaates. Im Nationalstaat wurden Identitäts- und Entscheidungsräume deckungsgleich. Seinen Höhepunkt erreichte dien Idenzess zwischen 1860 und 1970. Historisch gesen ist dies jedoch

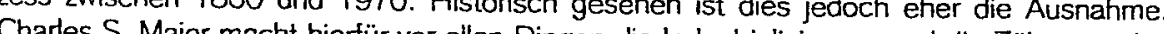
Charles S. Maier macht hierfür vor allen Dingen die Industrialisierung und die Zähmung des aumes durch die Eisenbahn verantwortlich.

Generell steht die Territorialisierung aber in einem ambivalenten Verhältnis zu Nation und Nationsbildung. Die territoriale Schließung von Staatlichkeit scheint historisch Demokratisierung und Wohlfahrtsstaat zu begünstigen. Auch hegt sie die expansiven Ansprüche des nationalen Machtstaates ein. Gerade die Nationalsozialisten setzten sich an dieser Stelle vehement von den herkömmlichen Nationalisten ab, die immer den Nationalstaat als eine territoriale Größe im Blick hatten. Andererseits bedeutete die territoriale geschlossene Staatlichkeit den Ausschluss oder gar die gewaltsame Exklusion von bestimmten Gruppen. Intern stand die Territorialisierung von Staatlichkeit für ein Programm der Homogenisierung. Historisch ist dieser Prozess immer nur unvollkommen durchgesetzt worden, und es fragt sich, ob es nicht mehr der Anspruch als die soziale Praxis war, die den territorialisierten Nationalstaat ausmachte.

\section{Regionsbildung und Nationsbildung}

Die wechselseitige Konstitution der modemen Region und Nation bedeutet auch, dass der Regionalismus nur im Zusammenhang mit dem Nationalstaat sinnvoll denkbar ist. Jenseits des Nationalstaats verliert der explizite Regionalismus seinen Referenzpunkt. „Der Regionalismus ist außerhalb des Nationalstaates undenkbar" meinte Steward Woolf in seiner Studie zum Aosta-Tal. Die Nation ist also ein notwendiges Komplementärmodell zur Region, denn Regionen setzten sich von der Nation ab. Hierin liegt auch der Grund dafür, dass es weder in der Mediävistik noch in der Frühneuzeitforschung ein Regionalismuskonzept gibt und "dass sich die historiographische. Annäherung an die regionale identität von der anderer so"zialwissenschafflicher Disziplinen unterscheidet" ${ }^{4}{ }^{268}$

266 Die vorangehenden Zitate aus: Charles S. Maier, Transformation of territoriality 1600-2000, in: Gunilla Budde/Sebastian Conrad/Oliver Janz ( $\mathrm{Hg}$.). Transnationale Geschichte. Themen, Tendenzen und Theorien, Gottingen 2006, S. 32-55, 35f.; vgl. ders.. Consigning the 20th Century to History: Alternative narratives for the modem era, in: American Historical Review (2000), S. 807831. Maier unterscheidet hier zwei englische Bedeutungen von „territorry": frontier und field. Während Anthony Giddens den Ubergang von frontiers zu borders für das kennzeichnende Merkmal der Nationalstaatsbildung hält, sieht Maier ihn im Übergang von frontiers zu energiegeladenen fields.

267 Gerade darin unterscheidet sich die Territorialisierung der Politik seit dem 18. Jahrtundert von früheren poititischen Ordnungen. Im Feudalstaat konnten mehrere Feudalherren über das gleiche Ternitorium Rechte ausüben.

268 Küster, „Regionale Identität" als Forschungsproblem (wie Anm. 226), S. 24.

Neue Politische Literatur, Jg. 51 (2006) I 
Umstritten ist, ob das Vethältnis zwischen Region und Nation asymmetrisch oder symmetrisch ist Setzen sich beide wechselseitig voraus, oder benötigt nur die Region die $\mathrm{Na}$ meltisch ist. ion, die Nation Verhältnis asymmetrisch, weil die Nation ihrerselts sehr wohl unabhăgig von Regionen, diese jedoch nicht ohne Nationen existieren kann. ${ }^{2}$ Sein spani Nuñez Xeixas sprach dagegen von der Regionsbildung als einem von der Nationsbildung angestoßenem Prozess:

Nation-Building may also imply region-building, to the point, that the former may be very dependent on the latter. Collective identities must be seen as kind of concentrical spheres, overlapping and complementing each other, from the family to the nation and even further, and as all forms of social identity, they are the result of dynamic historical processes." ${ }^{270}$

Region und Nation stehen in einer ständigen Austauschbeziehung, was der nationalistiheg historischen Widersachem, entstehen. "It is no longer possible to maintain the tacit assumptions long made that the impact of national propaganda increases with its intensity sund that the advance of the nation-building process also means that thinking in national categories takes primacy over regional and local identities.271

Regionale und nationale Identität schlossen sich in der neuesten Literatur nicht mehr wie dies unter dem Theorem der modemisierungsgeschichtlich inspirierten Literatur der Fall war. Vielmehr zeichnen sich mehrere Konstellationen für die wechselseitige Inkluion von Nation und Region ab. Der Ausgangspunkt war in zahlreichen europäischen $\mathrm{Na}$ ion onalstaaten der gleiche. Der explzite oder implizite Anspruch von Regionen, zum Beispie von Parma und Hannover (Ernest Renan), selbst eine Nation zu werden, wurde zurückgewiesen. Dabei ist indessen wichtig, dass diese Akteure, wie Bayem, Hannover, Parma oder Wales ihr spezifisches Regionalbewusstsein erst vor dem Hintergrund der liberalen NatioWal ten bezog sich auf mehrere Ebenen und umfasste mehrere Dimensionen. Sie bezog sich auf die Politik, die Wirtschaft und die kulturelle Beziehung der Region zur Nation.

a. Politik

Während die gesellschaftstheoretische Tradition von Emile Durkheim bis Talcott Parsons den Grad der gesellschaftlichen Integration an der Ausbreitung und Tiefe des kulturellen Wertekonsenses maß, ging der Soziologe Georg Simmel davon aus, dass neben dem Konsens der Konflikt eine integrative Bedeutung hat. Der Konflikt besitzt vereinheitlichende Momente vor allem dann, wenn kontrollierte Formen des Konfliktaustrags vorherrschen. ${ }^{272}$

269. II regionalismo è inconcepibile al di fuori di uno stato-nazione; î nazionalismo, invece, può esistere, $\mathrm{e}$ anzi è di facto per lo piú esistito, indipendamente dalle regioni." Stuart Woolf $(\mathrm{Hg}$.), La Valle

270 X'Aosta, Turin 1995, S. 5 . ( $\mathrm{Hg}$.), Region und Regionsbildung in Europa (wie Anm. 226), S. 175-210, 176; vgl. ders., The reion as "essence" of the fatherland: regionalist variants of spanisch nationalism (1840-1936), in: European History Quarterly 31 (2001), S. 483-519.

271 Woolf/Haupt/Müller, Introduction (wie Anm. 240), S. 1-21, 4. Vgl. Georg Simmel, Der Streit, in: ders., Soziologie. Untersuchungen über die Formen der Ver-
gesellschaftung, Gesamtausgabe Bd. 11, Hg. Otthein Rammstedt, Frankfurt a. M. 1992 [1902], S. 284-382.

334 I Neue Politische Literatur, Jg. 51 (2006)
Helmut Dubiel nennt dies Integration durch Konflikt". ${ }^{273}$ Anders als es das Homogenitätsund Identitätspostulat der liberalen Nationalbewegung vorsah, schufen politische Konflikte wie die Kulturkämpfe oder der Antisozialismus des 19. Jahrhundert Verbindungen zwischen Gruppen, die sich vorher fremd waren. Dies gilt auch für das Verhältnis von Region und Nation.

\section{Konfliktbearbeitung durch Ebenenverlagerung}

Ausgangspunkt hierfür sind auf der lokalen oder der regionalen Ebene geführte scharfe weltanschauliche Auseinandersetzungen. Deren Ausweitung und ideologische Verschärfung trieb die Nationalisienung der Konfliktparteien voran. Bezeichnenderweise kandidierten die bayerischen Patrioten 1871 für den Deutschen Reichstag, nachdem sie den Beitritt Bayerns in den deutschen Nationalstaat zuvor vehement abgelehnt hatten. ${ }^{274}$ Die regionale Einfärbung der weltanschaulichen Gesinnungsgemeinschaften führte gerade nicht so weit, dass sich meinische Katholiken und meinische Liberale näher standen als meinische $\mathrm{Ka}$ tholiken und bayerische Katholiken, 275 Letztlich verbanden die durch die Konflikterfahrungen entstandenen sozialen Milieus, politischen Kulturen, Werthaltungen und Solidaritätsgefühle regional unterschiedliche Gruppen, die gleichwohl ihren regionalen Eigensinn beibehielten. Ihre Solidaritätsgefühle griffen weit über die Region hinaus. Für die Nationsbildung im Deutschen Kaiserreich spielte vor allem der Antisozialismus und der Kulturkampf gegen die katholische Kirche hier eine entscheidende Rolle. Beide stifteten Solidaritäten auf der gleichen Seite der Barrikade: sächsische Konservative entdeckten so trotz ihres starken Lokalpatrotismus Gemeinsamkeiten mit Preußen, nord- und süddeutsche Arbeiter fanden sich in der politisch ausgeschlossenen Sozialdemokratie wieder. Weltanschauliche Konflikte entfalteten eine stärkere integrative Wirkung als die klassischen Konflikte zwischen der gesamtstaatlichen Regierung und bestimmten Einzelstaaten. Die Präsenz regionaler Stimmen im Reichstag bedeutete die Verlagerung des Konflikts zwischen Religion und Nation in die nationalen Institutionen. Konsentiert war dabei, dass das Parlament die Konfliktaustragungsstätte bildete. Für diese Form der Konflikttransponierung war das Wahlrecht entscheidend. Verletzungen des Wahlrechtes berührten damit direkt das Interesse, überhaupt auf der nationalen Ebene mitzuwirken und diese anzuerkennen. Diesen Aspekt haben in jüngster Zeit die beiden Studien von Margaret $L$. Anderson "Practicing Democracy" und von Robert Arsenschek "Der Kampf um die Wahlfreiheit im Kaiserreich" vertieft. ${ }^{276}$ Beide Studien arbeiten heraus, mit welchen Mechanismen und in welchen Handlungsräumen die Partizipation der Parteien und damit auch regionaler Konfliktparteien auf der gesamtstaatlichen Ebene durchgesetzt wurde. Auch hier gibt es Entsprechungen in an-

273 Vgl. Helmut Dubiel, Integration durch Konflikt?, in: Jürgen Friedrichs/Wolfgang Jagodzinski ( $\mathrm{Hg}$.), Soziale Integration (Kölner Zeitschrift für Soziologie und Sozialpsychologie, Sonderheft 39), Wiesba-
den 19.99, S. 132-143; ders., Konsens oder Konflikt? Die normative Integration des demokratischen Staztes, in: Beate Kohler-Koch ( $\mathrm{Hg}$ ). Staat und Demokratie in Europa 18 . Wissenschaftlischen Slaates, in. Beate Kohler-Koch ( $\mathrm{Hg}$.). Stail und Demokratie in Europa. 18. WissenschatflHutchinson, Nations as zones of conflict, London 2005.

274 Vgl. Friedrich Hartmannsgruber, Die bayrische Patriotenpartei 1868-1887, München 1986.

275 So etwa die Annahme von Thomas Mergel, Milieu und Region. Uberlegungen zur Verortung kollektiver Identitäten, in: Retallack (Hg.). Sachsen in Deutschland (wie Anm. 1), S. 265-279. 279.

276 Vgl. Margaret L. Anderson, Practicing Democracy. Elections and political culture in Imperial Germany, Princeton UP 2000; Robert Arsenschek, Der Kampf um die Wahlfreiheit im Kaiserreich (wie Anm. 145): Simone Lässig. Wahlrechtskampf und Wahlreform in Sachsen (1895-1909), Weimar 1996.

Neue Politische Literatur, Jg. 51 (2006) 
deren Ländern. Die Studie von Ellen Evans etwa bestätigt diesen Mechanismus auch über Deutschland hinaus. ${ }^{277}$

Kulturelle Konflikte besaßen gegenüber sozialen Gegensäłzen eine stärker nationalisierende Wirkung, weil die Allgemeingültigkeit ihrer Wertladung die räumliche Entgrenzung vorwegnahm. Als generalisiertes Kommunikationsmedium bot sich die Nation für die Konfliktparteien an, Konflikte zu gewinnen, nicht sie zu schlichten. Damit wird eine weitere so-

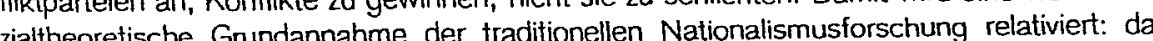
konflikttheoretische Modell von Loyalitätsproduktion, bei der die Summe der Loyalitäten konflikttheoretische Modell von Loyalitätsproduktion, bei der die Sum ledoch besser durch den konsenstheoretischen Ansatz beschreiben, der Macht und Loyalität für eine Ressource chor duziert wird. 278 Mit Niklas Luhmann lassen sich Macht und Loyalität im Nationalstaat als duziert wird.
"symbolisch Meneralisierte Kommunikationsmedien" beschreiben, die wachsen, aber auch schrumpfen können, mithin also nicht auf eine Deckungsgleichheit mit der gesamtstaatlichen Identität angelegt sind. ${ }^{279}$ Loyalität ist damit auch theoretisch kein Nulisummenspiel, chen sondern eine Ressource, die wachse

Beispiele dafür gibt es auch in Süd- und Mitteleuropa, in Italien, Spanien, Belgien oder Österreich, wo in den letzten Jahrzehnten des 19. Jahrhunderts teils scharfe Kuiturkämpfe geführt wurden. ${ }^{280} \mathrm{Ob}$ dieser Zusammenhang indessen allgemein gilt, ist unklar. In der gefuhrt wurden. Schweiz finden sich Parallelen zur "ntegration durch Konnt trotz territorialisierter Konflikte kein regionalisiertes Parteiensystem, sondern Parteien, die in der ganzen Eidgenossenschaft auftraten. Dies galt insbesondere für die katholische Volkspartei. ${ }^{281}$

Die Politikwissenschaft griff die "Integration durch Konflikt" als eines der in modemen politischen Systemen typischen Regelsysteme auf. Konflikte wurden entweder durch Konkurrenz oder durch Verhandlungen bearbeitet. Es gab Integration durch Konsens oder Belgium and the Netherlands, 1785-1985, Boston 1999. Vgl. Siegtried Weichlein, Corporate CaBelgium and the Netherlands, 1785-1985, Boston 1999. Vgl. Siegrried Weichlem, Corporale Catholicism and Social Change. Recent Amm.
of Urban History 28 (2002), S. 231-239.

278 Theoretisch ist diese Position ausgeführt bei Talcott Parsons: „Power is a generalized facility or ressource. It has to be devided or allocated, but it also has to be produced and it has collective as well as distributive functions "Talcott Parsons. The distribution of power in american society, in: World Politics 10 (1957), S. 123-143, 140

279 Vgl. Talcott Parsons, Über den Begriff der Macht, in: ders., Zur Theorie symbolischer Interaktionsmedien, Opladen 1980, S. 57-137, 71ff., 98-112; Niklas Luhmann, Die Gesellschaft der Gesellschaft, Erster Teilband. Frankfurt a. M. 1997, S. 318; Klaus von Beyme, Die politischen Theorien der Gegenwart. Eine Einführung, Opladen 7. Aufl. 1992, S. 141.

280 Vgl. James McMillan. Priest hits girl": on the front line in the ,war of the two Frances', in: Clark/ Kaiser $(\mathrm{Hg}$.). Culture wars (wie Anm, 151), S. 77-101; Julio de la Cueva, The assault on the city of the Levites, in: ebd., S. 181-201; Martin Papenheim, Roma o morte: culture wars in Italy, in: ebd., S. 202-226.

281 Vgl Andreas Ladner. Stabilität und Wandel von Parteien und Parteiensystemen: eine vergleichende Analyse von Konfliktlinien, Parteien und Parteiensystemen in den Schweizer Kantonen, Wiesbaden 2004. Urs Altermatt. Die Entkonfessionalisierung des politischen Katholizismus in der Schweiz: von der Katholischen Volkspartei 1894 zur CVP 1970, in: Albert Portmann-Tinguely ( $\mathrm{Hg}$.), Kirche, Staa der Kalholischen Volkspartei 1894 zur Neuzeit, Festschrift Heribert Raab, Paderborn 1989, S. 459und katholische Wissenschatt in der Neuzeit, Festschl. Urs Altermatt/Catherine Bosshart-Pfluger/ 477; zur inneren Nationsbildung in der Schweiz vgl. Urs Allermat/ 18.-20. Jahrtundert, Zürich 1998; Zimmer, A contested nation (wie Anm. 21).

336 I Neue Politische Literatur, Jg. 51 (2006) durch Konfliktaustragung und -bearbeitung. Idealtypisch werden Konkurrenzdemokratie und Verhandlungsdemokratie unterschieden. Die Konkurrenzdemokratie beendet den Konflikt mit der Entscheidung durch die Mehrheit. Der hierzu nötige Parteienwettbewerb setzt nationale politische Einheiten voraus. Diese Parteien entstanden in Deutschland aus Konfliktsituationen, die zumeist lokal und regional verortet waren und so weit angeheizt wurden, dass sie national ausgetragen wurden wie der Kulturkampf und der Antisozialismus der Sozialistengesetze. Für die Verhandlungsdemokratie unterschied Gerhard Lehmbruch zwei Typen: das Proporz- und Konkordanzsystem einerseits sowie föderale Lösungen andererseits. ${ }^{282}$ Alle drei - Parteienwettbewerb in der Konkurrenzdemokratie, Konkordanzsysteme und Föderalismus in der Verhandlungsdemokratie - lassen sich auch auf das Verhältnis von Region und Nationalstaat anwenden. Sie dienen als generelle Mechanismen für die historische Bearbeitung des Verhältrisses von Region und Nation.

Die föderative Nation

Nationalstaatlichkeit und Demokratisierungsprozesse komplementär zu lesen hatte für die Nationalismusforschung über einen langen Zeitraum die Konsequenz, den Föderalismus als demokratiehinderlich, wenn nicht sogar -feindlich zu interpretieren. Der Gegensatz „Föderalismus oder Demokratie" ist ein Strukturprinzip der Politik Bismarcks gewesen, der die demokratische Legitimation des Reichstags durch die bundesstaatliche Legitimation des Bundesrates zu überspielen suchte. Insofem hatte der Föderalismus in Deutschland lange Zeit eine schlechte Presse, was sich bis in die Gegenwart auf der politischen Linken hält. Im letzten Jahrehnt begann ein Umdenken bei den Historikem. Revisionistische Autoren wie Dieter Langewiesche, Georg Schmidt, Abigail Green, Maiken Umbach und Jürgen Müller werteten die föderalistische Tradition in Deutschland auf, interpretierten sie aber neu. Diese Autoren vertraten die Ansicht, dass die Identifikation der Nation mit dem Nationalstaat eine Verkürzung darstellte. Übersehen wurde hierbei die durch den Nationalstaat verdrängte Tradition der "föderativen Nation". Die "föderative Nation" und ihr Wunsch nach nationaler Einheit sei gerade nicht mit der Forderung nach einem Nationalstaat gleichzusetzen. Föderative Ordnungen wie diejenige des Alten Reiches oder des Deutschen Bundes seien national, aber nicht nationalstaatlich gewesen. Attraktiv an ithen waren Vorstellungen, Erwartungen und mentale Dispositionen, aber auch politische Schritte zur nationalen Einheit, ohne dass diese als Nationalstaat aufgefasst wird. 283 Diese These der föderativen Nation setzt eine kollektive Identität im Alten Reich voraus. Für Georg Schmidt ist klar, dass das Alte Reich seit 1495 in mehreren Phasen und sich wandelnden Formen eine solche kollek-

282 Vgl. Gerhard Lehmbruch, Parteienwettbewerb im Bundesstaat (wie Anm. 227)

$3 \mathrm{Vgl}$. Georg Schmidt/Dieter Langewiesche (Hg.), Föderative Nation. Deutschlandkonzepte von der Reformation bis zum Ersten Weltkrieg. München 2000; hierzu auch: Abigail Green, Fatherlands. State-building and Nationhood in Nineteenth-Century Germany, Cambridge UP 2001; dies., The federal alternative? A new view of modem german History, in: The Historical Journal 46 (2003), S. 187-202; Maiken Umbach, Federalism and enlightenment in Germany, 1740-1806, London 2000; dies. ( $\mathrm{Hg}$.), German Federalism. Past, present, future, Basingstoke 2002; Jürgen Müller, Deutscher Bund und deutsche Nation 1848 - 1866, Göttingen 2005. Kritisch: Heinz Schilling. Reichs-Staat und frünneuzeitliche Nation der Deutschen oder telmodernisiertes Reichssystem. Uberlegungen zu Charakter und Aktualität des Alten Reiches, in: Historische Zeitschrift 272 (2001) S. $377-395$. 
tive Identität besaß, wie sie etwa im Reichskammergenicht und in Wiener Holgericht zum Ausdruck kamen. ${ }^{284}$

Die Leistungsfähigkeit des Konzeptes der "föderativen Nation" besteht vor allem darin konzeptionell die Verengung der nationalen Vorstellung auf den Nationalstaat aufzubrechen Hierfür finden sich tatsächlich in Alten Reich eine Reihe von Anhaltspunkten. ${ }^{285}$ Inwiefern freilich die föderative Nation des Alten Reiches vor $1806 \mathrm{im}$ Deutschen Bund nach 1815 weiterlebte, darf bezweifelt werden. Es hieße zum einen, die föderative Nation ahistorisch zu verstehen und auf ihre Gestalt vor 1800 festzulegen, wenn man einfach nach Äquivalenten im Deutschen Bund suchte. Der nationale Gedanke, der noch nicht nationalstaatlich verengt war, entwickelte sich schließlich weiter. Vorstellungen von Gleichheit und Demokratie fanden in inn Eingang. Nationale Vorstellungen, die noch nicht den Nationalstaat zu Pointe hatten, waren durchaus verbreitet, wie die zu Beginn des 19. Jahrhunderts noch bikonfessionelle Bonifatiustradition als Apostel der Deutschen zeigte. ${ }^{286}$ Der Ursprung und das Wesen des Nationalen konnten ezählt werden, ohne dass darnit ein Aufruf zur Staatsgründung gemeint war. Die "föderative Nation" wird auch im Hinblick auf den Deutschen Bund diskutiert. Es hieße jedoch, die "föderative Nation" gegen die gesamte liberale Nationalbewegung vor 1866 auszuspielen, wollte man dem Deutschen Bund eine genuin nationale Berufung zuschreiben. Der Deutsche Bund als gegenseitiges Rückversicherungssystem semiabsolutistischer bürokralisch-monarchischer Systeme stand zur föderativen Nation in denkbar starkem Kontrast, selbst wenn er sich - vergeblich! - um die Herstellung vor aliem eines gemeinsamen Wirtschaftsraumes bemühte. Nicht nur von Preußens Sendung inspirierte Nationalisten sahen im Deutschen Bund mit seiner Politik der Freiheitsund Meinungsverweigenung das entscheidende Hernmnis auf dem Weg zur nationalen Einheit. ${ }^{287}$ In diese Richtung wirkte auch der wachsende Patriotismus der deutschen Einzelstaaten. Sie empfahlen sich durch öffentliche Feiern und Feste, Monarchenbesuche, Ausslellungen und den Ausbau der regionalen Infrastruktur als "Vateriand". Abigail Green spricht daher treffend mit Blick auf Hannover, Bayern und Württemberg von "fatherlands" im Plural. Dabei waren diese Vaterländer durchaus integrationsoffen in eine deutsche $\mathrm{Na}$ tion, sofem sie nicht zentralistisch und staatszentriert verstanden wurde. Bis weit ins Kaiserreich hinein benennt Dieter Langewiesche Beispiele für ein nationales, aber nicht nationalstaatliches Selbstverständnis. ${ }^{288}$

284 Vgl. hierzu Georg Schmidt, Geschichte des Alten Reiches. Staat und Nation in der frühen Neuzeit 1495-1806, München 1999. Vgl. auch die Verbindung der Frühneuzeitforschung mit der Kommunikationsforschung, in: Katrin Keller, Kommunikationsraum Altes Reich. Zur Funikionalität der Korrespondenznetze von Fürstinnen im 16. Jahrhundert, in: Zeitschrift für historische Forschung 31 (2004), S. 205-231; Ulrich Rosseaux, Das Reich und seine Territorien als Kommunikationsraum im frühen 17. Jahrhundert, in: Blätter fur deutsche Landesgeschichte 137 (2001), S. 73-101.

$285 \mathrm{Vgl}$. Wolfgang Burgdorl, Reichskonstitution und Nation. Verfassungsreformprojekte für das Heilige Rörmische Reich Deutscher Nation im politischen Schrifttum von 1648 bis 1806, Mainz 1998; Umbach. Federahsm and enlightenment (wie Anm. 283). Zur Patriotismusdebatte und den patriotischen Leitbildern vor 1800 vgl. Jörg Echternkamp, Der Aufstieg des deutschen Nationalismus

$286 \mathrm{Vgl.} \mathrm{Siegfried} \mathrm{Weichlein,} \mathrm{Der} \mathrm{Apostel} \mathrm{der} \mathrm{Deutschen.} \mathrm{Die} \mathrm{konlessionspolitische} \mathrm{Konstruktion} \mathrm{des}$ Bonifatius im 19. Jahrhundert, in: Olaf Blaschke ( $\mathrm{Hg}$.), Konfessionen im Konflikt. Deutschland zwi17. Affin 1800 und 1970: ein zweites konfessioneles Zeitalter, Göttingen 2002, S. 155-179.

287 Die Aftinität des Deutschen Bundes zur föderativen Nation verteidigt: Müller, Deutscher Bund und deutsche Nation (wie Anm. 283)

288 Vgl. Dieter Langewiesche, Föderalismus und Zentralismus im deutschen Kaiserreich: Staat, Wirtschaft, Gesellschaft, Kultur - eine Skizze, in: Janz u. a. ( $\mathrm{Hg}$.$) , Zentralismus und Föderalismus im$ 19. und 20. Jahrhundert (wie Anm. 244), S. 79-90; ders., Föderativer Nationalismus als Erbe der

\section{I Neue Politische Literatur, Jg. 51 (2006)}

Die verstaatlichte Region behielt in Deutschland auch im Kaiserreich Attribute de Staatlichkeit. Thre Integration in den Nationalstaat wurde durch die zeitgenössisch vorherr schende Vorstellung der geteilten oder teilbaren beziehungsweise doppelten Souveränita (Georg Waitz) erleichtert. ${ }^{289}$ Sie ermöglichte es den deutschen Einzelstaaten, ihre Eigenständigkeit auch theoretisch zu untermauem. Der Staatsrechtler Christoph Schönberger ha darauf hingewiesen, dass die staatsrechtliche Debatte um den Souveränitätsbegriff zwischen Paul Laband und Max von Seydel, so gegensätzlich die Protagonisten auch waren an diesem Punkt doch Konsens aufwies. Beide plädierten für eine unteilbare Souveränität sprachen sie aber entweder dem Gesamt- oder dem Teilstaat zu. Beide gingen also übe Waitz hinaus. Laband gab gerade nicht, wie weithin angenommen, die herrschende Mei. nung der Reichsgründungszeit, sonciern vielmehr den späteren Konsens, der sich seit der 1880 er Jahren herausgebildet hatte, wieder. ${ }^{290}$ Die Position Labands war zeitgenössiscl umstritten. Erst später wurde sie zur herrschenden Lehre. Unser Blick, mit dem wir das Kaiserreich beschreiben, verdankt sich nicht zuletzt staatsrechtlichen Kategorien wie dener Labands. Seine Kanonisienung ist aber erst ein Ergebnis späterer Entwicklungen. Nacl 1871 war noch offen, welche Position sich durchsetzen würde. Max von Seydel mag ir wilhelminischen Reich ein Außenseiter gewesen sein. Für die Reichsgründungszeit gilt da: nicht. Die staatsrechtliche Orthodoxie der späteren Jahre, wie sie Paul Laband verkörperte eignet sich nicht für eine historische Begrifflichkeit, um das Verhältnis von Region und $\mathrm{Na}$ tion in der Reichsgründungszeit zu erfassen.

Der Föderalismus vermittelte nicht nur in der politischen Öffentlichkeit Deutschiand: Nation und Region ${ }^{29}$, er war auch ein europaweit diskutiertes Ordnungsmodell für Natio. nalstaaten. Die Attraktivität des Föderalismus reichte über diejenigen Staaten, die sich tat sächlich föderaler organisierten, weit hinaus. Der Föderalismus war ein europäisches The ma in der Ära der Nationalstaatsgründungen. Dies zeigen die Positionen Carlo Cattaneos ir Italien genauso wie diejenige Pi y Margalls in Spanien.292

deutschen Reichsnation. Über Föderalismus und Zentralismus in der deutschen Nationalgeschichte in: ders., Nation, Nationalismus. Nationalstaat in Deutschland und Europa, München 2000, S. 55 79

289 Vgl. dazu Siegfried Weichlein, Europa und der Föderalismus. Zur Begriffsgeschichte politische Ordnungsmodelle, in: Historisches Jahrbuch 125 (2005), S. 133-152: Michael Stolleis, Geschicht des öffentichen Rechts in Deutschland, Bd. 2: 1800-1914, München 1992, S. 83-85. Allgemeir hierzu mit historischem Tiefgang: Stefan Oeler, Souveränität und Demokratie als Probleme in de Verassungsentwicklung der Europaischen Union. Fragen aus Verfassungstheorie und Verfas sungsgeschichte an die deutsche Debatte um Souveranitat, Demokratie und die Verteilung polit Völkerrecht 55 (1995), S. 659-712

290 Vgl. Christoph Schönberger, Die Europäische Union als Bund. Zugleich ein Beitrag zur Verabschie dung des Staztenbund-Bundesstaat-Schemas, in: Archiv des öffentlichen Rechts 129 (2004) S. $81-120$.

291 Vgl. hierzu die Einzelstudien in: Thomas Kühne/Cornelia Rauh-Kühne (Hg.), Raum und Geschichte (wie Anm. 1).

292 Vgl. Carlo Moos, Das italienische Risorgimento zwischen Cattaneo und Cavour, in: Otto Sigg ( $\mathrm{Hg}$.) Mit der Geschichte leben. Festschrift für Peter Stadler, Zürich 2003, S. 233-244; ders., Cattaneo inodello elvelico, Jutglar, Pi y Margall y el federalismo espagñol, Madrid 1975. 


\section{b. Wirtschaftliche Marktbildung}

Dass Räume und Regionen durch die Wirtschaft geprägt werden, ist eine der Gegenwart zutiefst vertraute Ertahrung. Für das Deutschland und Europa des 19. Jahrhunderts liegen hierzu zahlreiche Einzelstudien vor. ${ }^{293}$ Mack Walker arbeitete anhand des bayerischen Städtchens WeiBenburg bereits vor längerer Zeit heraus, wie wirtschaftliche Verbindungen neue Wirtschaftsräume schufen, die selten deckungsgleich waren mit den politischen Einheiten. Die "movers und doers" in diesen Kleinstädten hatten einen Sinn für das Nationale. in dieser Schicht entfaltete sich früh die Begeisterung für die nationale idee, in der politische Neuordnung und wirtschaftliche Markbildung Hand in Hand gingen. ${ }^{294}$ Traditionell wurden Marktbildung und Nationalstaatsbildung, also Ausweitung der wirtschaftlichen Räume und politische Neuordnung im Sinne des Nationalstaates als komplementäre Phänomene gesehen. In diese Richtung sprechen vor allem die Befunde aus der Gesetzgebung und der Rechtsgeschichte. Schließlich stellten das nationale Handels- und Aktienrecht unverzichtbare Voraussetzungen für eine überregionale Stabilisienung der Marktbeziehungen dar. Die methodische und theoretische Weiterentwicklung der Regionsforschung hat indessen diese enge Kopplung von Wirtschaftsraum und nationalem Raum gelockert. Neue Raumgliederungen, die quer zu den regionalen, aber auch den nationalen Strukturen verlaufen, treten so in den Vordergrund: Wirtschaftsräume, Verkehrsräume und Absatzmärkte.

Für die wirtschaftliche Dimension des Verhältnisses von Nation und Region wurden mehrere theoretische Zugriffe entwickelt: soziale Kommunikation, Infrastruktur-Geschichte sowie die klassische wirtschaftsgeschichtliche Untersuchung industrialisierter Räume. Gemeinsam ist diesen Untersuchungen eine Differenzierung der politischen, staatlich verfassten Räume. So bedeutete weder die Gründung des Zollvereins noch die Reichsgründung, dass ihnen ein Kommunikationsraum mit gleicher Ausdehnung zugrunde lag. Bis weit ins Kaiserreich hinein differenzierte sich etwa die deutsche Presselandschaft nicht nur weltanschaulich, sondern auch regional. Die Kommunikationsräume folgten im Nationalstaat von 1871 zwei Tendenzen: Sie weiteten sich aus und sie verdichteten sich. Dies ist etwa ablesbar am Wachstum der Postsendungen, der Telegramme, später auch der Telefonanschlüsse und Telefonanrufe. ${ }^{295}$ Die Ausweitung der Infrastruktur bedeutete jedoch nicht automatisch, dass nun jeder mit jedem kommunizierte, wie dies etwa der Vorstellung des Einheitsportos zugrunde lag. Der sozialdemokratische Abgeordnete Reinhold Scharps brachte die-

293 Vgl. jüngst Lorenz Steinke. Die Bedeutung der Lübeck-Büchener Eisenbahn für die Wirtschaft der Region Hamburg-Lübeck in den Jahren 1851 bis 1937, Lübeck 2006; Jörg Reimann, Neapel und Sizilien 1450 bis 1650: Politik, Wirtschaft, Bevölkerung und Kultur, Hamburg 2005; Jon Stobart, The first industrial region. North-West England 1700-60. Manchester 2004; Rainer Fremdling/Richard $\mathrm{H}$. Tilly $(\mathrm{Hg}$.), Industrialisierung und Raum. Studien zur regionalen Differenzierung im Deutschland des 19. Jahrhunderts. Stuttgart 1979; Dieter Pfau, Regionale Identität zwischen Konstruklion und Wirklichkeit. Das Beispiel der "Siegerland-Mentalität", in: Westfälische Forschungen 52 (2002), S. 357-370 sowie den Forschungsüberblick: Küster, "Regionale Identität" als Forschungsproblem (wie Anm. 226)

294 Vgl. Mack Waiker, German Home Towns. Community, State, and General Estate, 1848-1871, 1thaca Comell UP 1971. ND 1998.

295 Vgl. zur Ausweitung des Kommunikationsraumes durch das Telefon: Horst A. Wessel, Die Rolle des Telefons in der Kommunikationsrevolution des 19. Jahrhunderts, in: Michael North $(\mathrm{Hg}$.$) , Kommu-$ nikationsrevolutionen, Die neuen Medien des 16. und 19. Jahrhunderts, Köln 1995, S. 101-127, Dic Verbreitung des Telephons bis zur Gegenwart, in: Hans-Jürgen Teuteberg/Comelius Neutsch ( $\mathrm{Hg}$.$) , Vom Flügeltelegraphen zum Internet. Geschichte der modernen Telckommunikation, Stutt-$ gait 1998 , S. 67-112.

3401 Neue Politische Literatur, Jg. 51 (2006) sen Unterschied in der Debatte um das Einheitsporto im Norddeutschen Reichstag 186: auf den Punkt: "Weit korrespondiert nur, wer weite Verbindungen hat, und in der Nähe der der nur nahe Verbindungen hat." 296 Die Ausbildung kommunikativer Räume spiegelte so zialgeschichtliche Zusammenhänge wider: Sie knüpfie an Interessen an, schuf für sich ge nommen aber kaum neue Interessen. Dass die Bedürnisse und Interessen aber auct ideeller und politischer Natur sein konnten, zeigte das Wachstum der Presse und generei der Öffentlichkeit im zaristischen Russland nach dem verlorenen Krimkrieg. Erst jetzt wur den die infrastrukturellen Voraussetzungen für einen nationalen Kommunikationsraum ge schaffen, so dass sich später eine russische Nationalbewegung bilden konnte. ${ }^{297}$

Ausweitung und Verdichtung von Kommunikationsräumen werden sichtbar in der Ge. schichte des Transports, des Verkehrs und der Post. Sie organisierten die jeweilige Aus. dehnung und Intensität von Öffentlichkeit. Transport, Verkehr und Medien bildeten und ver änderten daher Räume und Strukturen der Öffentlichkeit. ${ }^{298}$ Die Akteure der Extensivieruns wie auch der Intensivierung von Kommunikation waren sowohl private Unternehmen, Zeitungen, Nachrichtenagenturen etc. wie auch öffentliche und staatliche institutionen unc Regierungen. Das Jahr 1848 stellte eine Zäsur in der Ausbildung regionaler wie auch nationaler Öffentlichkeiten dar, weil zuvor ein strenges Zensurregiment geherrscht hatte Deutsche Kleinstaaten nutzten nach 1848 ihre Pressepolitik, um in der Öffentlichkeit ihre Bedeutung zu unterstreichen. Dabei spielte weniger die hinreichend bekannte Propaganda der Herrscherhäuser die zentrale Rolle, sondern die Kontrolle über Informationen und Nachrichtenfluss: "The positive press policy introduced after 1848 depended as much upon the successful dissemination of officially endorsed news as it did upon the expression of pro-government views. Indeed, in many ways news, rather than polemic, was the cornerstone of government press policy."299 Offen blieb bei diesen Studien zur Intensivierung regionaler Identität vor der Reichsgründung indessen, welchen Gestaltwandel Region und Regionalismus unter den Bedingungen des existierenden Nationalstaats durchlaufen würden.

Eine übergreifende Kategorie für das Verhältnis von Region und Nation bildeten Verkehrs- und Wirtschaftsräume. Andreas Helmedach interpretierte das Verkehrssystem des Habsburger Reiches im 18. Jahrhundert als einen Modemisierungsfaktor für Politik und Wirtschaft. Indem seit dem frühen 18. Jahrhundert vermehrt neue Straßen das Habsburgerreich durchzogen und das Post- und Verkehrswesen generell modernisiert wurde. wurden neue infrastrukturelle Grundlagen für wirtschaftliches Wachstum und politische Stabilität gelegt. Helmedach zeichnet ein modemisienungsfreundliches und optimistisches Bild

296 Stenographische Berichte des Norddeutschen Reichstages, 24.10.1867, S. 622; vgl. Weichlein, Nation und Region (wie Anm. 145), S. 119

297 Vgl. Andreas Renner, Russischer Nationalismus und Öffentlichkeit im Zarenreich 1855-1875 Köln 2000; ders., Defining a russian nation: Mikhail Katkov and the Slavonic and East European Review 81 (2003), S. 659-683.

298 Vgl. Jörg Requate, Offentlichkeit und Medien als Gegenstände historischer Analyse, in: Geschichte und Gesellschaft 25 (1999), S. 5-32; Manfred Rühl, Kommunikation und Öffentlichkeit. Schlüsselbegriffe zur kommunikationswissenschaftlichen Rekonstruktion der Publizistik, in: Günter Bentele/Manfred Rühi $(\mathrm{Hg}$.$) , Theorien öHentlicher Kommunikation. Problemfelder, Positionen, Perspekti-$ ven, München 1993, S. 77-102; Michael Schenk, Schutzschild. Öffentliche Meinung und soziale Netzwerke, in: Wolfgang Wunden $(\mathrm{Hg}$.), Öffentlichkeit und Kommunikationskultur. Beiträge zur Medienethik, Hamburg 1994, S. 79-91.

299 Abigail Green, Intervening in the public sphere: German governments and the press: 1815-1870 in: Historical Journal 44 (2001), S. 155-175, 164; vgl. dies., Fatherlands (wie Anm. 283), S. 148188.

Neue Politische Literatur, Jg. 51 (2006) / 341 
des habsburgischen Post-und Verkehrswesens. Die "Hauptkommerzialstraßen" schienen einen Weg in die Modeme und den Weiterbestand des Habsburgerreiches anzuzeigen. Er ergänzt diese Geschichte der Entgrenzung von Kommunikation und Reisen durch eine Analyse von sechs Reiseberichten, die den Wandel dokumentieren sollen. Wie viele habsburgische Eisenbahnbeamte und Postschaffner sind nicht Vorbilder für Romanstoffe geworden! Seine Studie belegt eine tiefgreifende Veränderung der Wahmehmungs- und Erfahnungswelten durch die engere Vemetzung des Verkehrs. ${ }^{300}$

Generell bildete Infrastruktur wie diejenige von Post und Eisenbahn „ein Bindeglied zwischen Stadt und Land, Zentrum und Peripherie und eine Voraussetzung urbaner Lebensweise. [...] Erschließungs- und Verkehrsinfrastrukturen gehören zu den nachhaltigsten Agenten landschaftlicher und lebensräumlicher Umgestaltung, die im 20. Jahrhundert Agen war." 301 In Italien waren es nationale Eliten, die sich des Themas Verkehrsinfrastruktur bemächtigten, um die innere Nationsbildung voranzutreiben. Der Minister für öffentliche Arbeiten Stefano Jacini war zugleich verantwortlich für den Aufbau des italienischen Eisenbahnnetzes. Er sah sich in der Rolle eines Architekten der italienischen Einheit. Mehr als die Hälfte der Staatsausgaben für Infrastruktur flossen in Italien bis 1880 in den Eisenbahnbau. Die Kosten für die Eisenbahnen machten ganze 13 Prozent aller Staatsausgaben zwischen 1861 und 1913 aus. $^{302}$

Hiervon unterschied sich die Entwicklung in Deutschland gründlich. Beim Ausbau de Verkehrsinfrastruktur wirkten im 19. Jahrhundert private Besitzinteressen, die einzelstaatliche und die gesamtstaatliche Politik zusammen - oft auch gegeneinander. Die süddeutschen Reservatrechte erlaubten es etwa dem Königreich Bayem, eine eigene Verkehrsinfrastruktur auch im Nationalstaat beizubehalten und auszubauen. Die Reichsgründung trieb auch hier die Modernisierung und vor allem die Zentralisierung in den Einzelstaaten voran, um mit den politischen Normierungsansprüchen des Reiches Schritt zu halten. Seit 1876 verstaatlichten die deutschen Einzelstaaten ihre Privatbahnen und nutzten sie für eine staatsgelenkte einheitliche Verkehrspolitik. Eisenbahnen waren also nicht nur nach einem Diktum Bismarcks die "stählernen Sehnen der Nation"303, sondem auch das Rückgrat der regionalen infrastruktur. Neben dem nationalen Verkehrsnetz behaupteten sich regionale Netze. Nach der liberalen Phase, die noch einen breit verankerten privaten Besitz an EisenNetze. Nach der liberalen Phase, die noch einen breit verankerten privaten Besitz an Eisen-
bahnen in Preußen, Sachsen und Bayern kannte, kam die staats- oder volkswirtschaftliche Phase der Verkehrspolitik. „Volkswirtschaft gegen Privatwirtschaft" war das eingängige Schlagwort, mit der die Verstaatlichung privater Verkehrsbetriebe durchgesetzt wurde. Hatten sich die Liberalen von der Leitsemantik des Netzes in der Verkehrspolitik inspineren lassen, so folgte jetzt die Bewirtschaftung der Fläche, was sich vor allem im Ausbau der Nahverkehrssysteme niederschlug. Im Ergebnis schafften die regionalen Eliten damit zweierlei. Sie gehorchten den Imperativen der Marktbildung und verhielten sich integrationsoffen zu einem nationalen Verkehrssystem. Gleichzeitig intensivierte sich der Verkehr

$300 \mathrm{Vgl}$. Andreas Heimedach, Das Verkehrssystem als Modemisierungsfaktor. Straßen, Post. Fuhrwe sen und Reisen nach Triest und Fiume vom Beginn des 18. Jahrhunderts bis zum Eisenbahnzeitalter. München 2002; ders., Integration durch Verkehr. Das Habsburgerreich, in: Osteuropa 55 (2005), S. 18-33.

301 Dirk van Laak, Infra-Strukturgeschichte, in: Geschichte und Gesellschaft 27 (2001). S. 367-393, 375.

302 Vgl. Albert Schramm, Railways and the formation of the Italian State in the 19th century, Cambridge 1997. S. 3

303 Zit. in: Otto Pflanze, Bismarck Bd. 2: Der Reichskanzler, München 1998, S. 62. und die Kommunikation in der Region, die dadurch gerade nicht an Bedeutung verlor. Bezeichnend ist, dass sich die bayerische Verkehrspolitik von dem am Zentralstaat ausgerichteten Verkehrsnetz Frankreichs inspirieren ließ. ${ }^{304}$ Das nationale und das regionale Verkehrsnetz blieben gleichsam kompatibel und wechselseitig integrationsoffen. Die Vernetzung von bereits bestehenden Netzen kann verstanden werden als eine Reihe von Aushandlungsprozessen wechselseitiger Durchdringung und gemeinsamer Vorteilsbildung. Das Netz organisierte gleichzeitig Zugang und Ausschluß vom nationalen Verkehr. Es relativierte die Bedeutung von absoluter Entfernung und übersetzte sie in relative Entfernung und Nähe. Das Netz homogenisierte nicht den nationalen Raum, denn die Zugangschancen zum Verkehr waren ungleich verteilt." ${ }^{305}$

Die Post im Deutschen Kaiserreich bot ganz andere Voraussetzungen. Im Ergebnis widersprachen die von der Postkommunikation veränderten Kommunikationsräume aber nich denen im Fisenbahnverkehr. Als Reichspost kam sie dem Zentralstaatsgedanken nahe zumal sie über 20 Jahre von Generalpostmeister Heinrich von Stephan geleitet wurde. ${ }_{n}$ Nothing is impossible with the German Postmaster-General" schrieb die englische "Times' ${ }^{306}$ Das Einheitsporto und der Bau von Posthäusem noch in den entlegenen Gebieten weiteten die Postkommunikation enorm aus. ${ }^{307}$ Darunter musste aber die regionale und noch nicht einmal die lokale Kommunikation nicht leiden. Mit dem Gesamtbriefverkehr wuchs auch der Ortsbriefverkehr. ${ }^{308}$ Die Verdichtung der Kornmunikation vor Ort hielt Schritt mit der nationalen Ausweitung.

304 Vgl. hierzu: Weichlein, Nation und Region (wie Anm. 145), S. 37-104; Allan Mitchell, The Great Train Race. Railways and the German-Franco Rivalry, 1815-1914, London 2000; Weichenstellungen. Eisenbahnen in Bayern 1835-1920. Eine Ausstellung des Bayerischen Hauptstzatsarchivs, München 2001; Claudia Albrecht, Bismarcks Eisenbahngesetzgebung. Ein Beitrag zur ,inneren' Reichsgründung in den Jahren 1871-1879, Köln 1994; Signid Amedick, Männer am Schienenstrang. Sozialgeschichte der unteren bayenischen Eisenbahnbeamten 1844-1914, Stuttgart 1997; James M. Brophy, Capitalism, politics, and rairroads in Prussia, 1830-1870 (Historical perspectives on business enterprise series), Columbus 1998; Rainer Fremdling/Günter Knieps, Competition, Regulation and Nationalization. The Prussian railroad System in the 19th century. Memorandum from Institute of Economic Research, Faculty of Economics, University of Groningen, Nr. 397, Groningen 1990; Lothar Gall/Manfred Pohl (Hg.), Die Eisenbahn in Deutschland. Von ihren Anfängen bis zur Gegenwart, München 1999; Dieter Ziegler, Eisenbahnen und Staat im Zeitalter der Industrialisierung: die Eisenbahnpolitik der deutschen Staaten im Vergleich, Stuttgart 1996; ders., Kommerzielle oder militärische Interessen, Partikularismus oder Raumplanung? Bestimmungsfaktoren für die Entwicklung des Eisenbahnnetzes in Deutschland im 19. Jahrhundert, in: Josef Wysocki ( $\mathrm{Hg}$.$) , Wirt-$ schaftliche Integration und Wandel von Raumstrukturen im 19. und 20. Jahrhundert, Berlin 1994, 5. 39-63; ders., Verstaatlichung oder staaliliche Regulierung. Eisenbahnpolitik in England und PreuBen im Vergleich, in: ders./Sidney Pollard $(\mathrm{Hg}$.), Markt, Staat, Planung. Historische Erfahrungen mit Regulierungs- und Deregulierungsversuchen der Wirtschaft. St. Katharinen 1992, S. 110-20; Ralf Roth, Die Verkürzung von Raum und Zeit: Konsequenzen der Eisenbahn für die Wahmehmung der Stadt, in: Günter Dinhobl ( $\mathrm{Hg}$.), Eisenbahn / Kultur - Railway / Culture. Mitteilungen des Österreichischen Staatsarchivs, Sonderband 7. Wien 2004, S. 137-159; statistische Angaben in: Rainer Fremdling/Ruth Federspiel/Andreas Kunz ( $\mathrm{Hg}$.), Statistik der Eisenbahnen in Deutschland 18351989 (= Historische Statistik von Deutschland, Bd. 17), St. Katharnen 1995.

305 Weichlein, Nation und Region (wie Anm. 145), S. 71.

306 Zit. in: Gundram Prüfer, Jetzt und überall und hier. Geschichte des Nachrichtenwesens, Berlin 1965, S. 264

307 Zur nationalen Ausbreitung der Posthäuser Agnes Seemann, Die „Postpaläste" Heinnich von Siephans. Zweckbauten für den Verkehr oder Architektur im Dienste des Reiches, Phil. Diss. Kie 1990; Weichlein, Nation und Region (wie Anm. 145), S. 133-139.

308 Zur Post als Nationalisierungsagentur vgl. Weichlein, Nation und Region (wie Anm. 145), S. 105 189; Jan-Otmar Hesse, Im Netz der Kommunikation. Die Reichs-Post- und Telegraphenverwaltung 
Die jüngste Geschichte der Industrialisienung in Deutschland kam zu ähnlichen Befunden und relativierte den nationalen Rahmen erheblich. Der Chicagoer Politikwissenschaftler Gary Herrigel rückte die für die Nationalismusforschung lange Zeit maßgeblichen Annahmen von Alexander Gerschenkron in ein neues Licht. Dieser hatte die späte und erfolgreiche deutsche Industrialisierung durch den Eingriff des unitarischen Zentralstaates erklärt. Die Industrialisierung habe große Einheiten aus der Abwesenheit einer größeren Konkurrenz heraus begünstigt. Auf diese Weise seien vertikal integrierte Konzeme entstanden, die die deutsche Wirtschaft prägten ${ }^{309}$ Gary Herrigel argumentierte gegen alle drei Grundannahmen und wies auf die Kleinteiligkeit der Industrieunternehmungen und ihre regionalen Schwerpunktbildungen hin. Deutschland kannte nach Herrigel eine dezentralisierte wirtschaftliche und keine national-unitarische Ordnung, die auf kleinen und nicht auf großen Untemehmen bestand. ${ }^{310}$ Damit wies die deutsche Wirtschaftsordnung im Kern formal ähnliche Strukturen auf. Herrigel sprach sich für den Primat der Region und der lokalen Wirtschaftsordnung aus, aus denen heraus sich durch kumulative Effekte und nicht durch einen Meisterplan oder durch Staatsintervention eine nationale Wirtschaftsordnung ergab. Damit aber ist auch für den Bereich der nationalen Wirtschaftsordnung die konzeptuelle Annahme von Zentrum und Peripherie relativiert. Die politische Kleinteiligkeit Deutschlands prägte auch noch lange nach der Reichsgründung die Wirtschaftsordnung und fand darin ihren Halt.

\section{c. Kulturelle Einschreibung und Aneignung der Region in die Nation}

Wie eng die wirtschaftliche Konstruktion und die kulturelle Imagination von Region und $\mathrm{Na}$ tion zusammenhingen, zeigten die Wettinerfeiern von 1889. Post und Bahn, Kommunikation und Verkehr standen für die neue Zeit. Mit der Verdichtung der regionalen Verkehrsräume bei gleichzeitiger Ausweitung kam ein neuer Mechanismus im Verhältnis zwischen Nation und Region ins Spiel: der Wettbewerb. Besonders im Eisenbahnverkehr bildeten Fortschritt und Modemität quasi das tertium, auf das hin sich die Einzelstaaten, aber auch der Gesamtstaat verglichen und worum sie wetteiferten. Die Leistungsschau im Huldigungszug zum 800jährigen Wettinerjubiläum zeigte am 19. Juni 1889 daher mit Stolz au die Eisenbahn und den Telegraphen als sächsische Leistungen. Sie stellte damit eine implizite Antwort auf das bayerische Dynastie-Jubiläum am 25. August 1880 dar, das die Treue zur Monarchie als die kulturelle Gestalt Bayems durch die Zeiten gefeiert hatte. ${ }^{311}$ Die Vorstellung, dass Regionen bezüglich Fortschritt und Entwicklung untereinander in einem Wettbewerb stehen, war nicht auf Sachsen und auch nicht auf das Deutsche Reich beschränkt. Sie fand sich auch im Habsburgerreich. Konrad Clewing weist in seiner Studie

1876-1914, München 2002; ders., Heinrich von Stephan (1831-1897). Unternehmer im Dienst der Staatsverwaltung, in: Post- und Telekommunikationsgeschichte 1 (1997), S. 10-12; Klaus Beyrer ( $\mathrm{Hg}$.), Kommunikation im Kaiserreich. Der Generalpostmeister Heinrich von Stephan, Heidelberg 1997.

$309 \mathrm{Vgl}$. Alexander Gerschenkron, Economic backwardness in Historical perspective. A book of essays, Cambridge 1966.

310 Vgl. Gary Herrigel, Industrial Constructions. The Sources of German industrial power, Cambridge

311 Vgl. Simone Mergen, Monarchiejubiäen im 19. Jahrhundert: die Entdeckung des historischen Jubiläums für den monarchischen Kult in Sachsen und Bayern, Leipzig 2005; Claudia Schnitzler, Adlige Selbstbehauptung in einer bürgerlichen Festform. Der Tumierzug des sächsischen Adels im Huldgungs7ug anläßlich der Wettiner-Jubelfeier 1889 in Dresden, in: Käl
$(\mathrm{Hg}$.$) , Geschichte des sächsischen Adels, Köln 1997, S. 167-186.$

344 I Neue Politische Literatur, Jg. 51 (2006) über den lllyrismus und die Versuche dalmatinischer Staatsbildung in der ersten Hälfte des 19. Jahrhunderts nach, wie der Fortschrittsgedanke, das Konzept der Nation und die Vorstellung von einem Entwicklungs-Wettbewerb die örtlichen Eliten antrieben. Hier war es nicht der Staat, der als Akteur von Modernisierung auftrat, sondem die Nation. ${ }^{312}$

Die Verbindung der Nation mit Marktbildung und wirtschaftlichem Erfolg galt auch für die Region - und zwar in beide Richtungen. Ausbleibender wirtschaftlicher Erfolg beziehungsweise eine Abweichung von der als Norm angesehenen nationalen Entwicklung konnten der Region angelastet werden. Zum Verhältnis von Nation und Region gehören daher auch Rückständigkeits- und Inferioritätsdiskurse. Nach den Krisen des italienischen Risorgimento fragten die sogenannten Meridionalisti - unter ihnen vor allem Pasquale Villan und Leopoldo Franchetti - nach den Ursachen der Unterschiede zwischen Nord- und Süditalien. Vorherrschend für ihre Antwort auf die "Süd-Frage" war die Dichotomie von Fortschritt und Rückständigkeit, die teilweise bis ins Mittelalter zurückverfolgt wurde. Der ,meridionalismo" trug ethnische Züge. Süditalien wurde zum "dunklen Italien" oder gar zum „barbarischen Italien" (Alfredo Niceforo). ${ }^{313}$ Rückständigkeitsdiskurse und Inferioritätsdebatten gab es auch in Spanien und Polen. Überall wurden bestimmte Räume und soziale Gruppen aus der engeren nationalen Fortschrittsgemeinschaft ausgesondert und zum Objekt nationalen Handelns gemacht.

Die Geschichte spielte nicht nur bei der Zuschreibung der Region, sondem auch bei ihrer Selbstbeschreibung eine entscheidende Rolle. Französische, italienische und deutsche lokale und regionale Geschichtsvereine verbanden in ihrer Arbeit nationale und regionale Interessen miteinander. Zumeist war die Zeit von besonderer Bedeutung, in der die betreffende Region oder Stadt eine überregionale Bedeutung gehabt hatte. Oft war dies das Mittelalter. Zwar schlossen sich die deutschen Geschichtsvereine 1852 im Gesamtverband der Deutschen Geschichts-und Altertumsvereine zusammen. Ihr organisatorischer Schwerpunkt lag aber in der Kommune und vor Ort. In Italien scheiterten etwa die Versuche, einen nationalen Gesamtverband der Geschichtsvereine zu errichten. Gabriele B. Clemens streicht in ihrer Habilitationsschrift über die deutschen und italienischen Geschichtsvereine deren Bedeutung als Konstruktionsmechanismus von regionaler Identität heraus. Dabe blieben sie freilich passfähig zu nationalen Mustem. ${ }^{314}$ Dies präzisiert die Studie von Georg Kunz über das regionale Geschichtsbewusstsein in den historischen Vereinen Bayreuths,

312 Vgl. Konrad Clewing, Staatlichkeit und nationale ldentitätsbildung (wie Anm. 1).

313 Vgl. John Dickie, Darkest ltaly: The nation and stereotypes of the mezzogiorno, 1860-1900, New York 1999. Vgl. auch in engem Zusammenhang mit dieser Debatte, die von der unterlegenen de mokratisch-republikanischen Richtung geführt wurde, die Biographie ihres Vorkämpfers Francesco Crispi: Christopher Duggan, Francesco Crispi 1818-1901. From nation to nationalism, Oxford 2002.

314 Vgl. Gabriele B. Clemens, Sanclus amor patriae. Eine vergleichende Studie zu deutschen und italienischen Geschichtsvereinen im 19. Jahrhundert, Tübingen 2004; dies., Geschichtsvereine in Italien zwischen regionaler und nationaler Historiographie, in: Marco Bellabarba/Reinhard Stauber $(\mathrm{Hg}$.) Identità e cultura politica nella prima età moderna, Bologna 1998, S. 381-405; dies., Regionaler Nationalismus in den historischen Vereinen des 19. Jahrhunderts?, in: Westfälische Forschungen 52 (2002). S. 133-159; dies., Historische Vereine in Italien - Geschichtsschreibung im Dienste des Vaterlandes, in: Blätter für deutsche Landesgeschichte 138 (2002). S. 95-115. Exemplarisch zur Verbindung der piemontesischen und der italienischen Identität: Umberto Levra, Dal Piemonte all'Italia, Turin 1995; zu den nationalen Mustern der Identitâtsstiftung in Italien: Alberto Banti, L'onore della nazione: identità sessuali e violenza nel nazionalismo europeo dal XVIII secolo alla grande guerra, Turin 2005; ders., La nazione del Risorgimento: parentela, santità e onore alle origini making Italy: The cultivation of national identity around the Risorgimento, Oxford 2001 . 
Bambergs, Thüringens, der Mark Brandenburg, des Bergischen Landes und SchleswigHolsteins. Das regionale Geschichtsbemusstsein reagierte zum einen auf die jeweiligen pofitischen und konfessionellen Konstellationen. Nach 1871 änderte sich dies jedoch nach Kunz: Jetzt bildete die Nation den Bezugsrahmen. Geschichtsvereine versuchten jetzt, itre Reichsioyalität seit dem Mittelalter nachzuweisen. Dabei neigten die Geschichtsvereine zur Ethnisierung der Geschichte, also dazu, ihre Region als ethnische Einheit in historischen Konflikten darzustellen. Im Ergebnis rückte dadurch die Region ins Zentrum der nationalen Erählung, vor allem dann, wenn sie am Rand des Reiches lag. Denn in der Erählung ethnischer Kämpfe wurde die Großethnie am Rand gegen ihre Angreifer verteidigt. Besonders die Ethnisierung regionaler Geschichtsentwürfe erlaubte die Integration von Randregionen in die nationale Erzählung. ${ }^{315}$ Dies ging so weit, dass die Region zum Zentrum der Nation wurde, sobald Konflikte historisch-ethnisch kodiert wurden. Die Region rückte ins Zentrum der Nation.

Hinzu kam die durchgreifende Historisierung der Region. Wenn die mittelalterliche Reichsloyalität im Zentrum der Enzählung stand, konnten Vertierergeschichten von 1866 als eigentliche Siegergeschichten erzählt werden. Beispiele hierfür finden sich zahlreich auf der Seite der im preußisch-österreichischen Krieg von 1866 unterlegenen Staaten. ${ }^{316}$ Verlierergeschichten konnten aber auch in der Schweiz als Siegergeschichten erzählt werden. Irène Hermann zeichnete diesen Prozess für Genf und Oliver Zimmer für die Schweizer Katholiken nach. ${ }^{317}$ Im Kampf um die Deutungshoheit über die Schweizer nationalen Mythen des Wilhelm Tell und des Rütli-Schwurs stilisierten sich Katholiken als Urschweizer mit einer längeren Schweizer Loyalität und Geschichte als der protestantische Liberalismus. In Deutschland waren es Bayem und Sachsen, die sich mit Blick auf die mittelalterliche Geschichte ihrer Dynastien als die besseren Deutschen darustellen wussten. Beide Dynastien wurden als urdeutsch stilisiert, denen gegenüber die Hohenzollern als jüngst auf den Thron gekommene Kretins erschienen.

Auch die Kulturalisienng der Region überwand den politischen Gegensatz zwischen Einzelstaatlichkeit und Gesamtstaatlichkeit. Die generelle Karriere der Kulturgeschichte im späten 19. Jahrhundert machte aus staatlich verfassten Regionen wie Bayem kulturelle Gebilde. Sittengeschichten, Denkwürdigkeiten und die allgemeine Aufwertung regionale Kultur begünstigten die Entpolitisierung der Einzelstaaten. ${ }^{318}$ Europäisch verallgemeinern lassen sich diese Ergebnisse freilich nicht. Spanische regionale Geschichtskulturen wie diejenigen in Saragossa und Valencia relativierten die politische Dimension der Region gerade nicht, sondem unterstrichen sie. Dazu trugen auch ihre historischen Bezugspunkte bei, die mittelalterlichen Sonderrechtstraditionen der "fueros", deren Verteidigung gegen die spanische Krone im Mittelpunkt der historischen Arbeit in den Regionen stand. ${ }^{319}$

Die Debalte um Konkurrenz und Komplementarität von Nation und Region hat auch dazu geführt, dass in der gegenwärtigen Diskussion um die politische Konstruktion der Euro-

$315 \mathrm{Vgl}$. Georg Kunz, Verortete Geschichte. Regionales Geschichtsbewusstsein in den deutschen Historischen Vereinen des 19. Jahrhunderts, Göttingen 2000

316 Beispiele: Weichlein, Nation und Region (wie Anm. 145), S. 342-370

317 V (1814. Herman, Geneve entre republque el canton: les vieissitudes dune integrahon nationale (17)

2. Retack (Hg.), Sachsen in Deutschland (wie Anm. 1).

319 Vgt. Brinkmann, Der Stolz der Provinzen (wie Anm.1). päischen Union föderale Modelle eine wichtige Rolle spielen ${ }^{320}$ Freilich stoßen hier politisch und begrifflich zwei in der kontinentaleuropäischen und der nordamerikanischen Geschichte historisch tief verwurzelte Konzeptionen des Föderalismus aufeinander: die kontinentaleuropäische Tradition des Föderalismus und die anglo-amerikanische des federalism, die von den Federalist papers inspiriert ist. Federalism hat in der nordamerikanischen Tradition anders als im Föderalismus - den politischen Beigeschmack, den Gesamtstaat gegenüber dem Einzelstaat zu stärken. In der derzeitigen Diskussion werden die Unterschiede zwischen beiden Modellen durch den Begriff der Subsidiaritäł aufgehoben. Für die Vermittlungsgeschichte von Gesamtstaat und Einzelstaat ist damit eine politische Leitbegrifflichikeit etabliert, die in die Zukunft weist. 321

Der Einfluss der historischen Bearbeitung des Verhältnisses von Nation und Geschichte auf die politische Gestaltung der Europäischen Union stöBt hier freilich an seine Grenzen. Die osteuropäischen Staaten kennen nicht Regionen in dem Sinne wie westeuropäische Staaten. Das inklusive Verhältnis beider ist kaum auf die Gesellschaften im Bereich der früheren osteuropäischen Großreiche zu übertragen, weil Regionen dort relativ schnell im Geruch des sezessionistischen Nationalismus standen und stehen. Unter Qualen und Schmerzen und bis heute ständig gefährdet haben sich dagegen in den westeuropäischen Staaten Ausgleichsformen der kulturellen Autonomie, der Sonder- und der Minderheitenrechte und des Föderalismus etabliert, die etwa in Katalonien, in Korsika und in Inland Konflikte entschärfen halfen und Integrationspotential bereitstellten.

\section{Ausblick}

Celia Applegate fasste die Ergebnisse der jüngsten Nationalismusforschung so zusammen "Scholarship on nation-building, nationalism, and national identity now tends to emphasize multiplicity and fragmentation, diversities and contingencies, uneven diffusion and incomplete projections. ${ }^{4322}$ Diese Beobachtung set die Nationalismusforschung vor allem von Nations- und Nationalismuskonzepten ab, die identitätslogisch die Nation eindeutig zu bestimmen versuchen. Unter dem Gesichtspunkt der Integration freilich setzt die Nationalismusforschung nicht auf Eindeutigkeit, sondem auf ständig neu ausgehandelte Nähe und Ferne unter ihren Akteuren. Die Systemintegration in den Nationalstaat ist möglich, wenn gleichzeitig Formen der sozialen Integration vortanden sind. Die kulturelle und wirtschaftliche Konstruktion sozialer Zusammengehörigkeit im Nationalstaat stellt nicht nur eine methodische Innovation der Nationalismusforschung dar. Auf der Sachebene war sie auch die

$320 \mathrm{Vgl.} \mathrm{Rall} \mathrm{Elm} \mathrm{(Hg.),} \mathrm{Europäische} \mathrm{ldentität} \mathrm{(wie} \mathrm{Anm.} \mathrm{1);} \mathrm{Applegate,} \mathrm{A} \mathrm{Europe} \mathrm{of} \mathrm{Regions} \mathrm{(wie} \mathrm{Anm}$ 246); Alexander von Bogdandy, Supranationaler Föderalismus als Wirklichkeit und ldee einer neuen Herrschaftsform, Baden-Baden 1999; ders., Die europaische Union als supranationale Foderation, in. Integration 22 (19. kutivföderalismus. Eine Studie zum Verhälnis von forderaler Ordnung und partamentarischer Demokratie in der Europinchen Union, Berli 2004. Weich krale in der Europaischen Union, Be

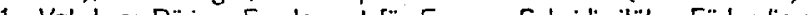

. Lars Doring, Fundament 2004, Stelan Deter. Integration und Subsidiantal im deutschen Bundesstaatsrecht: Untersuchungen zutie (wie Ann 289); ders, Europäische Integration als Konstitutionalisienungsprazess, in: Zeit-

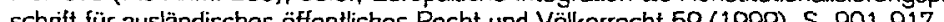

322 Applegate, A Europe of Regions (wie Anm. 246), S. 1164. 
Voraussetzung für die politische Systemintegration. Die soziale Integration im Nationsgedanken setzte auf sozial einlässige Leitbilder: auf Bildung und Recht, auf Erziehung und Fortschritt. ${ }^{323}$ Der Wertekanon der Nation verband sozial und kulturell heterogene Gruppen miteinander.

Die soziale Integration als Voraussetzung für die Systemintegration betraf an zentraler Stelle die Rolle der Frauen in der Nation. Geschlechterspezifische Leitbilder wie die der Mutter und der vaterländischen Patriotin in den weiblichen Vaterlandsvereinen konstruierten ein übergreifendes weibliches Interesse an der Nation. ${ }^{324}$ Dies galt besonders für die pflegenden und heilenden Aufgaben, die Frauen im Krieg übemahmen. Besonders der Krieg ist daher ein Feld der Nationalisierung der Frauenrollen. Kriege beschleunigten und verstärkten dabei gleichsam als ,Katalysator' die Nationalisierung der Geschlechterordnung und das 'gendering' der Nation und formten nachhaltig die Grundstrukturen des Verhältnisses von Frauen, Staat und Nation. ${ }^{325}$

Die nationale Rollenzuschreibung der Frau fügte sich in die übergreifende Politisienung des privaten Lebens ein. Die neueren Arbeiten zum Verhältnis von Nation und Geschlechterrollen relativieren den nationalen Topos einer privaten weiblichen und einer öffentlichen männlichen Sphäre. ${ }^{326}$ Dieser normative Entwurf spiegelte nicht die gesellschaftliche Wirklichkeit wider: „Die Einbeziehung von Frauen in Geselligkeit, Vereinskultur und Ökonomie unterlief diese Grenzziehungen ebenso wie die Zuweisung öffentlicher und nationaler bedeutsamer Funktionen." ${ }^{327}$ Auch der Topos, dass Frauen, die sich politisch äußern, auf der politischen Linken zu verorten seien, geriet ins Wanken. Deutschnationale Frauen und nationalistisch eingestellte Autorinnen wie Else Frobenius entfalteten eine erhebliche Wirkung. 1912 entstand die Vereinigung konservativer Frauen, und die Deutschnationale Volkspartei warb in ihrem Parteiprogramm 1919 um die Mitarbeit von Frauen „für das, was die deutsche Frau im Kriege geleistet hat". Frauen sollten deutschnational wählen, um das Vaterland zu retten. Und das taten sie auch: Nicht die Sozialdemokratie als die Vorkämpferin des Frauenwahlrechts profitierte von seiner schlussendlichen Einführung durch die Novemberrevolution 1918, sondem das Zentrum und die konservativen Parteien. Dies ermutigte die

323 Zu diesen Leitbildern der sozialen Integration durch die Nation vgl. Echternkamp. Der Aufstieg des deutschen Nationalismus (wie Anm. 285), S. 42-49, 62-77, 233-254, 444-479.

324 Vgl. den Forschungsbericht von Ute Planert, Vater Staat und Mutter Germania: Zur Pollisierung des weiblichen Geschlechts im 19. und 20. Jahrhundert, in: dies. (Hg.), Nation, Politik und Gedes weiblichen Geschlechts im 19. Und 20. Jahrhundert, in: dies. ( $\mathrm{Hg}$.), Nation, Politik und GePatricia Herminghouse/Magda Muller (Ho) Gender and Germanness. Cultural Productions of $\mathrm{Na}$ tion, Oxford 1997.

325 Karen Hagemann, ,Deutsche Heldinnen': Patriotisch-nationales Frauenhandeln in der Zeit der antinapoleonischen Kriege, in: Planert ( $\mathrm{Hg}$.), Nation, Politik und Geschlecht (wie Anm. 324), S. 86112, 105. Vgl. dazu dies., Be proud and firm, citizens of Austrial" Patriotism and masculinity in texts of the political romantics" written during Austria's anti-napoleonic wars, in: German Studies 29 (2006), S. 12-23; dies. Tod für das Vaterland: der patriotisch-nationale Heldenkult zur Zeit der Befreiungskriege, in: Miltärgeschichtiche Zeitschitt 60 (2001) S. 307-343. dies, Nation, Krieg und Geschiecherordnung Zum kulture Zeltsch politisch (2001), S. 307-343, dies., Nation, Krieg schen Erhebung PreuBens. Zum kulturellen und politischen Diskurs in der Zeit der antinapoleon

326 Ein Beispiel unter viens 1806-1815, in: Geschichte und Gesellschatt 22 (1996), S. 502-592. Machtphantasie Deutschland. Nationalismus, Männlichkeit und Fremdenhass im Vaterlandsdiskurs

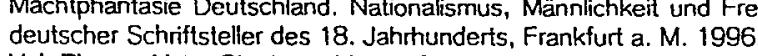

327 Vgl. Planert, Vater Staat und Mutter Germania (wie Anm. 324), S. 48
DNVP zu einer eigenständigen konservativen Frauenpolitik. 328 Es mehren sich die Anzeichen dafür, dass der ideologische Topos der Unterordnung der Frau unter den Mann noch nicht die voranschreitende Politisierung der Frau auf die Nation hin erklärt.

Dies zeigt sich auch bei der Frage der Staatsbürgerschaft, die im Kaiserreich patrilinear geregelt war, also sich von derjenigen des Ehemannes ableitete. Die nationale Politisierung rührte auch von der Fordenung her, Fraven eine eigene und genuine Staatsbürgerschaft zu verleihen, die sich nicht derjenigen ihres Mannes verdankte. Frauenrechtsverbände forderten in der Diskussion um das neue Staatsangehörigkeitsgesetz von 1913 die Selbstständigkeit von Frauen als Staatsbürgerinnen. ${ }^{329}$ Für das Verhältnis der Geschlechterordnung zur Nation stellt sich damit die grundlegende Frage: Muss die Geschlechterordnung in der Nation als Verdoppelung männlicher Lebenswelten auf der Seite politisch aktiver Frauen oder als Kopplung weiblicher Deutungsmuster an die der Männer beschrieben werden?

Der Schwerpunkt der historischen Nationalismusforschung lag bisher in der Phase der Nationsbildungen und der Nationalstaatsgründungen im 19. Jahrhundert. Hier hat die Literatur wichtige Deutungsmuster, die lange Zeit die Forschung leiteten, relativiert. So ist die Periodisierung des Nationalismus entiang einer früheren, friedlichen und emanzipatorischen und einer späteren aggressiven radikalen und nationalistischen Phase seit längerem nicht mehr haltbar. Dieter Langewiesche wies darauf hin, dass Partizipation und Aggression gleichzeitige Phänomene im Nationalismus sind. ${ }^{330}$ Christian Jansen insistiert darauf, dass der radikale Nationalismus nicht erst - wie Hans-Ulich Wehler meint - ab 1890 , sondern bereits seit etwa 1800 Kennzeichen der deutschen Nationalbewegung gewesen ist. Für Jansen bereitete die Kulturnation, die auf der deutschen Sprache aufbaute, die Ethnisierung des Nationalen vor. Bezeichnend ist vor allem, dass der Antiuniversalismus der deutschen Nationalbewegung aus dem Widerstand gegen Napoleon heraus nach dem Wiener Kongress im Deutschen Bund und im System Mettemich seine neuen Feinde fand. Auf die "Hauptstadt der Reaktion" Paris folgte Wien. Im Grunde vergleichbar mit der ideologischen Radikalisierung der Arbeiterbewegung unter den Sozialistengesetzen radikalisierte sich auch die Nationalbewegung in der Phase ihrer Unterdrückung nach 1819. Jansen wählte seine Beispiele aus dem politisch linken Spektrum, aus der liberalen und demokratischen Opposition gegen die Fürstenherrschaft und das Gottesgnadentum und konnte gerade dort radikalnationale Überlegenheitsgefühle, antifranzösische Ressentiments und die Umwertung des Nationalismus zur Ersatzreligion nachweisen. ${ }^{331}$ Andere Grundannahmen der Nationa-

328 Vgl. Kirsten Heinsohn, Im Dienste der deutschen Volksgemeinschaft: Die "Frauenfrage" und konservative Parteien vor und nach dem ersten Weltkrieg, in: Planert $(\mathrm{Hg}$.). Nation, Politik und Geschlecht (wie Anm. 324), S. 215-233, 225, 229.

329 Vgl. Gosewinkel, Einbürgern und Ausschließen (wie Anm. 145); Regina Wecker, „Ehe ist Schicksal, Vaterland ist auch Schicksal und Ausschließen (wie Anm. 145); Regina Wecker, „Ehe ist Schicksal, Vaterland ist auch Schicksal und dagegen ist kein Kraut gewachsen". Gemeindebürgerrecht und
Staatsangehörigkeitsrecht von Frauen in der Schweiz 1798-1998, in: L 'homme. Zeitschrift für feministische Geschichtswissenschaft 10 (1999), S. 13-38; Argast, Staatsbürgerschatt und Nation (wie Anm. 1).

330 Vgl. Dieter Langewiesche, Nationalismus im 19. und 20. Jahrhundert: zwischen Partizipation und Aggression, Bonn 1994.

331 Christian Jansen, Deutsches Volk und Deutsches Reich. Zur Pathologie der Nationalstaatsidee im 19. Jahrhundert, in: Wolfgang Bialas $(\mathrm{Hg})$. Die nationale Identiatat der Deutschen. Philosophische Imaginationen und historische Mentlititen. Die nalionale ldentitat der Deutschen. Phlosophische Imaginationen und historische Mentalitaten, Frankfurt a.M. 2002, S. 167-194; Jansen untersuchte die nationale Idee auf der politischen Linken in seiner Habilitationsschrift: ders., Einheit, Macht und 1867. Düsseldort 2000 und legte eine umfangreiche Quellenedition hierzu vor, die für die For1867, Düsseidort 2000 und legte eine umfangreiche Quellenedition hierzu vor, die für die For-
schung unverzichtbar sein wird. Vgl. ders. $(\mathrm{Hg}$.$) , Nach der Revolution 1848/49: Verfolgung, Real-$ 
lismusforschung wie das Drei-Phasen-Modell von Miroslav Hiroch sind in der Zwischenzeit ebenfalls relativiert worden. So scheint die erste Phase der nationalen Mobilisierung durch kulturelle Eliten nicht auf politische Motive verzichten zu können. ${ }^{332}$

Die Relativierung von Grundannahmen der Nationalismusforschung betrifft auch die Frage, ab wann wir von einem Nationalismus sprechen können. Mehrere Autoren versuchen, die nationalismusgeschichtliche Epochenzäsur der Französischen Revolution zu relativieren, indem sie auf Formen des Nationalismus in der Frühen Neuzeit aufmerksam machen. ${ }^{333}$ Die Kritik an dem Zäsurdatum 1789 weist daraufhin, dass sich vermeintlich modeme Kennzeichen der Nation wie Selbstbezeichnung, Kultumation und die politische Aufladung des Nationsbegriffes bereits in der Frühen Neuzeit beobachten lassen, während andere in der Literatur behauptete Spezifika auch für die modeme Entwicklung nicht zweifelsfrei nachzuweisen seien. Herfried Münkler und Hans Grünberger arbeiten Formen des frühen Nationalismus anhand der Schriften deutscher Humanisten heraus. Nationenbildung machen sie fest anhand von kollektiven Stereotypen, die vor allem durch Fremdzuschreibung Kollektive identifizieren, kategorisieren und sogar personalisieren. ${ }^{334}$ Der Schweizer Historiker Caspar Hirschi geht noch einen Schritt weiter und zeichnet eine lange historische Entwicklungslinie des Nationsdiskurses von der Antike bis in die Neuzeit nach, die nur noch mit den Dimensionen eines Adrian Hastings vergleichbar ist. ${ }^{335}$ Hirschi kann nachweisen, dass die Frühe Neuzeit nicht nur einen patria-, sondern auch einen Nationsdiskurs kannte. Über Münkler und Grünberger hinausgehend argumentiert Hirschi, dass die jeweiligen Fremdzuschreibungen als Ehrverletzungen zurückgewiesen wurden, was eine längere Debatte unter deutschen und italienischen Humanisten im 15. und 16. Jahrhundert auslöste. Organisiert war dieser Nationsdiskurs entlang der bipolaren Begriffe Zivilisation und Barbarei. Diese Binarität aber nahm die Nationsdiskurse des 18. Jahrhunderts im Zeichen der Aufklärung und des Intellektuellennationalismus in der Sache vorweg. Zivilisation versus

politik, Nationsbildung. Politische Briefe deutscher Liberaler und Demokraten 1849-1861, Düsseldorf 2004.

332 Zur Kritik vgi. Vulpius, Nationalisierung der Religion (wie Anm. 192).

3 So bereits: Wolfgang Hardtwig, Vom ElitebewuBtsein zur Massenbewegung. Frühformen des Nationalismus in Deutschland 1500-1840, in: ders.. Nationalismus und Bürgerkuitur in Deulschland 1500-1914. Ausgewählte Aufsätze, Göttingen 1994. S. 34-54. Vgl. Reinhard Stauber, Nationalismus vor dem Nationalismus? Eine Bestandsaufnahme der Forschung zu, Nation' und .Nationalismus' in der Fruhen Neuzet, in: Geschichte in Wissenschaft und Unterrich 47 (1996), S. 139-165; ders., Vaterland - Provinz - Nation. Gesamistaat, Lander und nationale Gruppen in der osterreichischen Monarchie 1750-1800, in. Autkarung 10 (1998), S. 55-73; Volker Reinhard, Nation und Nationalismus in der Fruhen Neuzert. Anmerkungen und Thesen zu einer methodischen Diskussion, in: Catherine Bosshart-Pfluger u. a. ( $\mathrm{Hg}$.), Nation und Nationalismus in Europa. Kulturelle Konstruktion von Identitälen, Frauenfeld 2002, S. 155-178.

$334 \mathrm{Vgl}$. Herfried Münkler/Hans Grünberger/Katrin Mayer ( $\mathrm{Hg}$.$) , Nationenbildung. Die Nationalisierung$ Europas im Diskurs humanistischer Intellektueller. Italien und Deutschland, Berlin 1998; Münkler/Grünberger, Nationale Identität im Diskurs der deutschen Humanisten, in: Helmut Berding ( $\mathrm{Hg}$.), Nationales Bewusstsein und kollektive Identität (wie Anm. 44), S. 211-248; Herfried Münkler, Nation as a model of Political order and the Growth of national Identity in Europe, in: Internatio-

335 So: Caspar Hirschi, Wettkampf der Nationen. Konstruktionen einer deutschen Ehrgemeinschaft an der Wende vom Mittelalter zur Neuzeit, Göttingen 2005; ders., Das humanistische Nationskonstruk vor dem Hintergrund modernistischer Nationalismustheorien, in: Historisches Jahrbuch 122 (2002),
S. 355-396.

350 I Neue Politische Literatur, Jg. 51 (2006)
Barbarei blieb ein Schlagwort und eine Ermächtigungsformel des modemen Nationalismus. ${ }^{336}$

Zu den Desideraten der Nationalismusforschung gehört die weitere methodische Differenzierung. Dazu zählt vor allem das Verhältnis der Nationsbildung zum Recht und zur Gesetzgebung. Schließlich beinhaltete die liberale Nationsidee immer den Gedanken der Rechtsgleichheit. ${ }^{337}$ Daneben stellt der Nationalismus im 20. Jahrhundert genauso ein Desiderat der Nationalismusforschung dar wie ihre Ausdehnung auf Europa als Gegenstand. Die jüngsten Kriege auf dem Balkan und in den Nachfolgestaaten der Sowjetunion rücken jedoch die vollständige Historisierung des Nationalismus in weite Ferne. ${ }^{338}$

Anschrift des Verfassers: Prof. Dr. Siegfried Weichiein, Europäische und Schweizerische Zeitgeschichte, Departement für Zeitgeschichte, Universität Fribourg. Av. de l'Europe 20, $\mathrm{CH}-1700$ Fribourg.

Email: siegfried.weichlein@unifr.ch
336 Zum Nationsdiskurs im 17. und der ersten Hälfte des 18. Jahrhunderts vgl. Martin Wrede, Das Zum Nationsdiskurs im 17. und der ersten Halfte des 18 . Jahnmunderts vgl. Martin Wrede, West fälischem Frieden und Slebenahigem K/M, Mainz 2004. Zum Nallon $(\mathrm{Hg})$. Patrotismus und NaReiches vgl. die Bentage in: OHto Dank King tionsbildung am Ende des Heiligen Romischen Reiches, $K$

337 Zur Nationsbildung durch Recht vgl. die Pionierstudien: Eckart Reidegeld, Bürgerschaftsregelungen, Freizügigkeit, Gewerbeordnung und Armenpflege im Prozess der Modernisierung, in: Zeitschrift der Savigny-Stiftung für Rechtsgeschichte. Germanistische Abteilung 116 (1999), S. 204-265; Michael Stolleis, "linere Reichsgrundung durch Rechtsvereinheithichung $1865-1880$, in: ders., Konstulton M. 2001, S. 195-225.

338 Vgl. Altermatt. Das Fanal von Sarajewo (wie Anm. 193), S. 157-176. 